FOLIA

Amazónica

Revista del Instituto de Investigaciones

de la Amazonía Peruana

\title{
DIVERSIDAD DE FLORA Y VEGETACIÓN DEL INTERFLUVIO NAPO-PUTUMAYO-AMAZONAS, PERÚ
}

\author{
Ricardo ZÁRATE-GÓMEZ1* ${ }^{*}$ Harvey Kuinsy Jonathan DEL ÁGUILA CACHIQUE², \\ María Claudia RAMOS-RODRÍGUEZ ${ }^{1,2}$, Juan José PALACIOS VEGA ${ }^{1}$, \\ Christian Paulo PÉREZ MACEDO ${ }^{1}$, Luis Andres VALLES PÉREZ ${ }^{1}$
}

1 Instituto de Investigaciones de la Amazonía Peruana (IIAP).

2 Soil-Plant Servis S.C.R.L., lquitos.

* Correo electrónico: rzarate@iiap.gob.pe

\section{RESUMEN}

El interfluvio Napo-Putumayo-Amazonas en la Amazonía peruana, alberga una gran diversidad de especies de plantas y tipos de vegetación que son muy requeridas por el poblador rural amazónico para subsistencia y comercialización, por lo tanto la comprensión de su diversidad contribuye con información básica para crear posibles estrategias de conservación que regulen su aprovechamiento. Los objetivos de este estudio fueron evaluar la diversidad de la flora y elaborar un modelo espacial de la vegetación del interfluvio NapoPutumayo-Amazonas. Los datos se obtuvieron de 10 estudios de inventarios de la flora realizados en el interfluvio. Para la similaridad de la flora se realizó un análisis de similitud (ANOSIM). Se generó un modelo de la distribución espacial de las unidades de vegetación en base a tres parámetros geomorfométricos, los cuales se calcularon a partir de un modelo de elevación digital (con imágenes del sensor Palsar del satélite Alos) e integrados con datos espectrales (de las imágenes ópticas del satélite Sentinel 2) y datos espaciales oficiales. Se encontraron 1807 especies correspondientes a 140 familias de plantas. Existen siete tipos de vegetación, los de mayor superficie corresponden al Bosque de terraza alta, Bosque de colina baja y Bosque de colina alta. La comunidad de plantas entre el bosque de tierra firme y bosque inundable fueron diferentes de acuerdo al análisis de similitud ( $\mathrm{p}$-value $=0,001$ ). Las especies: Oxandra euneura Diels, Mauritia flexuosa L. f., Euterpe precatoria Mart., Cynometra spruceana 
Benth., Pouteria gomphiifolia (Mart. ex Miq.) Radlk., Tovomita laurina Planch. \& Triana y Macrolobium limbatum Spruce ex Benth. estuvieron más relacionados a los bosques inundables.

PALABRAS CLAVE: Amazonía, hábitats, plantas, riqueza, similitud, geomorfometria.

\section{FLORA AND VEGETATION DIVERSITY IN THE INTERFLUVIUM NAPO-PUTUMAYO-AMAZONAS, PERU}

The Napo-Putumayo-Amazonas interfluvium in the Peruvian Amazon harbors a great diversity of plant species and types of vegetation that are greatly needed by the rural Amazonian population for subsistence and commercialization. Understanding plant diversity can possibly contribute to the creation of conservation strategies that regulate their usage. Therefore, the objectives of this study were to evaluate the diversity of flora and vegetation in the interfluvium and and to evaluate the similarity of the flora between the types of vegetation. The data were obtained from 10 inventory studies of the flora carried out in the Napo-Putumayo-Amazonas interfluvium. A similarity analysis (ANOSIM) was performed of the flora. A model of the spatial distribution of the vegetation units was generated based on three geomorphometric parameters, which were calculated from a digital elevation model (with images from the Palsar sensor of the Alos satellite) and integrated with spectral data (from the optical images from the Sentinel satellite 2) and official spatial data. In total, 1807 species corresponding to 140 plant families were found. There are seven types of vegetation, the largest corresponding to the high terrace forest, low hill forest and high hill forest. The plant community between the terra firme forest and the flooded forest were different according to the similarity analysis ( $p$-value $=0.001$ ); the species more associated with flooded forests are Oxandra euneura Diels, Mauritia flexuosa L. f., Euterpe precatoria Mart, Cynometra spruceana Benth., Pouteria gomphiifolia, Tovomita laurina Planch. \& Triana and Macrolobium limbatum Spruce ex Benth.

KEYWORDS: Amazon, habitats, plants, diversity, similarity, geomorphometry. 


\section{INTRODUCCIÓN}

El interfluvio Napo-Putumayo-Amazonas comprende una de las áreas más importantes de la Amazonía peruana debido a que alberga una gran diversidad biológica, étnica y cultural (Aquino et al., 2007; García-Villacorta et al., 2010). En esta zona, las comunidades de plantas se destacan por una amplia variedad de especies, con importancia socioeconómica que brindan alimentos, medicina y madera (Gilmore et al., 2010); las cuales son aprovechadas por pobladores para subsistencia o comercialización, pero también por intrusos que lo utilizan de manera inapropiada (Pérez et al., 2019b). En este sector las amenazas antrópicas como la deforestación, conversión de los bosques para agricultura migratoria, tala ilegal y minería; aceleran la pérdida de especies de plantas de gran valor ecológico y económico (García-Villacorta et al., 2010; Pitman et al., 2013a; Pitman et al., 2016). Asimismo, la caza de animales dispersores de semillas ocasiona una reducción significativa de la diversidad florística (Swamy et al., 2013; Aquino et al., 2016), lo que provocaría la desaparición de los recursos y aparición de serios problemas socioculturales y biológicos, y por ende el empobrecimiento de la calidad de vida del poblador del sector Napo y Putumayo (Gilmore et al., 2010; Pérez et al., 2019b).

Los inventarios de plantas realizados en el interfluvio Napo-Putumayo-Amazonas ayudaron a registrar especies nuevas para la ciencia o nuevas para el departamento de Loreto, como también poblaciones saludables de especies de interés comercial (Vriesendorp et al., 2008; García-Villacorta et al., 2010; Dávila et al., 2013; Ríos et al., 2016; Torres et al., 2019). Dicha información se utilizó para la creación de áreas naturales protegidas, las cuales permitieron regular la extracción y el aprovechamiento sostenible de sus recursos. Por lo tanto, el manejo de los bosques requiere de información confiable que permita una adecuada planificación a mediano y largo plazo. Por esta razón, se hace necesario el conocimiento de la diversidad y distribución de las comunidades de plantas, de manera que permita generar estrategias de conservación para aquellas especies utilizadas de manera intensiva y tomar decisiones acertadas en beneficio de las comunidades nativas quienes dependen directamente de este recurso para su supervivencia (Pérez et al., 2019a).

La distribución y diversidad de las comunidades de plantas (unidades de vegetación) expresadosenlos modelosespaciales, normalmenteson elaborados sobre imágenes de satélite y usando datos de campo, sin embargo, este procedimiento toma mucho tiempo y dinero. Mientras que una producción automatizada a partir de imágenes de satélite ópticas, radar y modelos de elevación digital resulta un procedimiento altamente eficaz (Martinez \& Le, 2007; Palacios \& Torres, 2014).

El Sistema de Información Geográfica (SIG) aplicando técnicas recientes, contribuye con la generación de información espacial. Una de las ventajas es que rápidamente provee de modelos espaciales del relieve, lo que es de gran utilidad al extrapolar unidades de vegetación a un territorio más amplio y con pocos datos disponibles (Tinós et al., 2014). Así mismo, existe una relación entre el espacio representado por las formas de relieve con el comportamiento y la dinámica de las especies, debido a la necesidad de estas por los recursos que se encuentran distribuidos espacialmente (Jenness, 2004; Zárate et al., 2019a,b). Actualmente los procesos de interpretación visual se vienen sustituyendo por procesos que cuantifican relativamente las formas del terreno, aplicando procesos de clasificación automática sobre modelos digitales de elevación (MDE) e imágenes satelitales ópticas o radar; los patrones de formas del relieve más 


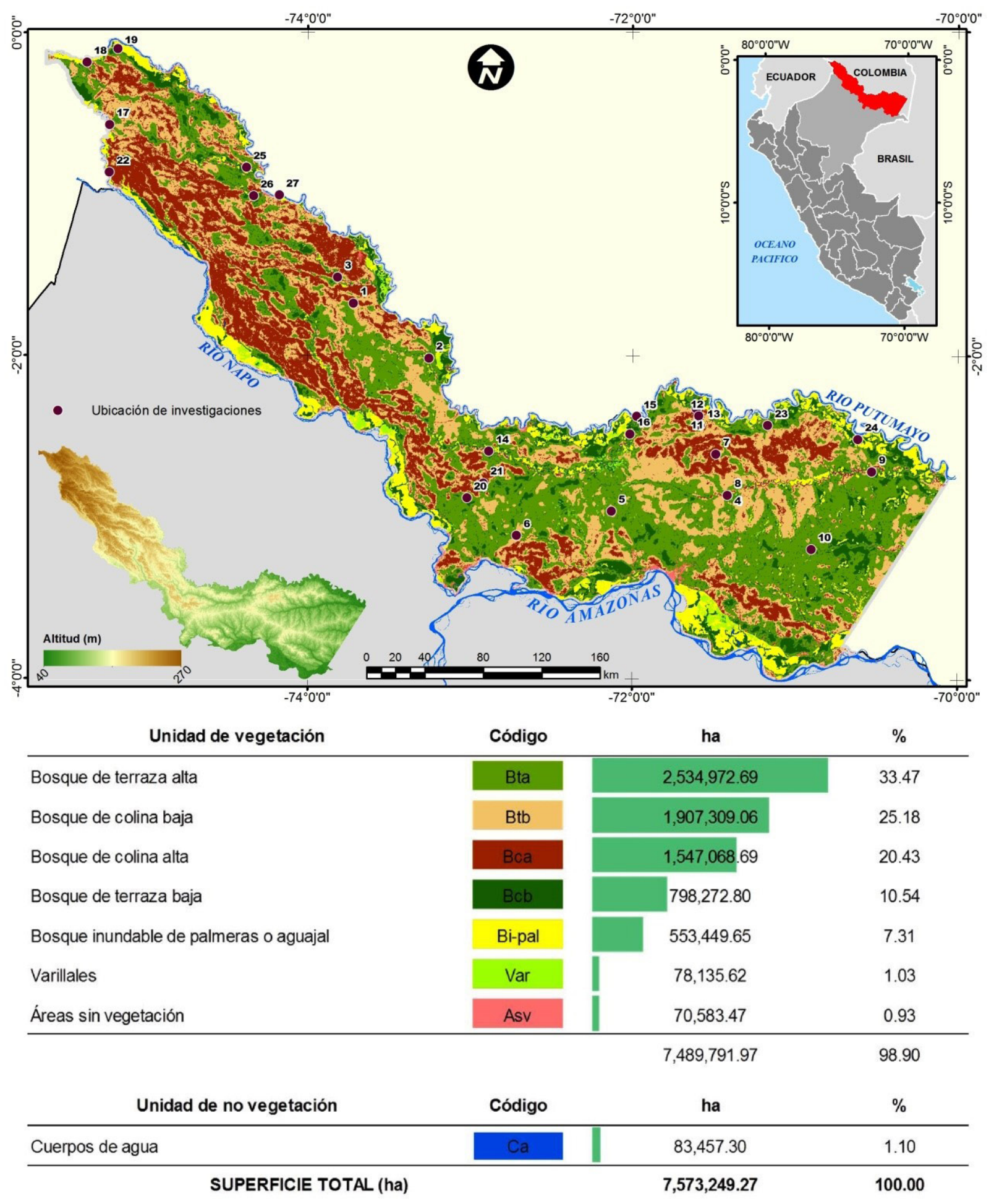

Figura 1. Mapa del área de estudio y tipos de vegetación del interfluvio Napo-Putumayo-Amazonas, Loreto, Perú. Donde $\mathrm{Btb}=\mathrm{B}$ osque de terraza alta; $\mathrm{Bta}=\mathrm{B}$ osque de colina baja; $\mathrm{Bcb}=\mathrm{B}$ osque de colina alta; $\mathrm{B} c \mathrm{a}=\mathrm{Bosque}$ de terraza baja; $\mathrm{Bi}$-pal=Bosque inundable de palmeras o aguajal; V=Varillales; $\mathrm{ASV}=A$ reas sin vegetación y $\mathrm{CA}=\mathrm{Cuerpos}$ de agua. La leyenda de los números de ubicación de investigaciones se puede ver en la Tabla 1. 
comunes a utilizar en un proceso de análisis son: la pendiente, amplitud, perfil de relieve, la rugosidad del terreno, curvatura, etc. (Palacios \& Torres, 2014; Tinós et al., 2014; Bortolini et al., 2017).

Tanto la información geomorfométrica obtenida de los modelos de elevación disponibles de descarga libre en la web, asi como, las plataformas de descarga de procesamiento de datos satelitales como Google Earth Engine (GEE) implementados con algoritmos de aprendizaje automático, se complementan tecnológicamente con un alto potencial para su aplicación en estudios de caracterización de variables territoriales como la vegetación, en los cuales las principales caracteristcas son el vacio de información de cuanto y donde se encuentran las comunidades de vegetación, las superficies extensas y el difícil acceso (Chen et al., 2017; Huang et al., 2017).

Por tal motivo, el presente estudio tiene como objetivos cuantificar la riqueza florística y elaborar un modelo espacial de los tipos de vegetación del interfluvio Napo-PutumayoAmazonas (Perú).

\section{MATERIAL Y MÉTODOS}

\section{ÁREA DE ESTUDIO}

El área de estudio se encuentra localizado al noreste del departamento Loreto del Perú y comprende la zona entre los ríos Napo, Putumayo y Amazonas, denominado interfluvio NapoPutumayo-Amazonas (Figura 1). Corresponde a la selva baja de la Amazonía peruana, tiene una cobertura vegetal variada y compleja, representada por bosques de tierra firme e inundable. Los lugares de estudio se ubican en la cuenca Lagartococha (Baldeón et al., 2012), cuenca baja del río Putumayo (Alva-Vela et al., en prensa), cuenca alta del río Putumayo (Zárate et al., 2019a), cuenca del río Aguarico (Zárate et al., 2019b), cuenca del río Ampiyacu, Apayacu, Yaguas y medio Putumayo (Vriesendorp et al., 2004), Cuyabeno-Güeppi (Vriesendorp et al., 2008), interfluvio medio Putumayo-Algodón (Ríos et al. 2016), las cuencas Ere-Campuya-Algodón (Dávila et al., 2013), ACR Maijuna (García-Villacorta et al., 2010) y el interfluvio cuencas Yaguas-Cotuhé (García-Villacorta et al., 2011). Las coordenas geográficas están disponibles en la Tabla 1.

En la cuenca del Putumayo, la temperatura promedio varía desde 25 a los $28{ }^{\circ} \mathrm{C}$, según los datos de Puerto Leguízamo (PEDICP, 1993). La precipitación anual promedio varía de 2400 a $2800 \mathrm{~mm}$ (Pitman et al., 2013a). En la cuenca del Napo la temperatura promedio anual es de $24.7^{\circ} \mathrm{C}$, la humedad relativa promedio anual es de 91,5.\%, y la precipitación anual es de 3,000 mm, siendo ésta la más alta en la selva baja (Kalliola et al., 1993; Tello-Martín \& García-Dávíla, 2015). La cuenca del río Napo tiene mayor precipitación comparado con la cuenca del Putumayo (Hijmans et al., 2005). La altitud relativa en el área de estudio varía desde los 40 hasta 270 msnm según el modelo de elevación digital.

\section{FUENTES DE INVENTARIOS FLORÍSTICOS}

Información de 10 estudios del interfluvio Napo-Putumayo-Amazonas fue recopilado de: Baldeón et al. (2012), Vriesendorp et al. (2004), Vriesendorp et al. (2008), García-Villacorta et al. (2010), García-Villacorta et al. (2011), Dávila et al. (2013), Ríos et al. (2016), Zárate et al. (2019 a,b), Alva-Vela et al. (en prensa), se elaboró una base de datos utilizando el programa Microsoft Office Excel, considerando el nombre del proyecto, parcela, familia, especie, hábitat, código de muestreo, código de colecta, hábito, entre otras informaciones.

La verificación de los nombres aceptados y sinónimos de las especies se realizaron en las páginas webs Taxonomic name resolution service (http://tnrs.iplantcollaborative.org/TNRSapp. 
Tabla 1. Lista de localidades de muestreo, coordenadas de ubicación y tipos de vegetación. BCA: bosque de colina alta, BCB: bosque de colina baja, BTA: bosque de terraza alta, BTB: bosque de terraza baja.

\begin{tabular}{|c|c|c|c|c|}
\hline $\mathbf{N}^{\circ}$ & Localidad & Longitud & Latitud & Hábitat \\
\hline 1 & Ere-Algodón & $73^{\circ} 43^{\prime} 10.8998^{\prime \prime}$ & $1^{\circ} 40^{\prime} 44.5001^{\prime \prime}$ & BTB \\
\hline 2 & Bajo Ere & $73^{\circ} 15^{\prime} 13.3999 "$ & $2^{\circ} 1^{\prime} 7.40028^{\prime \prime}$ & BTB \\
\hline 3 & Medio Campuya & $73^{\circ} 48^{\prime} 58.2001^{\prime \prime}$ & $1^{\circ} 31^{\prime} 3.4004^{\prime \prime}$ & BTB \\
\hline 4 & Yaguas & $71^{\circ} 24^{\prime} 54.0998^{\prime \prime}$ & $2^{\circ} 51^{\prime} 53.5002^{\prime \prime}$ & BTB \\
\hline 5 & Maronal & $72^{\circ} 7^{\prime} 40.2999^{\prime \prime}$ & $2^{\circ} 57^{\prime} 56.3000^{\prime \prime}$ & BTB \\
\hline 6 & Apayacu & $72^{\circ} 42^{\prime} 45.0000^{\prime \prime}$ & $3^{\circ} 7^{\prime} 0.0001^{\prime \prime}$ & BTB \\
\hline 7 & Choro & $71^{\circ} 29^{\prime} 8.6999^{\prime \prime}$ & $2^{\circ} 36^{\prime} 38.1999^{\prime \prime}$ & BTB \\
\hline 8 & Yaguas & 7124 54.099" & $2^{\circ} 51^{\prime} 53.5003^{\prime \prime}$ & BTB \\
\hline 9 & Cachimbo & $70^{\circ} 31^{\prime} 45.0998^{\prime \prime}$ & $2^{\circ} 43^{\prime} 5.8997^{\prime \prime}$ & BTB \\
\hline 10 & Alto Cotuhé & $70^{\circ} 53^{\prime} 56.5001^{\prime \prime}$ & $3^{\circ} 11^{\prime} 55.6000^{\prime \prime}$ & BTB \\
\hline 11 & Quebrada Bufeo & $71^{\circ} 36^{\prime} 27.1000^{\prime \prime}$ & $2^{\circ} 19^{\prime} 50.1999^{\prime \prime}$ & BTB \\
\hline 12 & Quebrada Agua Blanca & $71^{\circ} 35^{\prime} 34.2999 "$ & $2^{\circ} 22^{\prime} 30.2001^{\prime \prime}$ & BTB \\
\hline 13 & Quebrada Mutún & $71^{\circ} 35^{\prime} 1.7001^{\prime \prime}$ & $2^{\circ} 26^{\prime} 0.5999^{\prime \prime}$ & BTB \\
\hline 14 & Medio Algodón & $72^{\circ} 53^{\prime} 2.5998^{\prime \prime}$ & $2^{\circ} 35^{\prime} 42.2001^{\prime \prime}$ & BTB \\
\hline 15 & Bajo Algodón & $71^{\circ} 58^{\prime} 29.8482^{\prime \prime}$ & $2^{\circ} 22^{\prime} 44.0675^{\prime \prime}$ & BTB \\
\hline 16 & Chave Cocha & $72^{\circ} 0^{\prime} 51.0998^{\prime \prime}$ & $2^{\circ} 29^{\prime} 16.0000^{\prime \prime}$ & BTB \\
\hline 17 & Redondococha & $75^{\circ} 13^{\prime} 9.1999 "$ & $0^{\circ} 34^{\prime} 16.7001^{\prime \prime}$ & $\mathrm{BCA}$ \\
\hline 18 & Güeppí & $75^{\circ} 21^{\prime} 32.2999 "$ & $0^{\circ} 11^{\prime} 4.8998 "$ & $\mathrm{BCA}$ \\
\hline 19 & Aguas Negras & $75^{\circ} 10^{\prime} 4.6999 "$ & $0^{\circ} 6^{\prime} 1.6001^{\prime \prime}$ & BCA \\
\hline 20 & Curupa & $73^{\circ} 1^{\prime} 7.2001^{\prime \prime}$ & $2^{\circ} 53^{\prime} 6.1000^{\prime \prime}$ & BTA \\
\hline 21 & Piedras & $72^{\circ} 55^{\prime} 2.9002^{\prime \prime}$ & $2^{\circ} 47^{\prime} 33.9003^{\prime \prime}$ & BTA \\
\hline 22 & Río Aguarico & $75^{\circ} 13^{\prime} 14.4299^{\prime \prime}$ & $0^{\circ} 51^{\prime} 58.0802^{\prime \prime}$ & BTA \\
\hline 23 & Remanso & $71^{\circ} 10^{\prime} 2.9999^{\prime \prime}$ & $2^{\circ} 25^{\prime} 58.6700^{\prime \prime}$ & BTB \\
\hline 24 & Tres Esquinas & $70^{\circ} 36^{\prime} 45.7315^{\prime \prime}$ & $2^{\circ} 31^{\prime} 5.0537^{\prime \prime}$ & BTB \\
\hline 25 & Mashunta & $74^{\circ} 22^{\prime} 35.4853^{\prime \prime}$ & $0^{\circ} 50^{\prime} 15.0266^{\prime \prime}$ & $\mathrm{BCB}$ \\
\hline 26 & Santa Rita & $74^{\circ} 19^{\prime} 57.4291^{\prime \prime}$ & $1^{\circ} 0^{\prime} 48.3073 "$ & $\mathrm{BCB}$ \\
\hline 27 & Nuevo Jerusalén & $74^{\circ} 10^{\prime} 32.2701^{\prime \prime}$ & $1^{\circ} \mathrm{O}^{\prime} 32.5828 "$ & $\mathrm{BCB}$ \\
\hline
\end{tabular}


html) proprocionada por Boyle et al. (2013) y The Plant List (http://www.theplantlist.org/). Las especies indeterminadas fueron eliminadas de la lista compilada para evitar sobre estimar la riqueza de especies.

\section{ANÁLISIS DE DIVERSIDAD DE LA FLORA}

La diversidad de la flora se calculó mediante el conteo de especies válidas y su comparación fue mediante curvas de rarefacción que permiten comparar muestras con diferente esfuerzo de muestreo. La riqueza esperada fue calculada con el estimador no paramétrico Chao 1 utilizando el programa Past(Hammer etal.,2001) y estos fueron graficados con el programa Sigma Plot (Kornbrot, 2000). La similitud de la flora se determinó a través del Análisis de Componentes Principales (ACP), que permitió evidenciar especies que son más abundantes a un tipo de hábitat. Además, se realizó el Análisis de Similitud (ANOSIM, por su sigla en inglés), el cual es un análisis multivariado que usa la similitud de Bray-Curtis para evaluar si las comunidades de plantas son diferentes entre hábitats, para ambos análisis se utilizó el software Community Analysis Package CAP 4.0 (Henderson \& Seaby, 2007).

\section{MODELAMIENTO ESPACIAL DE LA VEGETACIÓN}

Se utilizó el modelo de elevación digital (DEM, por su sigla en inglés) del sensor ALOS PALSAR del año 2011 y resolución espacial 12,5 m, obtenido de www.search.asf.alaska.edu/\#/. Así mismo, se utilizaron las colecciones de datos satelitales del sensor Sentinel 2 en Google Earth Engine (GEE). El algoritmo de descarga y filtros en el módulo editor de códigos del GEE para la descarga en un mosaico de imágenes, con valores de reflectancia corregidas a nivel de la superficie terrestre de resolución espacial $10 \mathrm{~m}$ y periodo de captura 01/01/2020 al 31/01/2020.
También se utilizaron datos vectoriales y raster de distribución espacial de varillales del departamento de Loreto (GOREL, 2020), Mapa de Vegetación del Perú (MINAM, 2015) y distribución del Bosque y No Bosque del año 2018 elaborado por el Programa Nacional de Conservación de Bosques del MINAM (http://geobosques.minam. gob.pe/geobosque/view/descargas.php.)

Para el análisis y procesamiento de la geoinformación se utilizaron los programas ArcGIS 10.1 (Morgan \& Lesh, 2005; Artugyan \& Urdea, 2016), QGIS 3.10 (Metzen et al., 2019) y el módulo editor de código de GEE. El sistema de referencia utilizado para los análisis y procesamiento de la información geoespacial fue el WGS 84 y sistema de proyección UTM Zona 18 Sur.

La distribución espacial de las unidades de vegetación se generó mediante análisis espacial identificando las formas homogéneas de terreno o relieve clasificadas como formas fisiográficas (Ricaurte et al., 2012). Las geoformas del terreno se espacializaron utilizando el DEM del cual se extrajeron tres parámetros: 1) pendiente, 2) relieve y 3) perfil de relieve, y clasificados de forma cuantitativa (Hammond, 1964; Dikau, 1989; Morgan \& Lesh, 2005; Zárate et al., 2019a,b). Se identificaron y espacializaron otras formas de no relieve como los cuerpos de agua, áreas de intervención antrópica, áreas pantanosas, bosques de tipo varillal y comunidades de aguajales a partir de la clasificación de imágenes de satélite ópticas Sentinel 2. Los cuerpos de agua, áreas sin vegetación y bosques de varillales se integraron a partir de información vectorial del GOREL (2020). Los resultados anteriores se integraron con datos de unidades de vegetación sistematizados de estudios anteriores para ser extrapolados a otras áreas homogéneas que cumplan con las características evaluadas (Zárate et al., 2019a,b). Las unidades de vegetación se clasificaron de acuerdo al sistema y nomenclatura 
del MINAM (2015), con algunas modificaciones de Zárate et al. (2013).

\section{RESULTADOS}

\section{DIVERSIDAD DE FLORA}

En el interfluvio Napo-Putumayo-Amazonas desde el año 2004 hasta el 2019 se han registrado un total de 1807 especies, incluidas en 602 géneros y 140 familias de plantas vasculares (Tabla 2, 3).
El número de especies se ha incrementado progresivamente conforme se han desarrollado las investigaciones en el área de estudio (Figura 2a). Las especies con distribución más amplia fueron las palmeras de aguaje (Mauritia flexuosa), hungurahui (Oenocarpus bataua Mart.) y cashapona (Socratea exorrhiza (Mart.) H. Wendl.) ya que fueron reportadas en todas las fuentes de información. Así también las especies Abuta grandifolia (Mart.) Sandwith, Attalea insignis (Mart. ex H. Wendl.) Drude, Brosimum rubescens Taub, Brosimum utile (Kunth) Oken,

Tabla 2. Cantidad de especies por familia en los tipos de vegetación del interfluvio Napo-Putumayo-Amazonas, Perú.

\begin{tabular}{|c|c|c|c|c|c|c|}
\hline Familias & $\begin{array}{c}\text { Bosque } \\
\text { de colina } \\
\text { baja }\end{array}$ & $\begin{array}{c}\text { Bosque } \\
\text { de terraza } \\
\text { alta }\end{array}$ & $\begin{array}{c}\text { Bosque } \\
\text { de terraza } \\
\text { baja }\end{array}$ & $\begin{array}{c}\text { Bosque } \\
\text { inundable } \\
\text { denso }\end{array}$ & $\begin{array}{c}\text { Bosque } \\
\text { inundable } \\
\text { mixto }\end{array}$ & $\begin{array}{c}\text { Varillal } \\
\text { pantanoso }\end{array}$ \\
\hline Achariaceae & 1 & 2 & 1 & 0 & 0 & 0 \\
\hline Anacardiaceae & 1 & 2 & 1 & 1 & 1 & \\
\hline Annonaceae & 20 & 20 & 11 & 2 & 5 & 4 \\
\hline Apocynaceae & 5 & 3 & 3 & 3 & 4 & 2 \\
\hline Araceae & 4 & 4 & 2 & 0 & 3 & 3 \\
\hline Araliaceae & 1 & 1 & & & 1 & 1 \\
\hline Arecaceae & 16 & 10 & 9 & 7 & 9 & 9 \\
\hline Aspleniaceae & 1 & & & & 1 & 1 \\
\hline Begoniaceae & & & & 1 & & \\
\hline Bignoniaceae & 4 & 1 & 1 & 1 & 2 & 2 \\
\hline Blechnaceae & & & 1 & 1 & & \\
\hline Bromeliaceae & & & & 1 & & \\
\hline Burseraceae & 22 & 13 & 5 & 2 & 1 & \\
\hline Calophyllaceae & 1 & & 2 & 1 & 2 & \\
\hline Caryocaraceae & 2 & & 1 & 1 & & \\
\hline Celastraceae & 1 & 1 & & 1 & & \\
\hline Chrysobalanaceae & 13 & 9 & 8 & 3 & 0 & 2 \\
\hline Clusiaceae & 7 & 2 & 0 & 1 & 2 & 3 \\
\hline
\end{tabular}




\begin{tabular}{|c|c|c|c|c|c|c|}
\hline Familias & $\begin{array}{c}\text { Bosque } \\
\text { de colina } \\
\text { baja }\end{array}$ & $\begin{array}{c}\text { Bosque } \\
\text { de terraza } \\
\text { alta }\end{array}$ & $\begin{array}{c}\text { Bosque } \\
\text { de terraza } \\
\text { baja }\end{array}$ & $\begin{array}{c}\text { Bosque } \\
\text { inundable } \\
\text { denso }\end{array}$ & $\begin{array}{c}\text { Bosque } \\
\text { inundable } \\
\text { mixto }\end{array}$ & $\begin{array}{c}\text { Varillal } \\
\text { pantanoso }\end{array}$ \\
\hline Combretaceae & 5 & 1 & 1 & 2 & 3 & 2 \\
\hline Convolvulaceae & 1 & 1 & & & & \\
\hline Cordiaceae & 1 & & 1 & & & \\
\hline Costaceae & & & & & 1 & \\
\hline Cyatheaceae & & & & & 1 & \\
\hline Cyclanthaceae & & 1 & 1 & & 1 & \\
\hline Cyperaceae & & & & & 1 & 1 \\
\hline Dichapetalaceae & & & 1 & & & 1 \\
\hline Dilleniaceae & & & & & & 1 \\
\hline Dryopteridaceae & 4 & 0 & 1 & 1 & 0 & 1 \\
\hline Ebenaceae & 1 & & & & & \\
\hline Elaeocarpaceae & 9 & 6 & 1 & 2 & 2 & 3 \\
\hline Erythroxylaceae & 1 & 2 & & & 1 & 1 \\
\hline Euphorbiaceae & 8 & 9 & 9 & 4 & 4 & 8 \\
\hline Fabaceae & 46 & 15 & 14 & 21 & 12 & 23 \\
\hline Gentianaceae & 2 & & & & & \\
\hline Gesneriaceae & & & & & & 1 \\
\hline Goupiaceae & 1 & 1 & 1 & & & \\
\hline Humiriaceae & & & & & & 1 \\
\hline Hymenophyllaceae & 1 & & & & 1 & \\
\hline Hypericaceae & & & 2 & & & \\
\hline Lacistemataceae & 1 & & 1 & 1 & & 1 \\
\hline Lauraceae & 27 & 6 & 6 & 3 & 1 & 3 \\
\hline Lecythidaceae & 13 & 10 & 8 & 3 & 0 & 2 \\
\hline Lepidobotryaceae & & & 1 & & & \\
\hline Loganiaceae & 3 & 1 & 0 & 0 & 1 & 0 \\
\hline Lomariopsidaceae & 1 & 1 & 1 & & 1 & \\
\hline Malpighiaceae & 1 & & & & & 1 \\
\hline Malvaceae & 13 & 5 & 5 & 0 & 7 & 2 \\
\hline Marantaceae & 2 & & 1 & 1 & 1 & \\
\hline
\end{tabular}




\begin{tabular}{|c|c|c|c|c|c|c|}
\hline Familias & $\begin{array}{c}\text { Bosque } \\
\text { de colina } \\
\text { baja }\end{array}$ & $\begin{array}{c}\text { Bosque } \\
\text { de terraza } \\
\text { alta }\end{array}$ & $\begin{array}{c}\text { Bosque } \\
\text { de terraza } \\
\text { baja }\end{array}$ & $\begin{array}{c}\text { Bosque } \\
\text { inundable } \\
\text { denso }\end{array}$ & $\begin{array}{c}\text { Bosque } \\
\text { inundable } \\
\text { mixto }\end{array}$ & $\begin{array}{c}\text { Varillal } \\
\text { pantanoso }\end{array}$ \\
\hline Melastomataceae & 9 & 8 & 7 & 12 & 4 & 3 \\
\hline Meliaceae & 10 & 7 & 1 & 1 & 4 & 0 \\
\hline Menispermaceae & 1 & 1 & & & & 1 \\
\hline Moraceae & 23 & 14 & 11 & 1 & 2 & 3 \\
\hline Myristicaceae & 21 & 14 & 14 & 4 & 4 & 2 \\
\hline Myrtaceae & 11 & 1 & 4 & 7 & 1 & 7 \\
\hline Nephrolepidaceae & 1 & & & & & \\
\hline Nyctaginaceae & 5 & 2 & 1 & & & 1 \\
\hline Ochnaceae & 3 & 1 & & 1 & 1 & \\
\hline Olacaceae & 1 & 1 & 2 & & 2 & 2 \\
\hline Opiliaceae & & 1 & & & & \\
\hline Piperaceae & 5 & 2 & 2 & 0 & 1 & 0 \\
\hline Polygalaceae & & & 1 & & & \\
\hline Polygonaceae & 1 & & & 1 & 3 & 2 \\
\hline Polypodiaceae & 2 & 1 & & & & \\
\hline Primulaceae & & 1 & & 1 & & \\
\hline Putranjivaceae & & & & & & 1 \\
\hline Rubiaceae & 19 & 9 & 17 & 5 & 7 & 5 \\
\hline Sabiaceae & 3 & 1 & & & & \\
\hline Salicaceae & 4 & 3 & 1 & 0 & 1 & 1 \\
\hline Sapindaceae & 7 & 1 & 1 & 3 & 1 & 2 \\
\hline Sapotaceae & 28 & 13 & 10 & 3 & 3 & 13 \\
\hline Simaroubaceae & 4 & 2 & & & & \\
\hline Siparunaceae & 1 & & & & & \\
\hline Strelitziaceae & 1 & & 1 & & & \\
\hline Ulmaceae & & & & 1 & & \\
\hline Urticaceae & 6 & 3 & 4 & 1 & 3 & 1 \\
\hline Violaceae & 5 & 2 & 2 & & & \\
\hline Vochysiaceae & 1 & 2 & 2 & & & \\
\hline Zingiberaceae & & 1 & & & & \\
\hline 78 & 412 & 218 & 181 & 105 & 106 & 123 \\
\hline
\end{tabular}


Coussapoa trinervia Spruce ex Mildbr, Duroia hirsuta (Poepp.) K. Schum, Eschweilera coriacea (DC.) S.A. Mori, Euterpe precatoria Mart, Guarea macrophylla Vahl, Helicostylis tomentosa (Poepp. \& Endl.) Rusby, Nealchornea yapurensis Huber, Oxandra xylopioides Diels, Pseudolmedia laevis (Ruiz \& Pav.) J.F. Macbr, Tapirira guianensis Aubl, Virola calophylla (Spruce) Warb, Virola elongata
(Benth.) Warb y Virola pavonis (A. DC.) A.C. Sm. estuvieron presentes en nueve de diez estudios realizados.

Se reportan 140 familias de plantas vasculares, esta cantidad se ha mantenido durante los tres últimos estudios realizados en el área de evaluación (Figura 2b). La mayor cantidad de familias se reportaron en Yaguas-Cotuhé
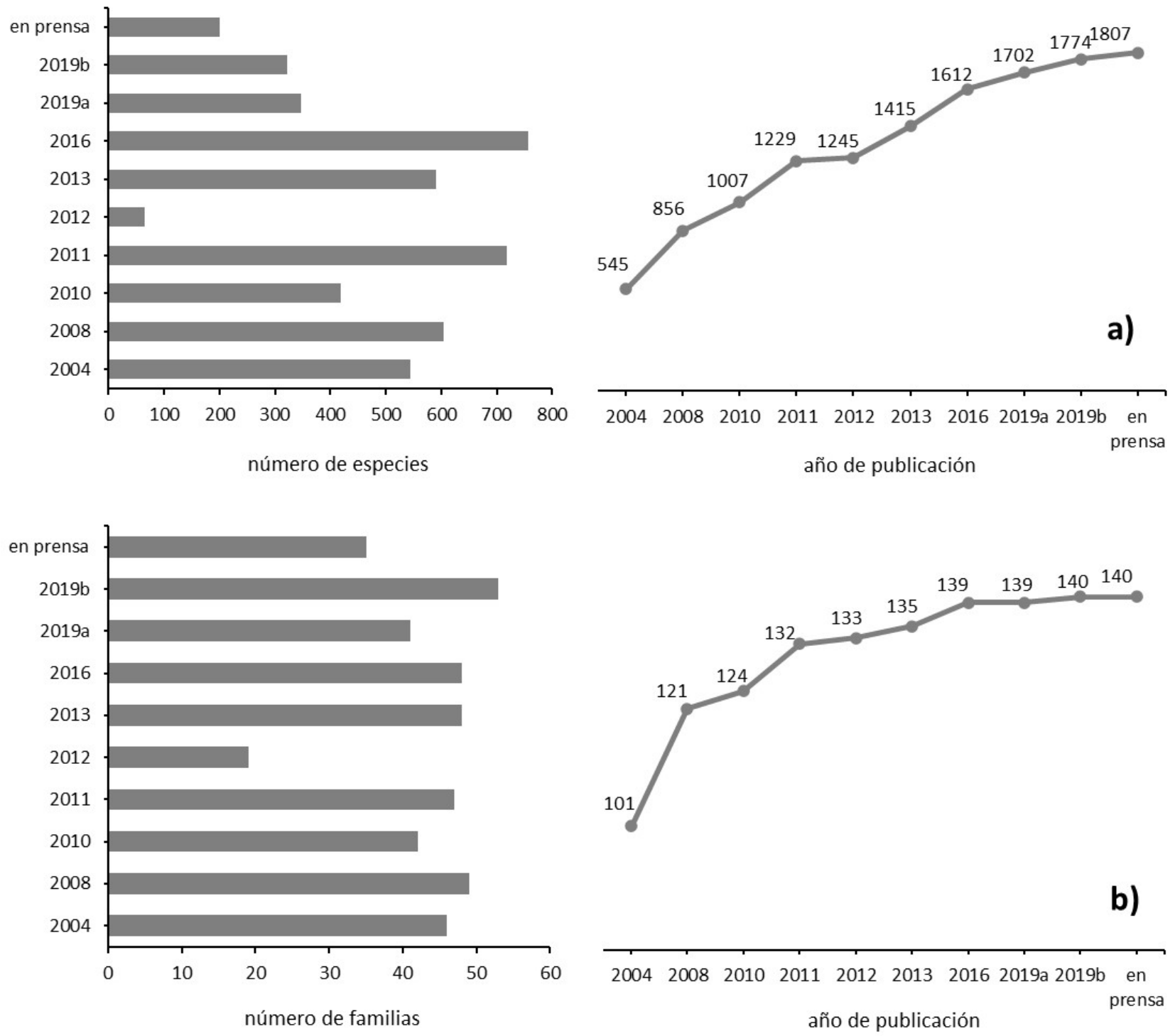

Figura 2. a) Riqueza de especies, b) Riqueza de familias, registradas desde 2004 (izquierda) y su acumulación en el interfluvio Napo-Putumayo-Amazonas (derecha). Los registros se obtuvieron de Vriesendorp et al. (2004), Vriesendorp et al. (2008), García-Villacorta et al. (2010), García-Villacorta et al. (2011), Baldeón et al. (2012), Dávila et al. (2013), Ríos et al. (2016), Zárate et al. (2019 a, b), Alva et al. (en prensa). 
(García-Villacorta et al., 2011), Cuyabeno-Güeppi (Vriesendorp et al., 2008) y el Medio PutumayoAlgodón (Ríos et al., 2016). Las familias que tuvieron especies con amplia distribución fueron Arecaceae, Lecythidaceae, Rubiaceae, Myristicaceae, Euphorbiaceae, Menispermaceae, Moraceae, Urticaceae, Anacardiaceae y Meliaceae.

Las familias con la mayor cantidad de géneros fueron Fabaceae (52 géneros), Rubiaceae (42), Arecaceae (25), Euphorbiaceae (25), Malvaceae (21),Annonaceae(18), Araceae(14),Apocynaceae (13), Moraceae (13) y Melastomataceae (12). Los géneros con la mayor cantidad de especies fueron Miconia (57 especies), Inga (34), Protium (26), Ficus (21), Pouteria (21), Palicourea (20), Philodendron (20), Piper (20), Psychotria (20), Heliconia (18), Sloanea (18) y Virola (18).

\section{TIPOS DE VEGETACIÓN DEL INTERFLUVIO} NAPO-PUTUMAYO-AMAZONAS

En el modelo espacial de unidades de vegetación encontramos siete tipos de vegetación, siendo de mayor superficie los Bosques de terraza alta $(33,47 \%)$, Bosques de colina baja $(25,18 \%)$ y Bosques de colina alta $(20,43 \%)$, en tanto los bosques inundables densos, mixtos y varillal pantanoso tienen menor cobertura espacial.

Las especies que se encontraron en todos los tipos de vegetación fueron Euterpe precatoria y Virola pavonis, y los que se encontraron en cinco de los seis tipos de vegetación fueron Eschweilera albiflora (DC.) Miers, Eschweilera coriacea, Guarea macrophylla, Macrolobium limbatum, Oenocarpus bataua, Pouteria torta (Mart.) Radlk, Pseudosenefeldera inclinata (Müll.Arg.) Esser, Socratea exorrhiza y Tapirira guianensis. La mayor riqueza de especies se registró en el Bosque de colina baja (617 especies esperadas y 411 especies observadas), seguido del Bosque de terraza alta (430 especies esperadas y 216 especies observadas) y Bosque de terraza baja (354 especies esperadas y 171 especies observadas). Mientras los tipos de vegetación con menos especies (Figura 3), fueron el Aguajal

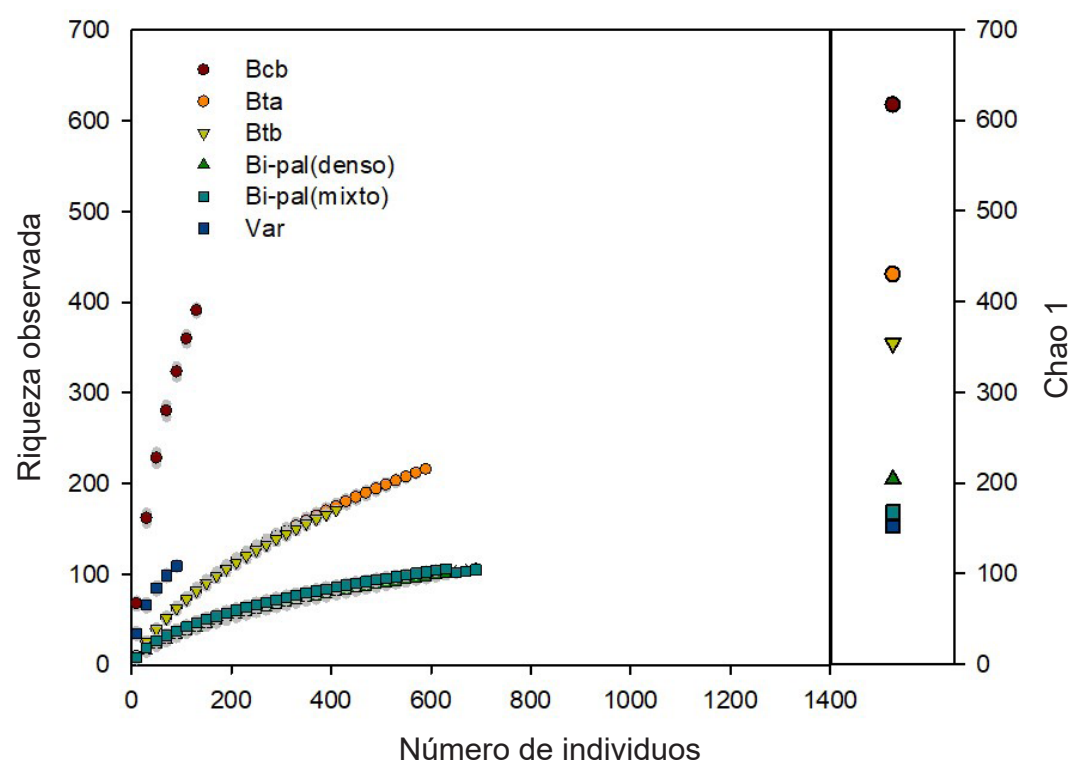

Figura 3. Riqueza de especies observadas (izquierda) y riqueza esperada usando el estimador no paramétrico de Chao1 (derecha) en los tipos de vegetación del interfluvio Napo-Putumayo-Amazonas, Perú. Bcb=Bosque de colina baja, Bta=Bosque de terraza alta, Btb=Bosque de terraza baja, Bi-pal(denso)=Bosque inundable de palmeras denso, Bi-pal(mixto)=Bosque inundable de palmeras mixto, Var=Varillales. 
denso (204 especies esperadas y 105 especies observadas), Aguajal mixto (152 especies esperadas y 107 especies observadas) y Varillal pantanoso (152 especies esperadas de 116 especies observadas).

En cuanto a las familias delas plantas vasculares por tipo de vegetación tenemos que los Bosques de tierra firme conformado por colina baja, terraza alta y terraza baja evidenciaron mayor cantidad de familias con referencia a los Bosques inundables conformado por aguajal denso, aguajal mixto y varillal pantanoso. El Bosque de colina baja tuvo mayor representatividad con 59 familias, seguido del Bosque de terraza alta con 48 familias y Bosque de terraza baja con 46 familias. Mientras que los bosques de aguajal mixto, varillal pantanoso y aguajal denso tuvieron 40 , 39 y 36 familias, respectivamente. Las familias que fueron reportadas en todos los estudios fueron Annonaceae, Apocynaceae, Arecaceae, Bignoniaceae, Combretaceae, Elaeocarpaceae, Euphorbiaceae, Fabaceae, Lauraceae, Melastomataceae, Moraceae, Myristicaceae, Myrtaceae, Rubiaceae, Sapindaceae, Sapotaceae y Urticaceae.

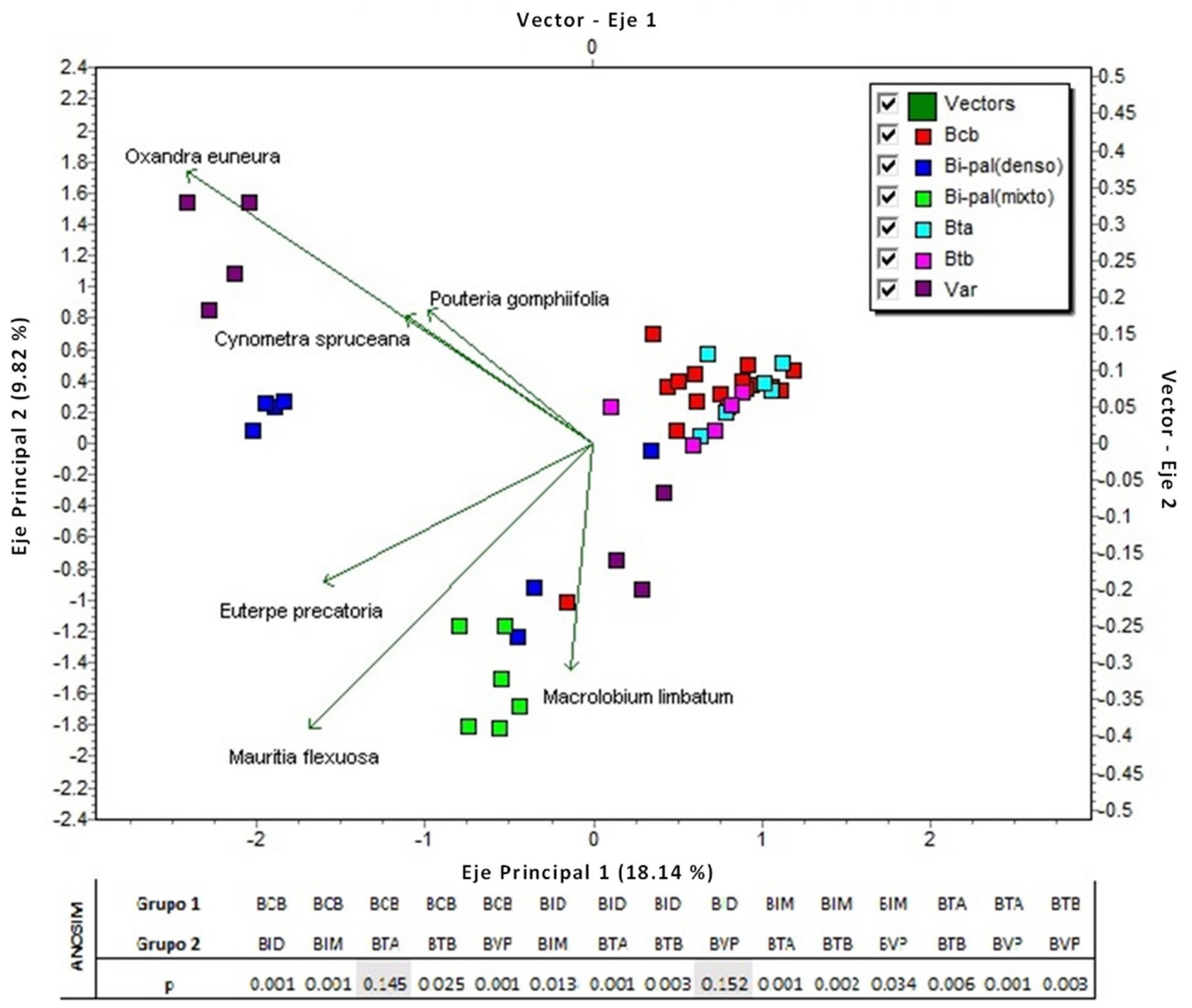

Figura 4. Similitud de especies entre los tipos de bosques en el interfluvio Napo-Putumayo-Amazonas, Perú. $\mathrm{Bcb}=$ Bosque de colina baja, Bi-pal (denso)=Bosque inundable de palmeras denso, Bi-pal (mixto)=Bosque inundable de palmeras mixto, Bta=Bosque de terraza alta, Btb=Bosque de terraza baja, Var=Varillales. 
Los tipos de vegetación estuvieron representados mayormente por especies de la familia Fabaceae (84 especies). El Bosque de colina baja y Varillal pantanoso tuvieron mayor cantidad de especies de las familias Fabaceae y Sapotaceae; en el Bosque de terraza alta fueron más representativas las familias Annonaceae y Fabaceae; en el Bosque de terraza baja fueron Rubiaceae, Fabaceae y Myristicaceae, mientras que en el Aguajal denso fueron Fabaceae y Melastomataceae; y en el Aguajal mixto fueron Fabaceae y Arecaceae (Tabla 2).

El análisis de similitud refleja que la composición de especies de plantas resultan similares cuando se relacionan los bosques de colina baja con terraza alta y el bosque inundable denso con varillal pantanoso (ANOSIM, p > 0.005), en tanto la relación de los otros tipos de bosques difieren significativamente (ANOSIM $\mathrm{p}<0.001$ ). El análisis de componentes principales explica una variabilidad de especies al $27.96 \%$ en sus dos componentes principales. El primer componente explica una variabilidad al $18.14 \%$, donde las especies Oxandra euneura, Mauritia flexuosa, Euterpe precatoria, Macrolobium limbatum, Cynometra spruceana y Pouteria gomphiifolia, fueron más abundantes en los Bosques de Aguajal denso, Aguajal mixto y Varillal pantanoso (Figura 4). Mientras que el segundo componente explica una variabilidad al 9.82\%, donde las especies Mauritia flexuosa, Euterpe precatoria y Macrolobium limbatum estuvieron relacionados solo a bosques inundables, en tanto las otras especies no estarían relacionadas a un tipo de bosque específico.

Una de las parcelas del Bosque de colina baja, evidenció varias especies compartidas con bosques inundables, entre ellos Mauritia flexuosa, Euterpe precatoria, Virola pavonis, Socratea exorrhiza y Macrolobium limbatum, probablemente esta parcela estuvo relacionada con un parche de bosque de aguajal mixto.

\section{DISCUSIÓN}

En este trabajo reportamos que la diversidad de flora del interfluvio Napo-PutumayoAmazonas, tiene al menos 1807 especies, lo cual representa casi la cuarta parte $(22,7 \%)$ de las especies reportadas para Loreto por Pitman et al. (2013b), quienes reportaron 7959 especies (incluyendo otras subcategorías taxonómicas); y el 8,9\% de la flora reportada para el Perú (Smith et al., 2005 y Rodríguez et al., 2006) quienes reportaron 20108 especies de plantas vasculares. Probablemente la diversidad de la flora es mayor en esta área, según el Visor de publicaciones científicas (http://visores.iiap.gob. pe/publicaciones) esta área representa uno de los lugares poco estudiados en Loreto. La mayor cantidad de especies de plantas se reportaron cerca de Iquitos (Ter Steege et al., 2003), para el ámbito de la carretera Iquitos-Nauta (sin incluir la Reserva Nacional Allpahuayo Mishana) se reportaron 1907 especies de plantas vasculares (Zárate \& Mori, 2012) y en tres reservas cerca a Iquitos se reportaron 2740 especies (Vásquez, 1997). Estas diferencias estan influenciadas por los diferentes métodos aplicados en cada trabajo.

Las especies más frecuentes en el área fueron Mauritia flexuosa, Oenocarpus bataua, Socratea exorrhiza, Abuta grandifolia, Attalea insignis, Brosimum rubescens, Brosimum utile, Coussapoa trinervia, Duroia hirsuta, Eschweilera coriacea, Euterpe precatoria, Guarea macrophylla, Helicostylis tomentosa, Nealchornea yapurensis, Oxandra xylopioides, Pseudolmedia laevis, Tapirira guianensis, Virola calophylla, Virola elongata y Virola pavonis; resultados similares se pueden observar en varias publicaciones, como por ejemplo Honorio et al. (2008), Vásquez (1997) y Zárate et al. (2013), aparentemente estas especies son abundantes y están ampliamente distribuidos en Loreto. 
En cuanto a las comunidades vegetales, en esta investigación reportamos siete tipos de vegetación para el interfluvio Napo-PutumayoAmazonas, esta cantidad es media al compararlo con el departamento Loreto que tiene 15 tipos de vegetación (MINAM, 2015). Nuestro resultado es similar a lo reportado por MINAN (2015), en el mismo interfluvio se reporta ocho tipos de vegetación. Las diferencias encontradas son que en nuestro modelo espacial de los tipos de vegetación no detectamos el Bosque de llanura meándrica y el Herbazal hidrofítico, contrariamente nosotros reportamos al Bosque de colina alta y Varillales, que no están incluidos como unidad en el trabajo de MINAM (2015), por lo tanto se recomienda aumentar la lista de tipos de vegetación de la Amazonía peruana (para añadir a los Varillales sobre pantanos) y su distribución que esta reportada oficialmente en MINAM (2015).

Los tipos de vegetación más importantes por la extensión de la superficie son los Bosque de terraza alta, Bosque de colina baja y Bosque de colina alta. Esto concuerda con Zárate et al. (2013) y Encarnación et al. (2014) solamente en el Bosque sobre colinas bajas; pero difiere en cuanto a los Bosque de terraza baja y Bosque inundable de palmeras o aguajal. Esto se debe a que la parte norte de Loreto esta dominado por los bosques de tierra firme, mientras que en la provincia Alto Amazonas esta dominada por Bosques inundables, variando los tipos de vegetación más extensos segun cada sector de Loreto.

Deltotal de especies registradas en el interfluvio Napo-Putumayo-Amazonas, 13 especies se encuentran amenazadas, de acuerdo al Decreto Supremo 043, resultados similares se reportan en el ámbito de la carretera Iquitos-Nauta (sin incluir la Reserva Nacional Allpahuayo Mishana) donde se reportaron 12 especies amenazadas (Zárate \& Mori, 2012). Entre las especies amenazadas se encuentran Cedrela odorata L, Parahancornia peruviana Monach, Handroanthus incanus (A.H. Gentry) S.O. Grose y Zamia ulei Dammer, especies que probablemente siguen siendo extraidas, por lo cual resulta ineludible la implementación de proyectos que viabilicen la conservación de estos recursos, ya que debido a usos antropogénicos estarían declinando sus poblaciones, dejándolas propensas a la extinción local.

Algunas amenazas ocurren en el interfluvio Napo-Putumayo-Amazonas como la deforestación, malas prácticas en agricultura migratoria, cultivos ilicitos, tala selectiva, malas prácticas en minería, mal manejo en la extracción de fauna dispersora de plantas. Para contrarrestar estas amenazas se requiere la implementación de proyectos sostenibles acorde al potencial del área de estudio. La agricultura es una actividad que permite a la población el alimento básico a través de la cosecha de yuca, plátano, entre otros; sin embargo, se realiza de forma migratoria, esto implica la constante deforestación de áreas de bosque, por tanto, es necesario aplicar un análisis de costo beneficio de esta actividad con relación a tener el bosque en pie. La extracción ilegal de recursos de flora se debe regular, extendiendo programas que permitan al poblador acceder a las regulación y capacitación para el aprovechamiento sostenible de la flora amazónica. La conservación de los recursos de flora silvestre podría encaminarse en proyectos que viabilicen la economía del sector, que permitan la sostenibilidad de las especies y ecosistemas aprovechados. Además de generar actividades compatibles con la riqueza natural del territorio. Generar conciencia de proyección en las comunidades del sector sería lo ideal, donde progresivamente se eliminen actividades ilícitas de cultivos de coca y extracción informal de especies principalmente maderables. 


\section{CONCLUSIÓN}

La flora del interfluvio Napo-PutumayoAmazonas alberga una diversidad de 1807 especies de plantas vasculares, sin embargo, los vacios de información que aun existen puede elevar este número de especies. Mediante uso de un modelo espacial automatizado de vegetación se ha identificado siete tipos de vegetación, siendo los Bosque de terraza alta, Bosque de colina baja y Bosque de colina alta los tipos de vegetación con mayor superficie. Las principales amenazas a la flora silvestre en el interfluvio Napo-Putumayo-Amazonas son la deforestación, sobre extracción de fauna silvestre y el uso del mercurio en la minería.

\section{AGRADECIMIENTOS}

Este trabajo se realizó gracias al proyecto: Expedición Binacional Perú-Colombia: Inventarios de diversidad biológica en el Gran Putumayo, en el marco del programa presupuestal 144. Nuestros sinceros agradecimientos a todas las instituciones que realizaron los estudios en esta zona y a los pobladores locales que ayudaron en la ejecución de la misma.

\section{REFERENCIAS BIBLIOGRÁFICAS}

Alva-Vela, A.A.; Mozombite-Pinto, L.F.; PérezMacedo, C.P; (en prensa). Vegetación y Flora. In: Aquino, R.; Díaz, J.; Zárate, R. (Eds). Biodiversidad en la cuenca baja del Putumayo, Perú. Instituto de Investigaciones de la Amazonía Peruana. Iquitos, Perú. p. 15-46.

Aquino, R.; Pachecho, T.; Vásquez, M. 2007. Evaluación y valorización económica de la fauna silvestre en el río Algodón, Amazonía Peruana. Revista Peruana de Biología, 14(2):
187-192. DOI: https://doi.org/10.15381/rpb. v14i2.1730

Aquino, R.; López, L.; Arévalo, I.; Daza, J. 2016. Diversidad y abundancia de primates y sus amenazas en el interfluvio de los ríos Napo y Putumayo, Amazonía peruana. Revista Peruana de Biología, 23(3): 243-252. DOI: https://doi. org/10.15381/rpb.v23i3.12859

Artugyan, L.; Urdea, P. 2016. Using digital elevation model (DEM) in karst terrain analysis. Study case: Anina mining area (Banat Mountains, Romania). Carpathian Journal of Earth and Environmental Sciences, 11(1), 55-64.

Baldeón, S.M.; Macanilla, E.; Tangoy, A.R.; Campos, R.; Vargas, J.J. 2012. Flora de la cuenca Lagartococha. In: Usma, J.S.; Ortega, C.P.; Valenzuela, S.; Deza, J.; Rivas. J. (Eds.). Diversidad biológica y cultural del corredor trinacional de áreas protegidas La PayaCuyabeno-Güeppí Sekime. Colombia-EcuadorPerú. p. 226-235.

Bortolini, W.; Silveira, C.T.; Silveira, R.M.P. 2017. Emprego de técnicas geomorfométricas na identificação de padrões de relevo. Raega-O Espaço Geográfico em Análise, 41: 131-150. DOI: http://dx.doi.org/10.5380/raega.v41i0. 51724

Boyle, B.; Hopkins, N.; Lu, Z.; Raygoza, J.A.; Mozzherin, D.; Rees, T.; Matasci, N.; Narro, M.L.; Piel, W.H.; Mckay, S.J.; Lowry, S.; Freeland, C.; Peet, R. K.; Enquist, B. 2013. The taxonomic name resolution service: an online tool for automated standardization of plant names. BMC Bioinformatics, 14(1), 16. DOI: https:// doi.org/10.1186/1471-2105-14-16

Chen, B.; Xiao, X.; Li, X.; Pan, L.; Doughty, R.; Ma, J.; Dong, J.; Qin, Y.; Zhao, B.; Wu, Z.; Sun, R.; Lan, G.; Xie, G.; Clinton, N.; Giri, C. 2017. A mangrove forest map of China in 2015: Analysis of time series Landsat 7/8 and Sentinel-1A imagery in Google Earth Engine cloud computing platform. ISPRSJournal of Photogrammetryand 
Remote Sensing, 131, 104-120. D0I: https:// doi.org/10.1016/j.isprsjprs.2017.07.011

Dávila, N.; Huamantupa, I.; Ríos, M.; Trujillo, W.; Vriesendorp, C. 2013. Vegetación y flora. In: Pitman, N.; Ruelas, E.; Vriesendorp, C.; Stotz, D.F.; Wachter, T.; del Campo, A.; Alvira, D.; Rodríguez, B.; Chase, R.; Sáenz Rodríguez, A. R.; Soria Ruiz, P. (Eds). Perú: Ere-CampuyaAlgodón. Rapid biological and social inventories, Report 25. p. 85-97.

Decreto Supremo $N^{\circ}$ 043-2006-AG. Aprueban categorización de especies amenazadas de flora silvestre. El Peruano. 13 de julio de 2006. p. 323527-323539.

Dikau, R. 1989. The application of a digital relief model to landform analysis in geomorphology. In: Raper, F. Three dimensional applications in geographical information systems. p. 51-77.

García-Villacorta, R.; Dávila, N.; Foster, R.; Huamantupa, I.; Vriesendorp, C.; 2010. Vegetación y flora. In: Gilmore, M.P.; Vriesendorp, C.; Alverson, W.S.; del Campo, Á.; von May, R.; Wong, C.; Ríos, S. (Eds). Perú: Maijuna. Rapid biological and social inventories, Report 22. p. 58-65.

García-Villacorta, R.; Huamantupa, I.; Cordero, Z.; Pitman, N.; Vriesendorp, C. 2011. Vegetación y flora. In: Pitman, N.; Vriesendorp, C.; Moskovits, D.K.; von May, R.; Alvira, D.; Wachter, T.; Stotz, D.F.; del Campo, A. (Eds). Perú: Yaguas-Cotuhé. Rapid biological and social inventories, Report 23. p. 86-97.

Gilmore, M.P.; Vriesendorp, C.; Alverson, W.S.; del Campo, A.; von May, R.; López, C.; Ríos, S. (Eds). 2010. Perú: Maijuna. Rapid biological and social inventories, Report 22. The Field Museum, Chicago. 140pp.

GOREL. 2020. Mapa y memoria descriptiva de los varillales del departamento Loreto, Perú. Gobierno Regional de Loreto, Iquitos, Perú. 91pp.
Hammer, Ø.; Harper, D.A.T.; Ryan, P.D. 2001. PAST: Paleontological statistics software package for education and data analysis. Palaeontologia Electronica 4(1): 9.

Hammond, E.H. 1964. Analysis of properties in landform geography: An application to broadscale landform mapping. Annals of the Association of American Geographers, 54: 11-19. Henderson P.A.; Seaby R.M. H. 2007. Community analysis package 4.0. Pisces Conservation, Lymington, UK.

Hijmans, R.J.; Cameron, S.E.; Parra, J.L.; Jones, P.G.; Jarvis, A. 2005. Very high resolution interpolated climate surfaces for global land areas. International Journal of Climatology, 25(15): 1965-1978. DOI: https://doi.org/ 10.1002/joc.1276

Honorio, E.N.; Pennington, T.R.; Freitas, L.A.; Nebel, G.; Baker, T.R. 2008. Análisis de la composición florística de los bosques de Jenaro Herrera, Loreto, Perú. Revista Peruana de Biología, 15(1): 53-60. DOI: https://doi. org/10.15381/rpb.v15i1.1670

Huang, H.; Chen, Y.; Clinton, N.; Wang, J.; Wang, X.; Liu, C.; Gong, P.; Yang, J.; Bai, Y.; Zheng, Y. \& Zhu, Z. 2017. Mapping major land cover dynamics in Beijing using all Landsat images in Google Earth Engine. Remote Sensing of Environment, 202(12): 166-176. DOI: https:// doi.org/10.1016/j.rse.2017.02.021

Jenness, J.S. 2004. Calculating landscape surface area from digital elevation models. Wildlife Society Bulletin, 32(3): 829-839.

Kalliola, R.; Puhakka, M.; Danjoi, W. 1993. Amazonía Peruana: Vegetación húmeda tropical en el llano sub andino. Universidad de Turku, Lima. 265pp.

Kornbrot, D. 2000. Statistical software for microcomputers: SigmaPlot 2000 and SigmaStat2. The British Journal of Mathematical and Statistical Psychology, 53(12): 335-337. DOI: https://doi.org/ 10.1348/000711000159268 
Martinez, J.M.; Le, T. 2007. Mapping of flood dynamics and spatial distribution of vegetation in the Amazon floodplain using multitemporal SAR data. Remote sensing of Environment, 108(3): 209-223. DOI: https:// doi.org/10.1016/j.rse.2006.11.012

Metzen, D.; Sheridan, G. J.; Benyon, R. G.; Bolstad, P. V.; Griebel, A.; Lane, P.N. 2019. Spatio-temporal transpiration patterns reflect vegetation structure in complex upland terrain. Science of the Total Environment, 694: 133551. DOI: https:// doi.org/10.1016/j.scitotenv.2019.07.357

MINAM. 2015. Mapa nacional de cobertura vegetal: memoria descriptiva. Ministerio del Ambiente, Lima. 100pp.

Morgan, J.M.; Lesh, A.M. 2005. Developing landform maps using ESRI'S Model-Builder. (https://proceedings.esri.com/library/ userconf/proc05/papers/pap2206.pdf).

Acceso: 09/10/2020.

PEDICP. 1993. Plan Colombo-Peruano para el desarrollo integral de la cuenca del río Putumayo: Diagnóstico regional integrado. Organización de los Estados Americanos. Washington D.C. 125pp.

Palacios, J.; Torres, G. 2014. Clasificación de parámetros de relieve utilizando el modelo digital de elevación (MDE), para describir el paisaje colinoso de la cordillera subandina. Folia Amazónica, 23(1):49-56. DOI: https:// doi.org/10.24841/fa.v23i1.7

Pérez, P.E.; Ramos, M.C.; Díaz, J.; Zárate, R.; Mejía, M. (Eds.) 2019a. Biodiversidad en la cuenca alta del Putumayo, Perú. Instituto de Investigaciones de la Amazonía Peruana. Iquitos, Perú. 155pp.

Pérez-Peña, P.E.; Ramos-Rodríguez, M.C.; Díaz, J.; Zárate, R.; Mejía, K. (Eds.) 2019b. Biodiversidad en las cuencas del Napo y Curaray, Perú. Instituto de Investigaciones de la Amazonía Peruana. Iquitos, Perú. 203pp.
Pitman, N.; Ruelas Inzunza, E.; Vriesendorp, C.; Stotz, D.F.; Wachter, T.; del Campo, A.; Alvira, D.; Rodríguez, B.; Chase, R.; Sáenz, A.R.; Soria, P. (Eds). 2013a. Perú: Ere-Campuya-Algodón. Rapid biological and social inventories, Report 25. The Field Museum. Chicago. 172pp.

Pitman, N.; Gagliardi, G.; Jenkins, C. 2013b. La biodiversidad de Loreto, Perú: el conocimiento actual de la diversidad de plantas y vertebrados terrestres. Center for International Environmental Law, Washington. 39pp.

Pitman, N.; Bravo, A.; Claramunt, S.; Vriesendorp, C.; Alvira Reyes, D.; Ravikumar, A.; del Campo, A.; Stotz, D.F.; Wachter, T.; Heilpern, S.; Rodríguez, B.; Sáenz, A.R.; Chase, R. (Eds). 2016. Perú: Medio Putumayo-Algodón. Rapid biological and social inventories, Report 28. The Field Museum, Chicago. 519pp.

Ricaurte, L.F.; Jokela, J.; Siqueira, A.; NúñezAvellaneda, M.; Marin, C.; Velázquez-Valencia, A.; Wantzen, K.M. 2012. Wetland habitat diversity in the amazonian piedmont of Colombia. Wetlands, 32(11): 1189-1202. DOI: https://doi.org/10.1007/s13157-012-0348-y Ríos, M.A., Torres-Montenegro, L.A.; BaronaColmenares, A.A.; Vriesendorp, C.; Pitman, N. 2016. Flora. In: Pitman, N.; Bravo, A.; Claramunt, S.; Vriesendorp, C.; Alvira Reyes, D.; Ravikumar, A.; del Campo, A.; Stotz, D.F.; Wachter, T.; Heilpern, S.; Rodríguez, B.; Sáenz, A.R.; Chase, R. (Eds). Perú: Medio Putumayo Algodón. Rapid biological and social inventories, Report 28. p. 101-119.

Rodríguez, E.F.; Vásquez, R.; Rojas, R.; Calatayud, G.; León, B.; Campos, J. 2006. Nuevas adiciones de angiospermas a la flora del Perú. Revista Peruana de Biología, 13(1): 129-138. DOI: http://dx.doi.org/10.15381/rpb.v13i1.1776

Smith, A.R.; León, B.; Tuomisto, H.; Van Der Werff, H.; Moran, R.C.; Lehnert, M.; Kessler, M. 2005. New records of pteridophytes for the flora 
of Peru. SIDA Contributions to Botany, 21(4): 2321-2342.

Swamy, V.; Terborgh, J.W.; Álvarez-Loayza, P.; Cornejo-Valverde, F.; Latorre, J.P.; Vela, C.; Chillihuani, J. 2013. El impacto de desfaunación sobre la regeneración del bosque en la cuenca del río Madre de Dios: resultados preliminares de un estudio de largo plazo. In: Groenendijk, J.; Tovar, A.; Wust, W. (Eds). Reporte Manu 2013: Pasión por la investigación en la Amazonia peruana. p. 138-53.

Tello-Marín, S; García, C. 2015. Evaluación hidrobiológica de los ríos Arabela y Curaray. Cuenca delrío Napo. Instituto de Investigaciones de la Amazonía Peruana, Iquitos, Perú. 145pp. Ter Steege, H.; Pitman, N.; Sabatier, D.; Castellanos, H.; van der Hout, P.; Douglas, D.C.; Silveira, M.; Phillips, O.; Vásquez, R.; van Andel, T.; Duivenvoorden, J.; Adalardo de Oliveira, A.; Ek, R.; Lilwah, R.; Thomas, R.; van Essen, J.; Baider, C.; Maas, P.; Mori, S.; Terborgh, J.; Nuñez, P.; Mogollón, H.; Morawetz, W. 2003. A spatial model of tree $\alpha$ diversity and tree density for the Amazon. Biodiversity and Conservation, 12(11): 2255-2277. DOI: https://doi.org/10. 1023/A:1024593414624

Tinós, T.M.; Ferreira, M.V.; Riedel, P.S.; Zaine, J.E. 2014. Aplicação e avaliação de metodologia de classificação automática de formas de relevo. Revista Brasileira de Geomorfologia, 15(3): 353-370. DOI: http://dx.doi.org/10.20502/ rbg.v15i3.455

Torres, L.A.; Ríos, M.A.; Pitman, N.C.A.; Vriesendorp, C.F.; Hensold, N.; Mesones, I.; Dávila, N.; Huamantupa, I.; Beltrán, H.W.; García-Villacorta, R.; Mori, T.J.; Neill, D.A.; Fine, P.V.A.; López-López, J.T.; Núñez, G.; Palacios, W.; Salinas, N.; Trujillo, W. 2019. Sesenta y cuatro nuevos registros para la flora del Perú a través de inventarios biológicos rápidos en la Amazonía peruana. Revista Peruana de Biología, 26(3): 379-392. DOI: https://doi. org/10.15381/rpb.v26i3.16780

Vriesendorp, C.; Pitman, N.; Foster, R.; Mesones, I.; Ríos, M. 2004. Flora y vegetación. In: Pitman, N.; Chase, R.; Vriesendorp, C.; Moskovits, D.; Piana, R.; Knell, G.; Wachter, T. (Eds). Perú: Ampiyacu, Apayacu, Yaguas, Medio Putumayo. Rapid biological and social inventaries, Report 12. p. 54-61.

Vriesendorp, C.; Alverson, W.; Dávila, N.; Descanse, S.; Foster, R.; López, J.; Lucitante, L.C.; Palacios, W.; Vásquez, O. 2008. Flora y vegetación. In: Alverson, W.S.; Vriesendorp, C.; del Campo, A.; Moskovits, D.K.; Stotz, D.F.; García, M.; Borbor, L.A. (Eds). Ecuador, Perú: Cuyabeno - Güeppí. Rapid biological and social inventaries, Report 20. p. $75-83$.

Zárate, R.; Mori, T. 2012. Vegetación, documento temático. Proyecto Microzonificación Ecológica y Económica del Área de Influencia de la Carretera Iquitos-Nauta. IIAP, Iquitos, Perú. 257pp.

Zárate, R.; Mori, T.; Maco, J. 2013. Estructura y composición florística de las comunidades vegetales del ámbito de la carretera IquitosNauta, Loreto, Perú. Folia Amazónica, 22(1-2): 77-89. DOI: https://doi.org/10.24841/fa.v 22i1-2.50

Zárate, R.; Mori, T.J.; Mozombite, L.F.; Palacios, J.; Valles, L.A.; Cohello, G. 2019a. Vegetación y flora. In: Pérez-Peña, P.E.; Ramos-Rodriguez, M.C.; Díaz, J.; Zárate, R.; Mejía, K. (Eds.). Biodiversidad en las cuencas del Napo y Curaray, Perú. p. 12-41.

Zárate, R.; Cohello, G.; Palacios, J.; Escobedo, R.; Calvache, S.; y Abdul, V. 2019b. Vegetación y flora. In: Pérez-Peña, P.E.; Ramos-Rodríguez, M.C.; Díaz-Alván, J.; Zárate-Gómez, R.; Mejía, K. (Eds.). Biodiversidad en la cuenca alta del Putumayo, Perú. p. 18-61. 
Apéndice 1. Lista de familias y especies de plantas vasculares registrados en el interfluvio Napo - Putumayo Amazonas (Perú)

\section{Etiquetas de fila}

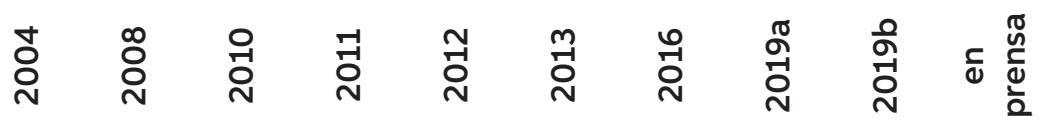

Acanthaceae

$x$

Aphelandra attenuata Wassh.

Aphelandra aurantiaca Lindl.

$x \quad x$

$x \quad x$

Justicia comata (L.) Lam.

Justicia scansilis (Rizzini) V.A.W. Graham

Mendoncia glomerata Leonard

Mendoncia lindavii Rusby

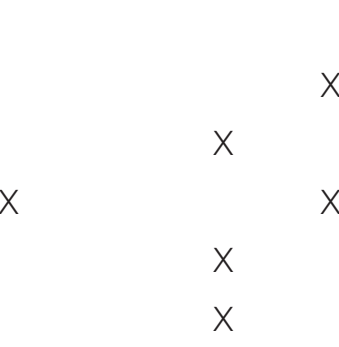

Pachystachys spicata (Ruiz \& Pav.)

Wassh.

$x$

Pulchranthus adenostachyus (Lindau)

V.M. Baum, Reveal \& Nowicke

Sanchezia oblonga Ruiz \& Pav.

Achariaceae

Carpotroche froesiana Sleumer

Carpotroche longifolia (Poepp.) Benth.

Lindackeria paludosa (Benth.) Gilg

$x$

Mayna grandifolia (H. Karst.) Warb.

$x$

$x$

Mayna odorata Aubl.

Amaryllidaceae

Crinum erubescens Aiton

Eucharis candida Planch. \& Linden

$x$

Eucharis cyaneosperma Meerow

\section{Anacardiaceae}

Anacardium giganteum W. Hancock ex Engl.

Astronium graveolens Jacq.

Spondias mombin L.

Spondias venulosa (Engl.) Engl.

Tapirira guianensis Aubl.

$x$

$\begin{array}{lllll}x & x & x & x & \\ x & & x & \end{array}$

X $\quad X$

$\begin{array}{lllll}X & & & & \\ X & X & X & X & X\end{array}$

Tapirira obtusa (Benth.) J.D. Mitch.

Tapirira retusa Ducke

$x$

Thyrsodium herrerense Encarn.

Thyrsodium spruceanum Benth.

\begin{tabular}{|c|c|c|c|}
\hline$x$ & $x$ & $x$ & \\
\hline & $x$ & $x$ & $x$ \\
\hline & $x$ & $x$ & \\
\hline
\end{tabular}

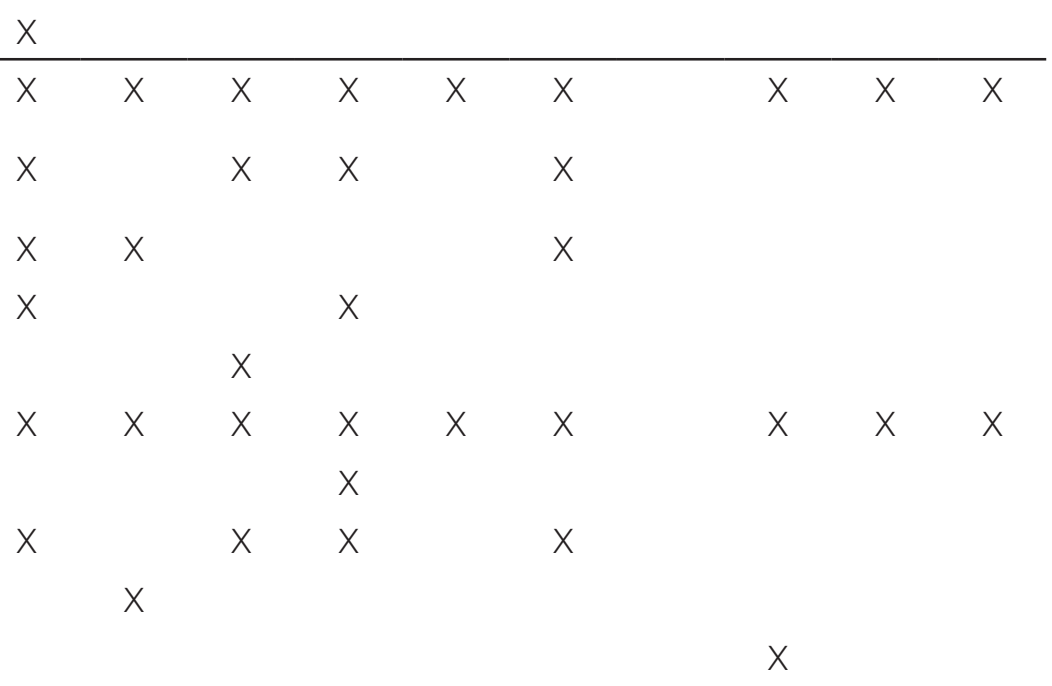




\section{Anisophylleaceae

\begin{tabular}{l} 
Anisophyllea guianensis Sandwith \\
\hline Annonaceae
\end{tabular}

Anaxagorea brachycarpa R.E. Fr.

Anaxagorea brevipes Benth.

Anaxagorea dolichocarpa Sprague \& Sandwith

Anaxagorea floribunda Timmerman

Anaxagorea phaeocarpa Mart.

Annona ambotay Aubl.

Annona duckei Diels

Annona edulis (Triana \& Planch.) $\mathrm{H}$.

Rainer

Annona hypoglauca Mart.

Cremastosperma cauliflorum R.E. Fr.

Cremastosperma gracilipes R.E. Fr.

Cremastosperma megalophyllum R.E. Fr.

Cymbopetalum alkekengi N.A. Murray

Cymbopetalum sanchezii N.A. Murray

Diclinanona calycina (Diels) R.E. Fr.

Diclinanona tessmannii Diels

Duguetia cauliflora R.E. Fr.

Duguetia decurrens R.E. Fr.

Duguetia flagellaris Huber

Duguetia hadrantha (Diels) R.E. Fr.

Duguetia latifolia R.E. Fr.

Duguetia macrophylla R.E. Fr.

Duguetia odorata (Diels) J.F. Macbr.

Duguetia quitarensis Benth.

Duguetia riparia Huber

Duguetia spixiana Mart.

Duguetia surinamensis R.E. Fr.

Ephedranthus guianensis R.E. Fr.

Fusaea longifolia (Aubl.) Saff.

Fusaea peruviana R.E. Fr.

Goniothalamus sesquipedalis (Wall.)

Hook. f. \& Thomson

Guatteria decurrens R.E. Fr. $x$

$x$

$x$

$X$

X

$\begin{array}{llll}x & x & x\end{array}$

$\begin{array}{llllll}X & & X & X & & x \\ X & x & x & x & x & x\end{array}$

$x$

X

$x$ X

$\begin{array}{ll} & x \\ x & x \\ x & x \\ & x\end{array}$

$x$

X

$x$

$x$

$x$

$x$

$x$

$x$

$x$

$x$

X

$x$

$x$

$x$

$x \quad x$

$x$

X

X

$x$

$x \quad x$

$x$

$x \quad x$

$x$

$x$

$x$

$x$ $x$

X

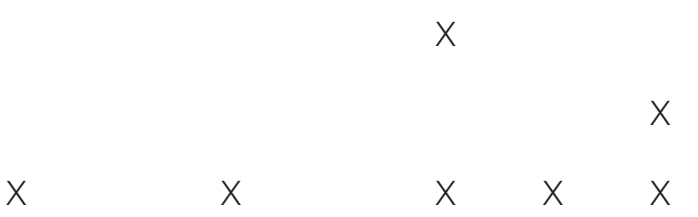


Guatteria dura R.E. Fr.

Guatteria elata R.E. Fr.

$\begin{array}{lll} & x \\ x & x & x \\ x & x\end{array}$

Guatteria guianensis (Aubl.) R.E. Fr.

Guatteria hirsuta Ruiz \& Pav.

$\begin{array}{lll}x & x \quad x \\ x & x \\ x & \\ x & \end{array}$

Guatteria stipitata R.E. Fr.

$$
X
$$

Guatteria ucayalina Huber

Oxandra espintana (Spruce ex Benth.)

Baill.

Oxandra euneura Diels

$x \quad x$
$x$
$x$

Oxandra riedeliana R.E. Fr.

Oxandra sphaerocarpa R.E. Fr.

Oxandra xylopioides Diels

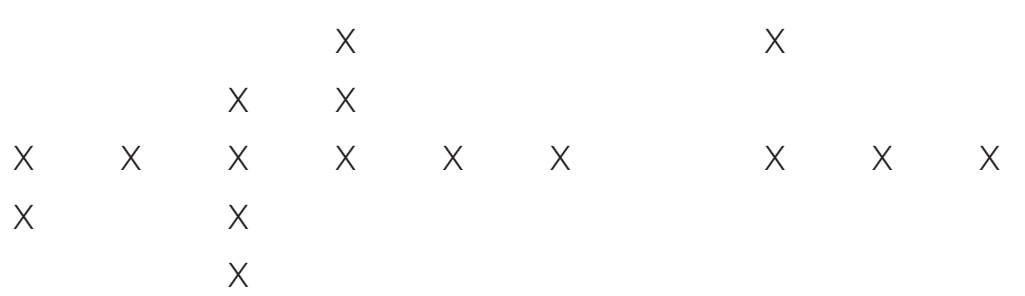

Pseudoxandra polyphleba (Diels) R.E. Fr.

Rollinia danforthii Standl. $\quad X$

Ruizodendron ovale (Ruiz \& Pav.) R.E. Fr. $\quad X$

Tetrameranthus laomae D.R. Simpson $\quad X$

Trigynaea triplinervis D.M. Johnson \&

N.A. Murray

$x$

Unonopsis elegantissima R.E. Fr.

Unonopsis floribunda Diels

$x$

Unonopsis spectabilis Diels

Unonopsis stipitata Diels

$X$

Unonopsis veneficiorum (Mart.) R.E. Fr. $\quad X$

Xylopia calophylla R.E. Fr.

$x$

Xylopia cuspidata Diels

$x \quad x \quad x$

Xylopia micans R.E. Fr.

$x$ 


\begin{tabular}{|c|c|c|c|c|c|c|c|c|c|}
\hline Xylopia nitida Dunal & $x$ & & & & & & & & \\
\hline Xylopia parviflora Spruce & $x$ & $x$ & & $x$ & & $x$ & $x$ & $x$ & $x$ \\
\hline Xylopia sericea A.St.-Hil. & $x$ & & & & & $x$ & $x$ & & \\
\hline Apiaceae & & & & & & & & $x$ & \\
\hline Eryngium foetidum L. & & & & & & & & $x$ & \\
\hline Apocynaceae & $x$ & $x$ & $x$ & $x$ & $x$ & $x$ & $x$ & $x$ & $x$ \\
\hline Ambelania occidentalis Zarucchi & $x$ & & $x$ & & & & & & \\
\hline Aspidosperma excelsum Benth. & $x$ & & & & & $x$ & & $x$ & \\
\hline Aspidosperma rigidum Rusby & $x$ & & & $x$ & & & & $x$ & \\
\hline Aspidosperma schultesii Woodson & $x$ & & & & & $x$ & & & \\
\hline Couma macrocarpa Barb. Rodr. & $x$ & $x$ & $x$ & $x$ & & $x$ & $x$ & $x$ & \\
\hline $\begin{array}{l}\text { Himatanthus sucuuba (Spruce ex Müll. } \\
\text { Arg.) Woodson }\end{array}$ & $x$ & $x$ & & $x$ & $x$ & $x$ & & & $x$ \\
\hline Lacmellea floribunda (Poepp.) Benth. & & & & & & & $x$ & $x$ & \\
\hline Lacmellea klugii Monach. & & & & & & $x$ & & $x$ & \\
\hline Lacmellea lactescens (Kuhlm.) Markgr. & & $x$ & & & & & & & $x$ \\
\hline Lacmellea oblongata Markgr. & & & & & & & & & $x$ \\
\hline $\begin{array}{l}\text { Lacmellea peruviana (Van Heurck \& } \\
\text { Müll. Arg.) Markgr. }\end{array}$ & & & & $x$ & & & & & $x$ \\
\hline Macoubea guianensis Aubl. & $x$ & $x$ & & & & $x$ & & & \\
\hline Macoubea sprucei (Müll. Arg.) Markgr. & & & & & & & $x$ & & \\
\hline $\begin{array}{l}\text { Malouetia flavescens (Willd. ex Roem. \& } \\
\text { Schult.) Müll. Arg. }\end{array}$ & & $x$ & & & & & & & \\
\hline Mucoa duckei (Markgr.) Zarucchi & $x$ & & & & & & & & \\
\hline Odontadenia killipii Woodson & & & & $x$ & & & & & \\
\hline Odontadenia puncticulosa (Rich.) Pulle & & & & $x$ & & & & & \\
\hline Parahancornia peruviana Monach. & $x$ & & & & & $x$ & $x$ & & \\
\hline Rauvolfia sprucei Müll. Arg. & $x$ & & & $x$ & & & & & \\
\hline $\begin{array}{l}\text { Rhigospira quadrangularis (Müll. Arg.) } \\
\text { Miers }\end{array}$ & $x$ & & $x$ & & & $x$ & & & \\
\hline Tabernaemontana heterophylla Vahl & $x$ & & & & & $x$ & & & \\
\hline $\begin{array}{l}\text { Tabernaemontana markgrafiana J.F. } \\
\text { Macbr. }\end{array}$ & & & $x$ & & & & & & \\
\hline Tabernaemontana sananho Ruiz \& Pav. & $x$ & $x$ & & $x$ & & & & & \\
\hline $\begin{array}{l}\text { Tabernaemontana siphilitica (L. f.) } \\
\text { Leeuwenb. }\end{array}$ & $x$ & & & $x$ & & & & & \\
\hline Tabernaemontana undulata Vahl & & & $x$ & & & & & & \\
\hline Aquifoliaceae & & $x$ & & & & $x$ & & & \\
\hline Ilex inundata Poepp. ex Reissek & & $x$ & & & & & & & \\
\hline
\end{tabular}


Ilex nayana Cuatrec.

\section{Araceae}

Anthurium atropurpureum R.E. Schult. \& Maguire

Anthurium aureum Engl.

Anthurium brevipedunculatum Madison

Anthurium breviscapum Kunth

Anthurium clavigerum Poepp.

Anthurium croatii Madison

Anthurium diazii Croat

Anthurium eminens Schott

Anthurium ernestii Engl.

Anthurium gracile (Rudge) Schott

Anthurium kunthii Poepp.

Anthurium obtusum (Engl.) Grayum

Anthurium pseudoclavigerum Croat

Anthurium uleanum Engl.

Caladium bicolor (Aiton) Vent.

Caladium smaragdinum K. Koch \& C.D.

Bouché

Dieffenbachia parvifolia Engl.

Epipremnum pinnatum (L.) Engl.

Heteropsis oblongifolia Kunth

Heteropsis spruceana Schott

Monstera adansonii Schott

Monstera lechleriana Schott

Monstera obliqua Miq.

Montrichardia linifera (Arruda) Schott

Philodendron aureimarginatum Croat

Philodendron deflexum Poepp. ex Schott

Philodendron elaphoglossoides Schott

Philodendron ernestii Engl.

Philodendron exile G.S. Bunting

X $\quad x$

$x \quad x$

X

$x$

$x$

$X$

$X$

X $x$ $X$

$\begin{array}{lllll}x & & & x & x \\ x & x & x & x & \\ x & & & x & \\ & & x & & x\end{array}$

Philodendron fragrantissimum (Hook.)

G. Don

X $\quad x \quad x$

X

$x \quad x \quad x$

$x \quad x \quad x$

$x \quad x$

$X \quad X$

X

$X$

X

$X \quad X$

$x \quad x$

X

$X$

$X$

$X$

$x \quad X$

$X$

$x \quad x$

$x$

X

X $\quad x$

Philodendron goeldii G.M. Barroso

Philodendron grazielae G.S. Bunting

$x \quad x \quad x$

$X$

X

X

X

X

X 
Philodendron guttiferum Kunth

Philodendron herthae K. Krause

Philodendron hylaeae G.S. Bunting

Philodendron inaequilaterum Liebm.

Philodendron insigne Schott

Philodendron linnaei Kunth

Philodendron megalophyllum Schott

Philodendron micranthum Poepp. ex

Schott

Philodendron panduriforme (Kunth)

Kunth

Philodendron surinamense (Miq.) Engl.

Philodendron tripartitum (Jacq.) Schott

Philodendron wittianum Engl.

Pistia stratiotes L.

Rhodospatha latifolia Poepp.

Rhodospatha oblongata Poepp.

Spathiphyllum cannifolium (Dryand. ex

Sims) Schott

Stenospermation amomifolium (Poepp.)

Schott

Urospatha sagittifolia (Rudge) Schott

Xanthosoma viviparum Madison

Araliaceae

Dendropanax arboreus (L.) Decne. \&

Planch.

Dendropanax macropodus (Harms)

Harms

Dendropanax umbellatus (Ruiz \& Pav.)

Decne. \& Planch.

Didymopanax confusus (Marchal)

Fiaschi \& G.M. Plunkett

Schefflera morototoni (Aubl.) Maguire,

Steyerm. \& Frodin

\section{Arecaceae}

Aiphanes deltoidea Burret

Aiphanes ulei (Dammer) Burret

Ammandra decasperma O.F. Cook

Astrocaryum aculeatum G. Mey.

Astrocaryum chambira Burret $x$

$x$

$x$

$x$

$x$

$x$

$x$

$x$

$x$

$x$

$x$

$x$

$x \quad x$

$x$

$x \quad x \quad x$

$x$

$x \quad x$

$x$

$x \quad x$

$x \quad x$

$x \quad x \quad x$

$\begin{array}{lllllllllllll}x & x & x & x & x & x & x & x\end{array}$

$x \quad x \quad x$

$x$

$x$

$x$

X $\quad x$

$x \quad x \quad x \quad x$

$x \quad x \quad x \quad x$

$x$

$x$

$x \quad x$

$x$

$x \quad x \quad x \quad x \quad x \quad x$


Astrocaryum ciliatum F. Kahn \& B. Millán

Astrocaryum jauari Mart.

Astrocaryum murumuru Mart.

Attalea butyracea (Mutis ex L. f.) Wess.

Boer

Attalea insignis (Mart. ex H. Wendl.)

Drude

Attalea maripa (Aubl.) Mart.

Attalea microcarpa Mart.

Attalea phalerata Mart. ex Spreng.

Attalea racemosa Spruce

Bactris acanthocarpa Mart.

Bactris bifida Mart.

Bactris brongniartii Mart.

Bactris concinna Mart.

Bactris corossilla $\mathrm{H}$. Karst.

Bactris fissifrons Mart.

Bactris gasipaes Kunth

Bactris hirta Mart.

Bactris macroacantha Mart.

Bactris maraja Mart.

Bactris riparia Mart.

Bactris schultesii (L.H. Bailey) Glassman

Bactris simplicifrons Mart.

Bactris tomentosa Mart.

Chamaedorea pauciflora Mart.

Chamaedorea pinnatifrons (Jacq.) Oerst.

Chelyocarpus repens F. Kahn \& K. Mejía

Chelyocarpus ulei Dammer

Desmoncus giganteus A.J. Hend.

Desmoncus mitis Mart.

Desmoncus orthacanthos Mart.

Desmoncus polyacanthos Mart.

Euterpe precatoria Mart.

Geonoma aspidiifolia Spruce

Geonoma brongniartii Mart.

Geonoma camana Trail

Geonoma cuneata H. Wendl. ex Spruce

$\begin{array}{llllllllll} & & x & x & & & x & & x \\ x & x & & x & & x & x & x & \\ x & x & x & x & x & & x & x & \\ x & x & x & x & x & x & x & x & x \\ x & x & & x & & x & x & & & \\ x & & & x & & x & x & & & \\ & & & & x & & & & & \\ & & & & & & x & & \end{array}$

$x \quad x$

$x \quad x$

$x$

$x \quad x$

X

$x$

$X$

X $\quad x$

$\begin{array}{lll}x & x & x \\ x & x & \end{array}$

$x$

$x \quad x$

$x \quad x$

X

$x \quad x$

$x$

$x$

$x \quad x$

$x \quad x \quad x \quad x$

$x$

$x \quad x$

$x$

$x$

$x \quad x$

$x \quad x$

$\begin{array}{lll}x & x\end{array}$

$x \quad x \quad x$

$x \quad x \quad x \quad x$

$x \quad x \quad x$

$x \quad x$

$x \quad x$

$x \quad x$

$x$

$x \quad x$

$x \quad x$

$x \quad x$

X

$$
x
$$

$x$

$$
x
$$

$x$

$x$

$x$

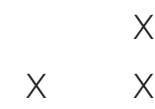

$x$ 
Geonoma deversa (Poit.) Kunth

Geonoma leptospadix Trail

Geonoma longipedunculata Burret

Geonoma macrostachys Mart.

Geonoma maxima (Poit.) Kunth

Geonoma orbignyana Mart.

Geonoma poeppigiana Mart.

Geonoma poiteauana Kunth

Geonoma stricta (Poit.) Kunth

Geonoma triglochin Burret

Hyospathe elegans Mart.

Iriartea deltoidea Ruiz \& Pav.

Iriartella setigera (Mart.) H. Wendl.

Iriartella stenocarpa Burret

Itaya amicorum H.E. Moore

Lepidocaryum tenue Mart.

Manicaria saccifera Gaertn.

Mauritia carana Wallace

Mauritia flexuosa L. f.

Mauritiella aculeata (Kunth) Burret

Mauritiella armata (Mart.) Burret

Oenocarpus bataua Mart.

Oenocarpus mapora $\mathrm{H}$. Karst.

Pholidostachys synanthera (Mart.) H.E.

Moore

Phytelephas macrocarpa Ruiz \& Pav.

Phytelephas tenuicaulis (Barfod) A.J.

Hend.

Prestoea schultzeana (Burret) H.E.

Moore

Socratea exorrhiza (Mart.) H. Wendl.

Wendlandiella gracilis Dammer

Wettinia drudei (O.F. Cook \& Doyle) A.J.

Hend.

\section{Aspleniaceae}

Asplenium angustum Sw.

Asplenium cuneatum Lam.

Asplenium hallii Hook.

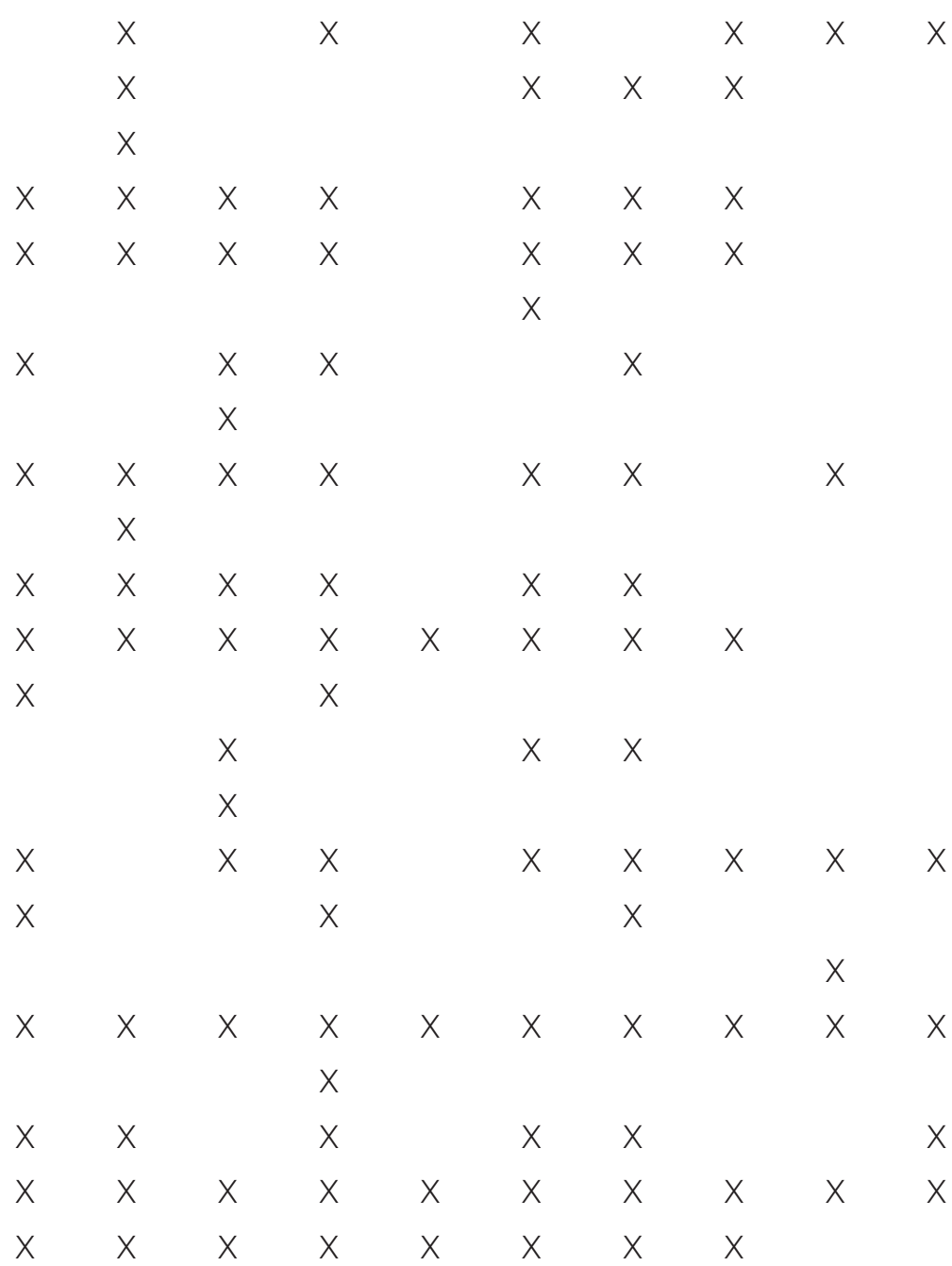

$x$

X $\quad x \quad x$

X $\quad x$

X $\quad x \quad x \quad x$

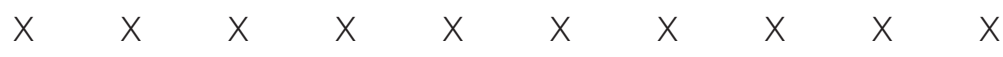

$x$

$\begin{array}{llll}x & x & x\end{array}$

$\begin{array}{cccccc}x & x & x & x & x & x \\ x & x & x & x & & x\end{array}$

$x$ 
Asplenium juglandifolium Lam.

$x \quad x$

Asplenium sulcatum Lam.

\section{Asteraceae}

Mikania micrantha Kunth

Piptocarpha poeppigiana (DC.) Baker

\section{Athyriaceae}

Diplazium andicola (Stolze) M. Kessler \&

A.R. Sm.

Diplazium grandifolium (Sw.) Sw.

\section{Balanophoraceae}

Helosis cayennensis (Sw.) Spreng.

\begin{tabular}{|c|c|c|c|c|c|c|c|c|c|}
\hline Begoniaceae & $x$ & $x$ & $x$ & $x$ & & $x$ & $x$ & & \\
\hline Begonia glabra Aubl. & $x$ & $x$ & $x$ & $x$ & & & $x$ & & \\
\hline Begonia rossmanniae A. DC. & & & $x$ & $x$ & & $x$ & & & \\
\hline Bignoniaceae & $x$ & $x$ & $x$ & $x$ & $x$ & $x$ & $x$ & & $x$ \\
\hline $\begin{array}{l}\text { Amphilophium magnoliifolium (Kunth) } \\
\text { L.G. Lohmann }\end{array}$ & & & & & $x$ & & & & \\
\hline Callichlamys latifolia (Rich.) K. Schum. & $x$ & $x$ & & $x$ & $x$ & $x$ & & & \\
\hline $\begin{array}{l}\text { Fridericia cinnamomea (DC.) L.G. } \\
\text { Lohmann }\end{array}$ & & & & & & $x$ & & & \\
\hline $\begin{array}{l}\text { Handroanthus chrysanthus (Jacq.) S.O. } \\
\text { Grose }\end{array}$ & & $x$ & & & & & & & \\
\hline $\begin{array}{l}\text { Handroanthus incanus (A.H. Gentry) S.O. } \\
\text { Grose }\end{array}$ & & & $x$ & & & & & & \\
\hline $\begin{array}{l}\text { Handroanthus obscurus (Bureau \& K. } \\
\text { Schum.) Mattos }\end{array}$ & & & & & & & $x$ & & $x$ \\
\hline $\begin{array}{l}\text { Handroanthus serratifolius (Vahl) S.O. } \\
\text { Grose }\end{array}$ & $x$ & $x$ & & & $x$ & $x$ & & & $x$ \\
\hline Jacaranda copaia (Aubl.) D. Don & $x$ & $x$ & & $x$ & $x$ & $x$ & $x$ & & \\
\hline $\begin{array}{l}\text { Jacaranda glabra (A. DC.) Bureau \& K. } \\
\text { Schum. }\end{array}$ & & $x$ & & & $x$ & $x$ & & & \\
\hline $\begin{array}{l}\text { Jacaranda macrocarpa Bureau \& K. } \\
\text { Schum. }\end{array}$ & $x$ & & & $x$ & & & & & \\
\hline $\begin{array}{l}\text { Tanaecium pyramidatum (Rich.) L.G. } \\
\text { Lohmann }\end{array}$ & & $x$ & $x$ & & & & & & \\
\hline Bixaceae & $x$ & & & $x$ & & & & & \\
\hline Bixa platycarpa Ruiz \& Pav. ex G. Don & $x$ & & & $x$ & & & & & \\
\hline Boraginaceae & $x$ & $x$ & $x$ & $x$ & $x$ & $x$ & $x$ & $x$ & \\
\hline Cordia bicolor A. DC. & $x$ & & & $x$ & & & & & \\
\hline Cordia nodosa Lam. & $x$ & $x$ & $x$ & $x$ & $x$ & $x$ & $x$ & $x$ & \\
\hline
\end{tabular}


Cordia tetrandra Aubl.

$x$

Cordia ucayaliensis (I.M. Johnst.) I.M. Johnst.

Cordia ulei I.M. Johnst.

Heliotropium cuspidatum (Kunth)

Feuillet

Tournefortia maculata Jacq.

\section{Bromeliaceae}

Aechmea abbreviata L.B. Sm.

Aechmea chantinii (Carrière) Baker

Aechmea contracta (Mart. ex Schult. f.)

Baker

Aechmea corymbosa (Mart. ex Schult. \&

Schult. f.) Mez

Aechmea longifolia (Rudge) L.B. Sm. \&

M.A. Spencer

Aechmea mertensii (G. Mey.) Schult. \&

Schult. f.

Aechmea nidularioides L.B. Sm.

Aechmea penduliflora André

Aechmea poitaei (Baker) L.B. Sm. \& M.A.

Spencer

Aechmea servitensis André

Aechmea strobilacea L.B. Sm.

Aechmea woronowii Harms

Aechmea zebrina L.B. Sm.

Bromelia tubulosa L.B. Sm.

Guzmania lingulata (L.) Mez

Guzmania vittata (Mart. ex Schult. f.)

$\mathrm{Mez}$

Neoregelia eleutheropetala (Üle) L.B.

Sm.

Neoregelia wurdackii L.B. Sm.

Pitcairnia sprucei Baker

Tillandsia adpressiflora Mez

\section{Burmanniaceae}

Campylosiphon purpurascens Benth.

Burseraceae

Crepidospermum prancei Daly

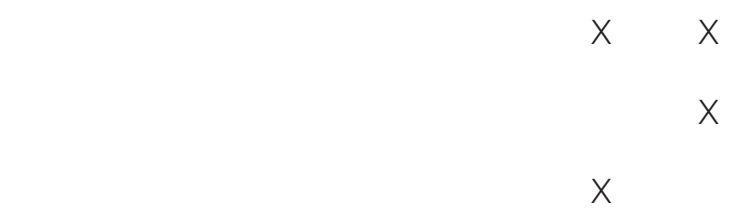

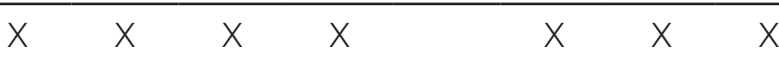

$x$

$\begin{array}{lll}x & x \\ x & x & x\end{array}$

$x$

X $x \quad x$

$\begin{array}{cccccc} & x & x & & x & \\ x & x & x & x & x & x \\ x & x & x & & & \\ & & x & & & \\ & & & & & \end{array}$

$x$

$x \quad x$

$x$

$\begin{array}{ll}x & x \\ x & x\end{array}$


Crepidospermum rhoifolium (Benth.) Triana \& Planch.

Dacryodes nitens Cuatrec.

Dacryodes peruviana (Loes.) H.J. Lam

Protium altsonii Sandwith

Protium amazonicum (Cuatrec.) Daly

Protium apiculatum Swart

Protium aracouchini (Aubl.) Marchand X X

Protium crassipetalum Cuatrec.

Protium decandrum (Aubl.) Marchand

Protium divaricatum Engl.

Protium ferrugineum (Engl.) Engl.

Protium gallosum Daly

Protium glabrescens Swart

Protium grandifolium Engl.

Protium hebetatum Daly

Protium heptaphyllum (Aubl.) Marchand

Protium klugii J.F. Macbr.

Protium nitidifolium (Cuatrec.) Daly

Protium nodulosum Swart

Protium opacum Swart

Protium pallidum Cuatrec.

Protium paniculatum Engl.

Protium peruvianum Swart

Protium sagotianum Marchand

Protium spruceanum (Benth.) Engl.

Protium stevensonii (Standl.) Daly

Protium subserratum (Engl.) Engl.

Protium tenuifolium (Engl.) Engl.

Protium trifoliolatum Engl.

Tetragastris altissima (Aubl.) Swart

Trattinnickia aspera (Standl.) Swart

Trattinnickia burserifolia Mart.

Trattinnickia glaziovii Swart

Trattinnickia peruviana Loes.

\section{Cactaceae}

Epiphyllum phyllanthus (L.) Haw.

$\begin{array}{cccc}x & x & & x \\ x & & & \\ x & & x & x \\ x & x & x & x \\ & & x & x \\ x & x & & x \\ & & x & x \\ x & & & x \\ x & & x & x \\ x & & x & x \\ & x & & x\end{array}$

$x$

$x$

$x$

$x$

$x \quad x \quad x$

$x$

$x$

$x$

$x$

$x \quad x \quad x \quad x$

$x \quad x \quad x$

$x \quad x \quad x$

$x \quad x \quad x$

$x$

$x$

$x$

$x \quad x \quad x$

$x \quad x \quad x$

$x \quad x \quad x$

$x \quad x \quad x$

$x \quad x$

$x$

$x$

$\begin{array}{llll}x & x & x & x \\ x & & x\end{array}$

$\begin{array}{llll} & x & x & \\ x & x & x & x\end{array}$

$x \quad x$

$x \quad x$

$x$

$x$

$\begin{array}{llll}x & x & x & x\end{array}$

$x \quad x$

$x \quad x$

$x$

$x$

$x \quad x$

$x \quad x$

$x$

$x \quad x \quad x$

X

$x$

$x \quad x \quad x$

$x \quad x \quad x$

$x$

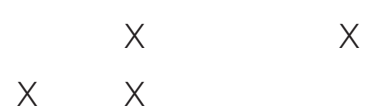




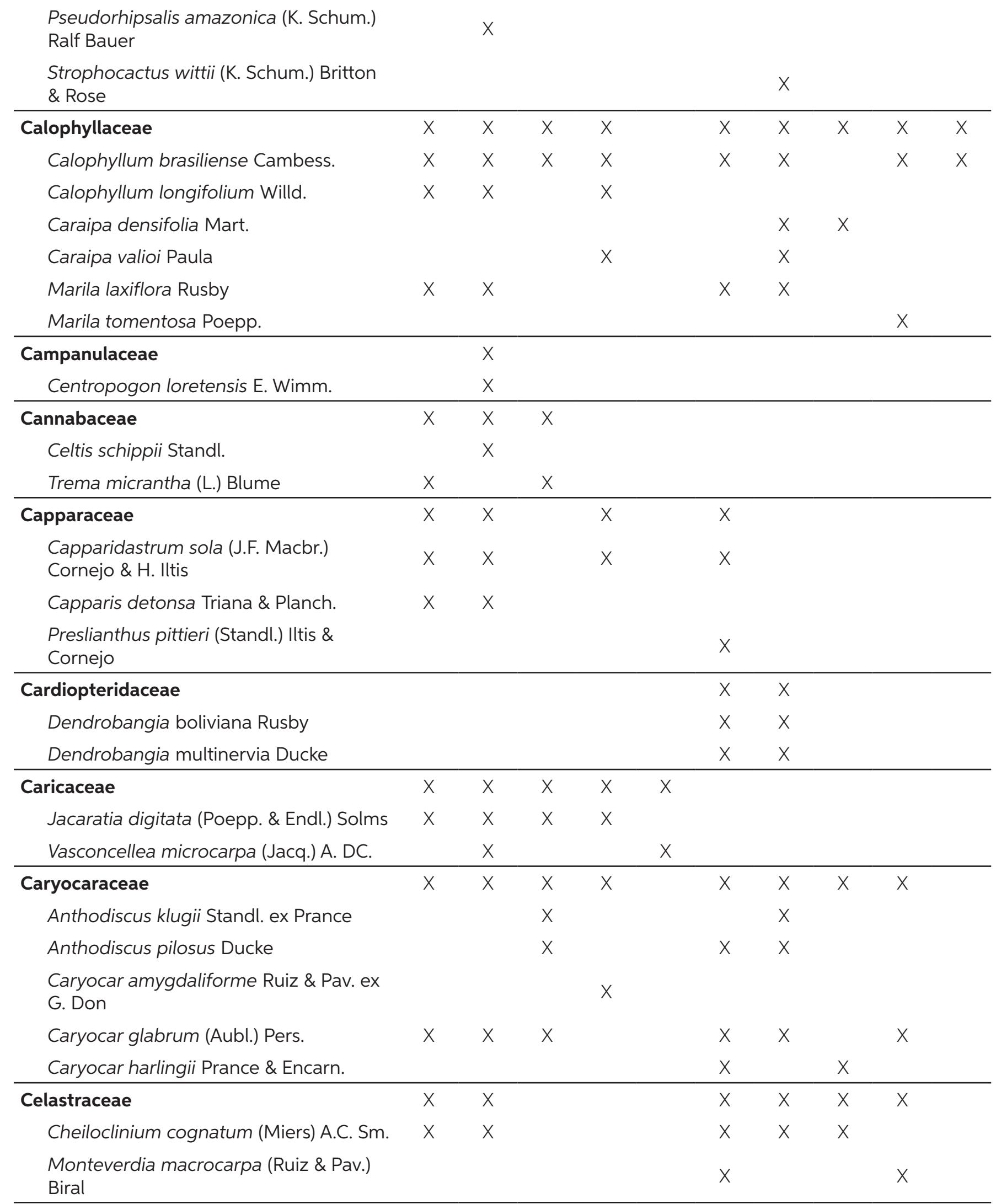




\begin{tabular}{|c|c|c|c|c|c|c|c|c|c|}
\hline Chrysobalanaceae & $x$ & $x$ & $x$ & $x$ & $x$ & $x$ & $x$ & $x$ & $x$ \\
\hline Couepia bernardii Prance & & & & & & $x$ & & $x$ & \\
\hline Couepia bracteosa Benth. & & & & & & $x$ & & & \\
\hline $\begin{array}{l}\text { Couepia chrysocalyx (Poepp.) Benth. ex } \\
\text { Hook. f. }\end{array}$ & $x$ & & $x$ & $x$ & & & & $x$ & $x$ \\
\hline Couepia dolichopoda Prance & & & $x$ & & $x$ & $x$ & & & \\
\hline Couepia latifolia Standl. & & & & & & & & & $x$ \\
\hline Couepia macrophylla Spruce ex Hook. f. & & & & & $x$ & & & & \\
\hline Couepia obovata Ducke & & & & & & $x$ & & & \\
\hline Couepia parillo DC. & & & $x$ & & & $x$ & $x$ & & $x$ \\
\hline Couepia williamsii J.F. Macbr. & & & & & & & $x$ & & \\
\hline Hirtella bicornis Mart. \& Zucc. & & & $x$ & & $x$ & & & & \\
\hline Hirtella bullata Benth. & & & & & & & $x$ & & \\
\hline Hirtella elongata Mart. \& Zucc. & $x$ & & & $x$ & $x$ & & & & $x$ \\
\hline Hirtella eriandra Benth. & & & $x$ & & & $x$ & $x$ & & \\
\hline Hirtella hispidula Miq. & & & & & & & $x$ & & \\
\hline Hirtella physophora Mart. \& Zucc. & $x$ & & $x$ & & $x$ & & & & \\
\hline Hirtella racemosa Lam. & & & & & $x$ & & & & \\
\hline Hirtella rodriguesii Prance & $x$ & & & $x$ & $x$ & $x$ & & & \\
\hline Hirtella triandra Sw. & & & & & & & $x$ & & $x$ \\
\hline $\begin{array}{l}\text { Hymenopus arachnoideus (Fanshawe \& } \\
\text { Maguire) Sothers \& Prance }\end{array}$ & & & & & $x$ & $x$ & & & \\
\hline $\begin{array}{l}\text { Hymenopus caudatus (Prance) Sothers } \\
\text { \& Prance }\end{array}$ & & & $x$ & & & & & & \\
\hline $\begin{array}{l}\text { Hymenopus heteromorphus (Benth.) } \\
\text { Sothers \& Prance }\end{array}$ & $x$ & & & $x$ & $x$ & $x$ & $x$ & & \\
\hline $\begin{array}{l}\text { Hymenopus latifolius (Benth. ex Hook. f.) } \\
\text { Sothers \& Prance }\end{array}$ & $x$ & & & & $x$ & $x$ & & & \\
\hline $\begin{array}{l}\text { Hymenopus macrophyllus (Benth.) } \\
\text { Sothers \& Prance }\end{array}$ & & & & & & & & & $x$ \\
\hline $\begin{array}{l}\text { Hymenopus reticulatus (Prance) Sothers } \\
\text { \& Prance }\end{array}$ & & & & & $x$ & & $x$ & & \\
\hline $\begin{array}{l}\text { Leptobalanus apetalus (E. Mey.) Sothers } \\
\text { \& Prance }\end{array}$ & & & & & & $x$ & $x$ & $x$ & \\
\hline $\begin{array}{l}\text { Leptobalanus emarginatus (Spruce ex } \\
\text { Hook. f.) Sothers \& Prance }\end{array}$ & & & $x$ & & & & & & \\
\hline $\begin{array}{l}\text { Leptobalanus latus (J.F. Macbr.) Sothers } \\
\text { \& Prance }\end{array}$ & & & & & $x$ & $x$ & $x$ & $x$ & \\
\hline $\begin{array}{l}\text { Leptobalanus octandrus (Hoffmanns. ex Rc } \\
\text { \& Schult.) Sothers \& Prance }\end{array}$ & & & & & $x$ & $x$ & $x$ & & \\
\hline
\end{tabular}


Licania blackii Prance

Licania bracteata Prance

Licania canescens Benoist

Licania harlingii Prance

Licania hypoleuca Benth.

Licania longistyla (Hook. f.) Fritsch

Licania macrocarpa Cuatrec.

Licania micrantha Miq.

Licania urceolaris Hook. f.

Moquilea brittoniana (Fritsch) Sothers \&

Prance

Moquilea egleri (Prance) Sothers \&

Prance

Moquilea guianensis Aubl.

Moquilea klugii (Prance) Sothers \&

Prance

Parinari excelsa Sabine

Parinari klugii Prance

Parinari occidentalis Prance

Parinari parilis J.F. Macbr.

Parinariopsis licaniiflora (Sagot) Sothers

\& Prance

\section{Clusiaceae}

Arawakia weddelliana (Planch. \& Triana) L. Marinho

Chrysochlamys membranacea Planch. \& Triana

Chrysochlamys ulei Engl.

Chrysochlamys weberbaueri Engl.

Clusia amazonica Planch. \& Triana

Clusia columnaris Engl.

Clusia flavida (Benth.) Pipoly

Clusia hammeliana Pipoly

Clusia loretensis Engl.

Clusia octandra (Poepp.) Pipoly

Clusia peruviana SzyszyÅ,.

Garcinia brasiliensis Mart.

Garcinia macrophylla Mart.

Garcinia madruno (Kunth) Hammel

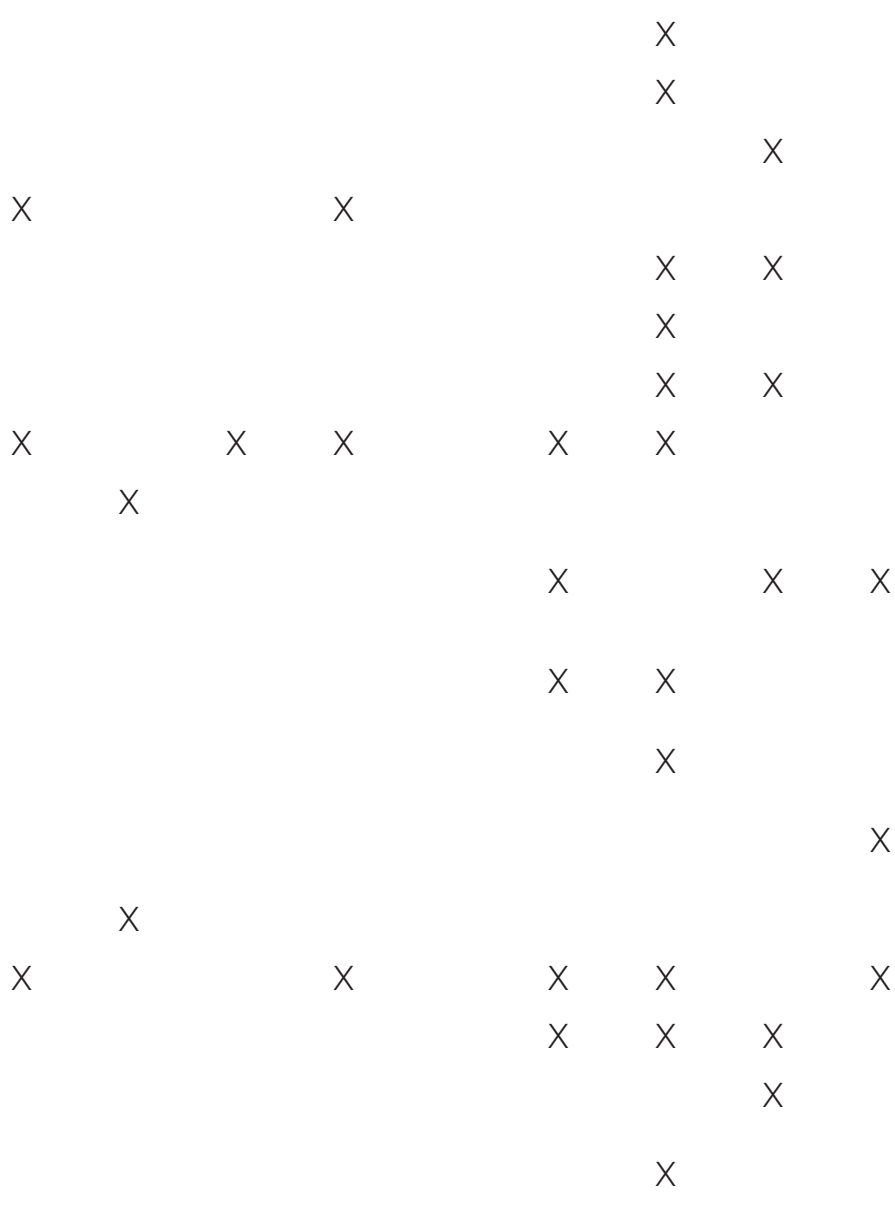

$x$

$x$

$x$

$x \quad x$

X

X

$x$

$x$

X

X

x

$\begin{array}{lll} & x & \\ x & x & \\ & & \\ & x & \\ & x \\ & x\end{array}$

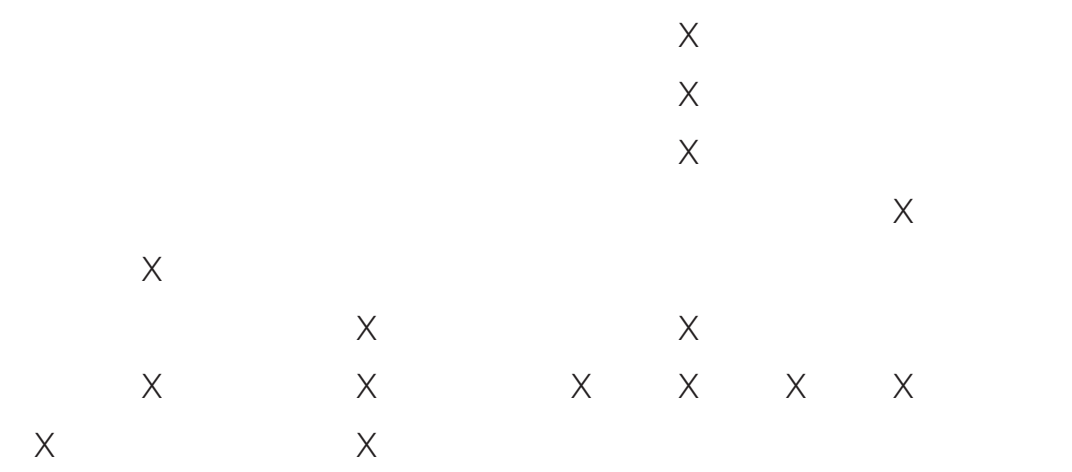


Moronobea coccinea Aubl.

Symphonia globulifera L. f.

Tovomita calophyllophylla García-

Villacorta \& Hammel

Tovomita fructipendula (Ruiz \& Pav.)

Cambess.

Tovomita krukovii A.C. Sm.

Tovomita laurina Planch. \& Triana

Tovomita pyrifolia Planch. \& Triana

Tovomita speciosa Ducke

Tovomita spruceana Planch. \& Triana

Tovomita stergiosii Cuello

Tovomita stylosa Hemsl.

Tovomita umbellata Benth.

\section{Combretaceae}

Combretum assimile Eichler

Combretum laxum Jacq.

Combretum llewelynii J.F. Macbr.

Terminalia amazonia (J.F. Gmel.) Exell

Terminalia corrugata (Ducke) Gere \&

Boatwr.

Terminalia dichotoma G. Mey.

Terminalia duckei Gere \& Boatwr.

Terminalia grandis (Ducke) Gere \&

Boatwr.

Terminalia macrophylla (Eichler) Gere \&

Boatwr.

Terminalia oblonga (Ruiz \& Pav.) Steud.

Terminalia oxycarpa Mart.

Terminalia parvifolia (Ducke) Gere \& Boatwr.

Terminalia tetraphylla (Aubl.) Gere \& Boatwr.

Terminalia viridiflora (Ducke) Gere \& Boatwr.

\section{Commelinaceae}

Commelina rufipes Seub.

Dichorisandra hexandra (Aubl.) C.B.

Clarke

Dichorisandra ulei J.F. Macbr.

$\begin{array}{lllllll}x & x & x & & \\ x & x & x & x \\ & x & & \end{array}$

$x$

$x$

$x \quad x$

$x$
$x \quad x \quad x$

$x$

$x$

$x$

\begin{tabular}{|c|c|c|c|c|c|c|c|c|}
\hline & & & & & & $x$ & & \\
\hline \multirow[t]{2}{*}{$x$} & $x$ & $x$ & $x$ & $x$ & $x$ & $x$ & $x$ & $x$ \\
\hline & $x$ & & & & & & & \\
\hline \multirow[t]{3}{*}{$x$} & & & $x$ & & $x$ & & & \\
\hline & & & $x$ & & & $x$ & & \\
\hline & $x$ & & & & $x$ & & & \\
\hline
\end{tabular}

$x \quad x$

$X$

$\begin{array}{llllll}x & x & & x & & \\ x & x & x & x & x & x \\ x & & & x\end{array}$


Floscopa elegans Huber

$\begin{array}{llll}x & x & x & x \\ x & x & x & x \\ & x & & \\ & x & & \end{array}$

Floscopa peruviana Hassk. ex C.B. Clarke Geogenanthus ciliatus G. Brückn.

$x \quad x$

$x$

X

Connaraceae

$x$

$X$

Geogenanthus rhizanthus (Üle) G.

Brückn.

Connarus ruber (Poepp. \& Endl.) Planch.

$x$

Pseudoconnarus agelaeoides ( $G$.

Schellenb.) Forero

$x$

Rourea amazonica (Baker) Radlk.

$x$

Rourea camptoneura Radlk.

\section{Convolvulaceae}

Dicranostyles densa Spruce ex Meisn.

Dicranostyles falconiana (Barroso) Ducke

Dicranostyles holostyla Ducke

$x$

Dicranostyles sericea Gleason

$x \quad x$

$x$

$x$

$\begin{array}{llll} & x & x & \end{array}$

$x$

Maripa janusiana D.F. Austin

Maripa peruviana Ooststr.

\section{Costaceae}

Costus arabicus L.

Costus lasius Loes.

Costus longibracteolatus Maas

Costus scaber Ruiz \& Pav.

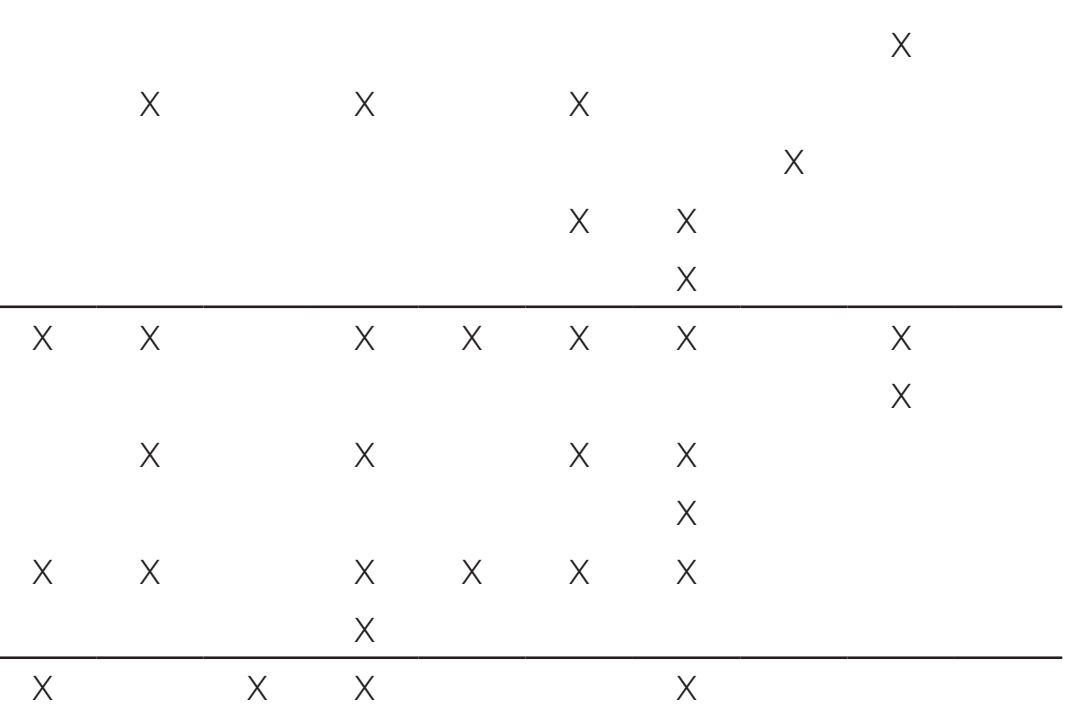

Dimerocostus strobilaceus Kuntze

\section{Cucurbitaceae}

Cayaponia glandulosa (Poepp. \& Endl.)

Cogn.

Fevillea cordifolia L.

Gurania rhizantha (Poepp. \& Endl.) C. Jeffrey

\section{Cyatheaceae}

Alsophila erinacea (H. Karst.) D.S. Conant

Cyathea lasiosora (Mett. ex Kuhn) Domin

Cyathea microdonta (Desv.) Domin

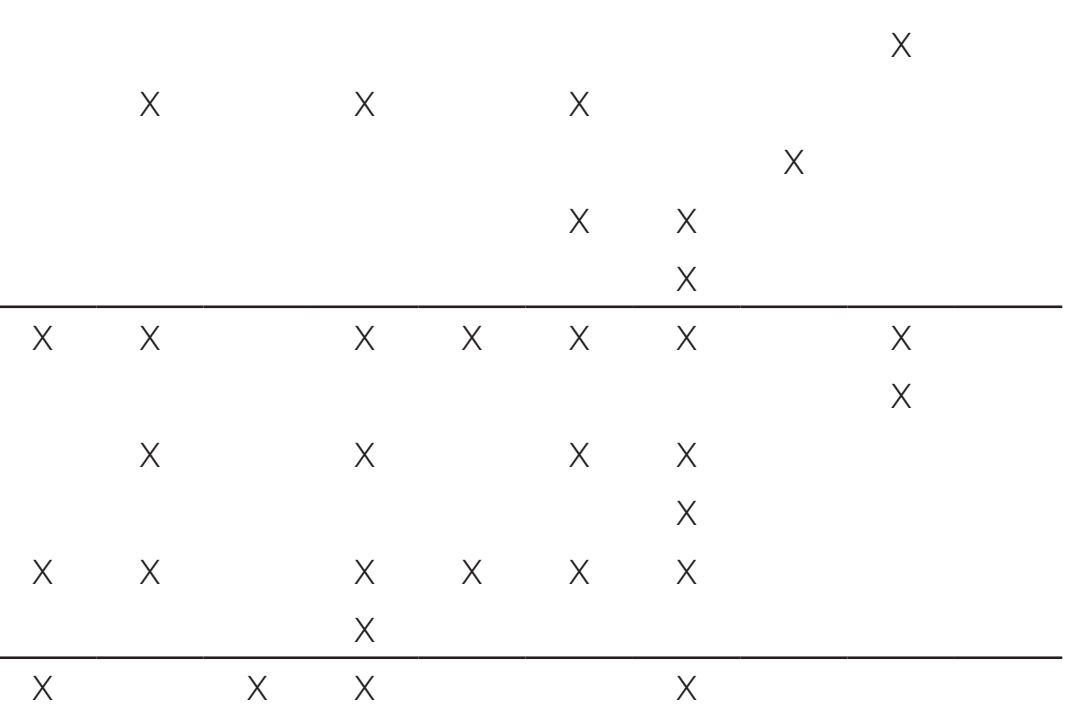

Cyathea pungens (Willd.) Domin

\section{Cyclanthaceae}

Asplundia acuminata (Ruiz \& Pav.)

Harling

$x$

$x+x$


Asplundia peruviana Harling

Asplundia schizotepala Harling

Carludovica palmata Ruiz \& Pav.

Cyclanthus bipartitus Poit. ex A. Rich.

Evodianthus funifer (Poit.) Lindm.

Ludovia lancifolia Brongn.

Thoracocarpus bissectus (Vell.) Harling

\section{Cyperaceae}

Becquerelia cymosa Brongn.

Calyptrocarya bicolor (H. Pfeiff.) T.

Koyama

Calyptrocarya glomerulata (Brongn.)

Urb.

Calyptrocarya luzuliformis T. Koyama

Calyptrocarya poeppigiana Kunth

Cyperus compressus L.

Cyperus odoratus L.

Diplacrum capitatum (Willd.) Boeckeler

Diplasia karatifolia Rich.

Rhynchospora amazonica Poepp. \&

Kunth

Scleria cyperina Willd. ex Kunth

Scleria secans (L.) Urb.

Davalliaceae

Nephrolepis biserrata (Sw.) Schott

Nephrolepis rivularis (Vahl) Mett. ex Krug

Dichapetalaceae

Dichapetalum latifolium Baill.

Dichapetalum rugosum (Vahl) Prance

Stephanopodium peruvianum Poepp. \& Endl.

Tapura amazonica Poepp.

Tapura coriacea J.F. Macbr.

Tapura peruviana K. Krause

Dilleniaceae

Davilla kunthii A. St.-Hil.

Davilla nitida (Vahl) Kubitzki

Doliocarpus dentatus (Aubl.) Standl. $x+x$

\begin{tabular}{|c|c|c|c|c|c|c|c|}
\hline & & & & & & $x$ & $x$ \\
\hline & & & & & & $x$ & \\
\hline$x$ & $x$ & & $x$ & & $x$ & $x$ & $x$ \\
\hline$x$ & $x$ & $x$ & $x$ & & $x$ & $x$ & \\
\hline & $x$ & & & & & & \\
\hline$x$ & $x$ & & $x$ & & & $x$ & \\
\hline$x$ & $x$ & & $x$ & $x$ & $x$ & $x$ & $x$ \\
\hline & & & & & & $x$ & $x$ \\
\hline & & & $x$ & & & $x$ & \\
\hline & & & & & & $x$ & \\
\hline & & & $x$ & & & $x$ & \\
\hline & $x$ & & & & & $x$ & \\
\hline & & & & & & $x$ & \\
\hline
\end{tabular}

$x$

$\begin{array}{llll} & x & x & x\end{array}$

$x$

\section{X}

$\begin{array}{ll}x & x \\ x & x \\ x & x\end{array}$


Doliocarpus major J.F. Gmel.

Doliocarpus multiflorus Standl.

Neodillenia peruviana Aymard

Pinzona coriacea Mart. \& Zucc.

Tetracera willdenowiana Steud.

Dioscoreaceae

Dioscorea amaranthoides C. Presl

Dioscorea crotalariifolia Uline

Tacca parkeri Seem.

\section{Dryopteridaceae}

Bolbitis lindigii (Mett.) C. Chr.

Bolbitis nicotianifolia (Sw.) Alston

Cyclodium meniscioides (Willd.) C. Presl

Didymochlaena truncatula (Sw.) J. Sm.

Elaphoglossum luridum (Fée) Christ

Elaphoglossum raywaense (Jenman) Alston

Mickelia guianensis (Aubl.) R.C. Moran, Sundue \& Labiak

Polybotrya caudata Kunze

Polybotrya crassirhizoma Lellinger

Polybotrya glandulosa Mett. ex Kuhn

Polybotrya pubens Mart.

\section{Ebenaceae}

Diospyros artanthifolia Mart. ex Miq.

Diospyros capreifolia Mart. ex Hiern

Diospyros dolmen B. Walln.

Diospyros micrantha Sandwith

Diospyros tessmannii Mildbr.

\section{Elaeocarpaceae}

Sloanea brevipes Benth.

Sloanea durissima Spruce ex Benth.

Sloanea eichleri K. Schum.

Sloanea erismoides Ducke

Sloanea floribunda Spruce ex Benth.

Sloanea fragrans Rusby

Sloanea grandiflora Sm.

Sloanea guianensis (Aubl.) Benth. $x \quad x$

$x$

$$
x
$$

$x$

$\begin{array}{llll}x & x & x & x \\ x & x & & x \\ & & x & x\end{array}$

$x$

$x$

$\begin{array}{lll} & x & \\ x & x & x \\ x & x & x\end{array}$

$x$

$x$

$x$

X

$x$

$x$

$x$

$x$

$\begin{array}{lllll}x & & & & x \\ x & x & x & x & x \\ & x & x & x & \end{array}$

$x$

$x \quad x$

\begin{tabular}{|c|c|c|c|c|c|c|c|c|}
\hline \multirow{7}{*}{$x$} & $x$ & $x$ & $x$ & $x$ & $x$ & $x$ & $x$ & $x$ \\
\hline & & $x$ & & $x$ & & $x$ & $x$ & \\
\hline & & & & $X$ & $x$ & $x$ & $x$ & \\
\hline & & & $X$ & $X$ & & & & \\
\hline & & $x$ & & & & & & \\
\hline & & & & $x$ & $x$ & $x$ & $x$ & \\
\hline & & $X$ & & & & $X$ & $x$ & \\
\hline$x$ & $X$ & $x$ & $x$ & $X$ & $X$ & $X$ & $x$ & \\
\hline$X$ & & & $x$ & $x$ & $x$ & $x$ & $X$ & $X$ \\
\hline
\end{tabular}


Sloanea latifolia (Rich.) K. Schum.

Sloanea laurifolia (Benth.) Benth.

Sloanea laxiflora Spruce ex Benth.

Sloanea macrophylla Benth. ex Turcz.

Sloanea obtusifolia (Moric.) K. Schum.

Sloanea pubescens Benth.

Sloanea robusta Uittien

Sloanea rufa Planch. ex Benth.

Sloanea sinemariensis Aubl.

Sloanea spathulata Earle Sm.

\section{Erythroxylaceae}

Erythroxylum citrifolium A. St.-Hil.

Erythroxylum fimbriatum Peyr.

Erythroxylum gracilipes Peyr.

Erythroxylum macrophyllum Cav.

Erythroxylum shatona J.F. Macbr.

Erythroxylum squamatum Sw.

Erythroxylum vasquezii Plowman

\section{Euphorbiaceae}

Acalypha cuneata Poepp.

Acalypha diversifolia Jacq.

Alchornea discolor Poepp.

Alchornea latifolia Sw.

Alchornea triplinervia (Spreng.) Müll.

Arg.

Alchorneopsis floribunda (Benth.) Müll.

Arg.

Aparisthmium cordatum (A. Juss.) Baill.

Caryodendron orinocense $\mathrm{H}$. Karst.

Conceveiba guianensis Aubl.

Conceveiba martiana Baill.

Conceveiba rhytidocarpa Müll. Arg.

Conceveiba terminalis (Baill.) Müll. Arg.

Croton cuneatus Klotzsch

Croton matourensis Aubl.

Croton palanostigma Klotzsch

Croton schiedeanus Schltdl.

Croton smithianus Croizat

$$
x \quad x
$$

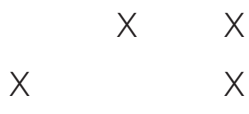

$X$

$x$

$x$

$x$

$x$

$x$

$x$

$x$

$x$

$x$

$\begin{array}{lllll}x & & & & x \\ x & x & x & x\end{array}$

$x$

$x \quad x \quad x$

$x$ $x$ 
Croton spruceanus Benth.

Dalechampia cissifolia Poepp.

$x$

Dalechampia magnoliifolia Müll. Arg.

Dalechampia scandens L.

Dodecastigma amazonicum Ducke

$x$

Gitara nicaraguensis (Hemsl.) Card.-

McTeag. \& L.J. Gillespie

$x \quad x$

$x$

Glycydendron amazonicum Ducke

Hevea brasiliensis (Willd. ex A. Juss.)

Müll. Arg.

Hevea guianensis Aubl.

Hevea pauciflora (Spruce ex Benth.)

Müll. Arg.

Hura crepitans L.

Mabea angularis Hollander

Mabea macbridei I.M. Johnst.

Mabea nitida Spruce ex Benth.

Mabea occidentalis Benth.

Mabea piriri Aubl.

Mabea pulcherrima Müll. Arg.

Mabea speciosa Müll. Arg.

$x \quad x \quad x$

$x \quad x \quad x$

Mabea standleyi Steyerm.

Mabea subsessilis Pax \& K. Hoffm.

Manihot brachyloba Müll. Arg.

Maprounea guianensis Aubl.

Micrandra elata (Didr.) Müll. Arg.

Micrandra spruceana (Baill.) R.E. Schult.

Nealchornea yapurensis Huber

Omphalea diandra L.

Pausandra hirsuta Lanj.

Pausandra trianae (Müll. Arg.) Baill.

Pogonophora schomburgkiana Miers ex Benth.

Pseudosenefeldera inclinata (Müll.Arg.)

Esser

Rhodothyrsus macrophyllus (Ducke)

Esser

Sagotia racemosa Baill.

Sapium glandulosum (L.) Morong $x$

$x$

$x$

$x$

$x$

X

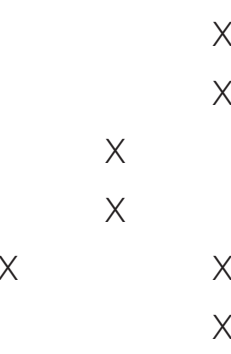

$x$

$x$

(1)

$x$

$x$

$x$

$x \quad x$

$x \quad x$

$x$

$\begin{array}{cccc}x & & x & x \\ x & x & x & x \\ x & x & & x \\ & & & x \\ x & x & x & x\end{array}$

$x \quad x \quad x$

$x$

$x$

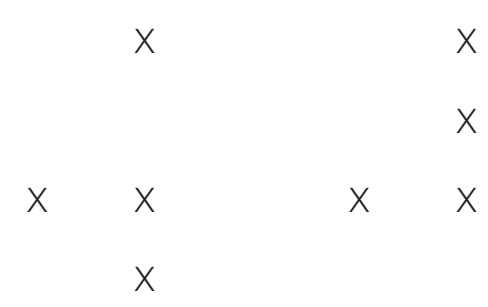

$x \quad x$

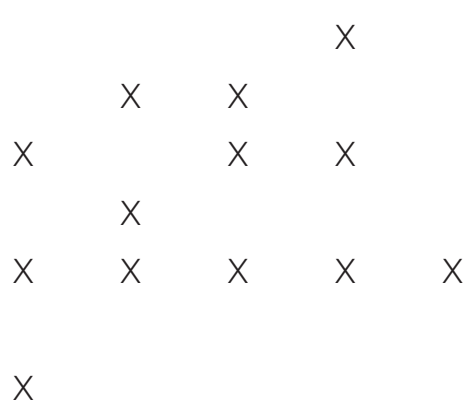

$x$

$x \quad x$

$\begin{array}{lllll}x & x & x & x & x\end{array}$

$x \quad x$

$X$

$x$

$x$

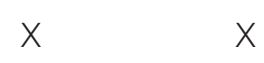

$x \quad x \quad x \quad x$ $x$

$x \quad x$ 


\begin{tabular}{|c|c|c|c|c|c|c|c|c|c|c|}
\hline Sapium marmieri Huber & $x$ & & $x$ & $x$ & & $x$ & & & & \\
\hline Tetrorchidium rubrivenium Poepp. & & & & & & & $x$ & $x$ & & \\
\hline Fabaceae & $x$ & $x$ & $x$ & $x$ & $x$ & $x$ & $x$ & $x$ & $x$ & $x$ \\
\hline $\begin{array}{l}\text { Abarema auriculata (Benth.) Barneby \& } \\
\text { J.W. Grimes }\end{array}$ & & & & & & $x$ & $x$ & & & \\
\hline Abarema jupunba (Willd.) Britton \& Killip & & $x$ & & & & $x$ & & & $x$ & \\
\hline $\begin{array}{l}\text { Abarema laeta (Benth.) Barneby \& J.W. } \\
\text { Grimes }\end{array}$ & & $x$ & & & & $x$ & $x$ & $x$ & & \\
\hline $\begin{array}{l}\text { Albizia niopoides (Spruce ex Benth.) } \\
\text { Burkart }\end{array}$ & & & & & & & $x$ & & & \\
\hline Amphiodon effusus Huber & & & & & & & & & $x$ & \\
\hline Andira inermis (W. Wright) Kunth ex DC. & $x$ & $x$ & & & & $x$ & & & & \\
\hline Andira macrothyrsa Ducke & & & & & & $x$ & & & $x$ & \\
\hline Apuleia leiocarpa (Vogel) J.F. Macbr. & & $x$ & $x$ & & & & $x$ & & & \\
\hline Bauhinia acreana Harms & & $x$ & & & & & & & & \\
\hline Bauhinia arborea Wunderlin & & $x$ & & & & & & & & \\
\hline Bauhinia brachycalyx Ducke & & $x$ & & & & $x$ & $x$ & $x$ & & \\
\hline Bauhinia glabra Jacq. & & $x$ & & & & & & & & \\
\hline Bauhinia guianensis Aubl. & $x$ & $x$ & $x$ & $x$ & & $x$ & $x$ & & $x$ & \\
\hline Bauhinia longicuspis Spruce ex Benth. & & & & & & & & & $x$ & \\
\hline $\begin{array}{l}\text { Bauhinia microstachya (Raddi) J.F. } \\
\text { Macbr. }\end{array}$ & & $x$ & & & & & & & & \\
\hline Bauhinia rutilans Spruce ex Benth. & & & & $x$ & & & & & & \\
\hline Bauhinia tarapotensis Benth. & & $x$ & & & & & & & & \\
\hline Brownea cauliflora Poepp. & & & $x$ & & & & & & & \\
\hline Brownea macrophylla hort. ex Mast. & & $x$ & & & & & & & $x$ & \\
\hline Browneopsis ucayalina Huber & $x$ & & & & & & & & & \\
\hline Calliandra guildingii Benth. & & & & & & $x$ & $x$ & & & \\
\hline Calliandra trinervia Benth. & $x$ & $x$ & $x$ & $x$ & & $x$ & $x$ & $x$ & & \\
\hline $\begin{array}{l}\text { Campsiandra angustifolia Spruce ex } \\
\text { Benth. }\end{array}$ & & & & $x$ & & & $x$ & & & $x$ \\
\hline Cassia grandis L.f. & & $x$ & & & & & & & & \\
\hline Cassia spruceana Benth. & & & & $x$ & & & & & & \\
\hline Cedrelinga cateniformis (Ducke) Ducke & $x$ & $x$ & $x$ & $x$ & $x$ & $x$ & $x$ & & & \\
\hline Clathrotropis macrocarpa Ducke & $x$ & $x$ & $x$ & $x$ & & $x$ & $x$ & & $x$ & \\
\hline Cojoba arborea (L.) Britton \& Rose & & $x$ & & & & & & & & \\
\hline Crotalaria nitens Kunth & & & & & & & $x$ & & & \\
\hline Crudia amazonica Spruce ex Benth. & & & & & & & & & $x$ & \\
\hline Crudia glaberrima (Steud.) J.F. Macbr. & & & & & & & & & $x$ & \\
\hline
\end{tabular}


Cynometra bauhiniifolia Benth.

Cynometra spruceana Benth.

Dalbergia monetaria L. f.

$x$

$$
X
$$

$x$

$$
x
$$

$X$

$x$

$x$

$x$ $x$ Azevedo ex M. Sousa

Dialium guianense (Aubl.) Sandwith

Dimorphandra macrostachya Benth.

Dioclea dictyoneura Diels

Diplotropis martiusii Benth.

Diplotropis purpurea (Rich.) Amshoff

Dipteryx micrantha Harms

Dussia tessmannii Harms

Enterolobium barnebianum Mesquita \& M.F. Silva

Enterolobium schomburgkii (Benth.)

Benth.

Erythrina peruviana Krukoff

Erythrina poeppigiana (Walp.) O.F. Cook

Hydrochorea corymbosa (Rich.) Barneby \& J.W. Grimes

Hymenaea courbaril L.

Hymenaea oblongifolia Huber

Hymenaea reticulata Ducke

Hymenolobium excelsum Ducke

Hymenolobium nitidum Benth.

Hymenolobium pulcherrimum Ducke

Inga acicularis T.D. Penn.

Inga acrocephala Steud.

Inga acuminata Benth.

Inga alba (Sw.) Willd.

Inga auristellae Harms

Inga brachyrhachis Harms

Inga capitata Desv.

Inga chrysantha Ducke

Inga ciliata C. Presl

Inga cordatoalata Ducke

Inga gracilifolia Ducke

Inga heterophylla Willd. $x \quad x \quad x \quad x$

$x$

$x$

$x$

$x_{x} \quad x$

$x \quad x \quad x$

$x \quad x$

$x \quad x$

$x \quad x \quad x$

$x$

X X $\quad X$
X

$x$

$x$

$x \quad x$
$x \quad x \quad x$

$x \quad x$

$x \quad x$

$x$

$x$

$x$

$x \quad x$

$x$

$x$

X

$x$

X $\quad X$

$x$

$x \quad x$

$x$

$x$

$x \quad x$

X

$\begin{array}{lll}x & x \\ x & x\end{array}$

$x$
X

$x$

$x$

$x$ $x$
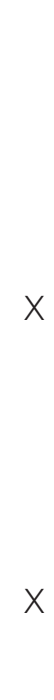

X 
Inga klugii Standl. ex J.F. Macbr.

Inga laurina (Sw.) Willd.

Inga leiocalycina Benth.

Inga macrophylla Humb. \& Bonpl. ex Willd.

Inga marginata Willd.

Inga megaphylla Poncy \& Vester

Inga nobilis Willd.

Inga oerstediana Benth. ex Seem.

Inga poeppigiana Benth.

Inga pruriens Poepp.

Inga psittacorum L. Uribe

Inga punctata Willd.

Inga ruiziana $\mathrm{G}$. Don

Inga semialata (Vell.) Mart.

Inga spectabilis (Vahl) Willd.

Inga stipulacea G. Don

Inga stipularis DC.

Inga tarapotensis Spruce ex Benth.

Inga tenuicalyx T.D. Penn.

Inga thibaudiana DC.

Inga umbellifera (Vahl) Steud.

Inga venusta Standl.

Lonchocarpus spiciflorus Mart. ex Benth.

Machaerium cuspidatum Kuhlm. \&

Hoehne

Machaerium floribundum Benth.

Machaerium macrophyllum Benth.

Machaerium multifoliolatum Ducke

Machaerium mutisii Killip ex Rudd

Macrolobium acaciifolium (Benth.)

Benth.

Macrolobium angustifolium (Benth.) R.S.

Cowan

Macrolobium archeri R.S. Cowan

Macrolobium bifolium (Aubl.) Pers.

Macrolobium gracile Spruce ex Benth.

Macrolobium ischnocalyx Harms

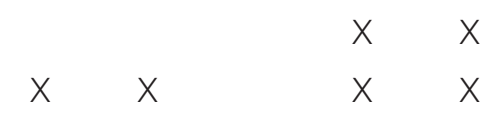

$x$

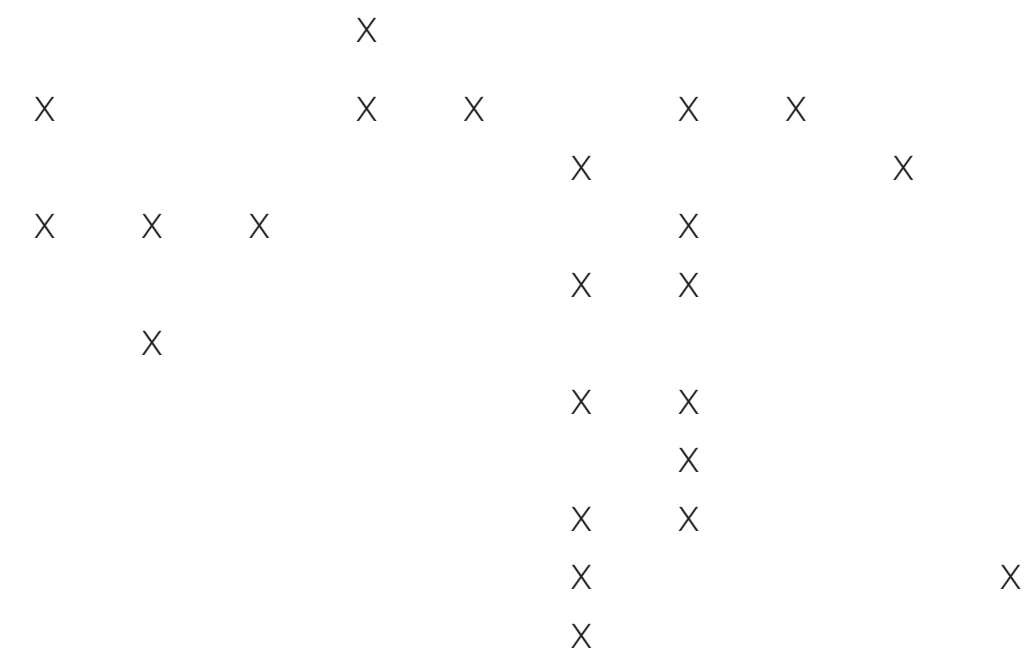


Macrolobium limbatum Spruce ex

Benth.

Macrolobium microcalyx Ducke

Macrolobium multijugum (DC.) Benth.

Marmaroxylon basijugum (Ducke) L. Rico $\quad X$

Monopteryx uaucu Spruce ex Benth.

Mucuna urens (L.) Medik.

Ormosia amazonica Ducke

Ormosia bopiensis Pierce ex J.F. Macbr.

Ormosia coccinea (Aubl.) Jacks.

Parkia balslevii H.C. Hopkins

Parkia igneiflora Ducke

Parkia multijuga Benth.

Parkia nitida Miq.

Parkia panurensis Benth. ex H.C.

Hopkins

Parkia velutina Benoist

Peltogyne altissima Ducke

Piptadenia anolidurus Barneby

Piptadenia uaupensis Spruce ex Benth.

Platymiscium stipulare Benth.

Poecilanthe amazonica (Ducke) Ducke

Poeppigia procera C. Presl

$x$

Pterocarpus amazonum (Mart. ex

Benth.) Amshoff

Pterocarpus rohrii Vahl

Pterocarpus santalinoides L'HÃ@r. ex

DC.

Senegalia polyphylla (DC.) Britton

Senna multijuga (Rich.) H.S. Irwin \&

Barneby

Senna reticulata (Willd.) H.S. Irwin \&

Barneby

Senna ruiziana (G. Don) H.S. Irwin \&

Barneby

Senna silvestris (Vell.) H.S. Irwin \&

Barneby

Senna surattensis (Burm. f.) H.S. Irwin \&

Barneby

Swartzia arborescens (Aubl.) Pittier

\section{$x$

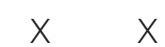

$x$

$x$

$x \quad x$

$x$


Swartzia auriculata Poepp.

Swartzia benthamiana Miq.

Swartzia calva R.S. Cowan

Swartzia cardiosperma Spruce ex Benth.

Swartzia gracilis Pipoly \& A. Rudas Lleras

Swartzia klugii (R.S. Cowan) Torke

Swartzia laevicarpa Amshoff

Swartzia pendula Spruce ex Benth.

Swartzia peruviana (R.S. Cowan) Torke

Swartzia polyphylla DC.

Swartzia racemosa Benth.

Swartzia rosea Mart. ex Benth.

Swartzia simplex (Sw.) Spreng.

Tachigali bracteosa (Harms) Zarucchi \&

Pipoly

Tachigali chrysophylla (Poepp.) Zarucchi

\& Herend.

Tachigali formicarum Harms

Tachigali loretensis van der Werff

Tachigali macbridei Zarucchi \& Herend.

Tachigali melinonii (Harms) Zarucchi \& Herend.

Tachigali paniculata Aubl.

Tachigali pilosa van der Werff

Tachigali polyphylla Poepp.

Tachigali ptychophysca Spruce ex

Benth.

Tachigali rusbyi Harms

Tachigali schultesiana Dwyer

Tachigali setifera (Ducke) Zarucchi \&

Herend.

Tachigali vasquezii Pipoly

Tachigali vaupesiana van der Werff

Taralea oppositifolia Aubl.

Vatairea erythrocarpa (Ducke) Ducke

Vatairea fusca (Ducke) Ducke

Vatairea guianensis Aubl.

Zygia cataractae (Kunth) L. Rico

Zygia cauliflora (Willd.) Killip $x$

$x$

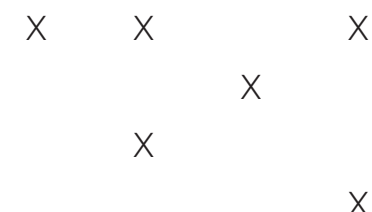

$x \quad x \quad x$

$x \quad x$

$x \quad x$

$X$

$x \quad x$

$\begin{array}{llll}x & x & x\end{array}$

$x \quad x \quad x$

$x$

X

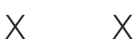

X $x \quad x$

$x$

$x \quad x$

$x \quad x$

$x$

$x \quad x$

$x$

$x \quad x \quad x \quad x$

X $\quad X$

$x$

$x$

$x$

X $\quad X$

$x \quad x$

$x \quad x$

$x$

$x$

X

$$
\text { X }
$$

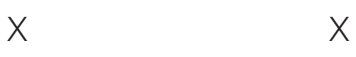

$x$

$x$

$x$

$x$
$x \quad x$ 
Zygia coccinea (G. Don) L. Rico

Zygia inaequalis (Humb. \& Bonpl. ex Willd.) Pittier

Zygia juruana (Harms) L. Rico

Zygia latifolia (L.) Fawc. \& Rendle

Zygia longifolia (Humb. \& Bonpl. ex Willd.) Britton \& Rose

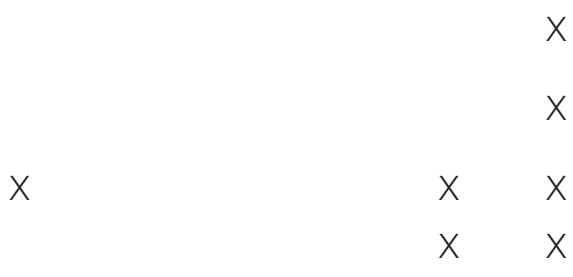

Zygia racemosa (Ducke) Barneby \& J.W.

Grimes

Zygia unifoliolata (Benth.) Pittier

Gentianaceae

Potalia amara Aubl.

Potalia coronata Struwe \& V.A. Albert

Voyria aphylla (Jacq.) Pers.

Voyria flavescens Griseb.

Voyria pittieri (Standl.) L.O. Williams

Voyria spruceana Benth.

Voyria tenella Hook.

\section{Gesneriaceae}

Besleria aggregata (Mart.) Hanst.

Besleria solanoides Kunth

Codonanthe crassifolia (H. Focke) C.V.

Morton

Codonanthe macradenia Donn. Sm.

Codonanthe uleana Fritsch

Codonanthopsis ulei Mansf.

Columnea ericae Mansf.

Columnea inaequilatera Poepp.

Drymonia affinis (Mansf.) Wiehler

Drymonia anisophylla L.E. Skog \& L.P.

Kvist

Drymonia coccinea (Aubl.) Wiehler

Drymonia macrophylla (Oerst.) H.E.

Moore

Drymonia pendula (Poepp.) Wiehler

Drymonia semicordata (Poepp.) Wiehler

Drymonia serrulata (Jacq.) Mart.

Drymonia warszewicziana Hanst.

Episcia reptans Mart.
X $\quad x$

$x$

$X$$$
x^{2}
$$

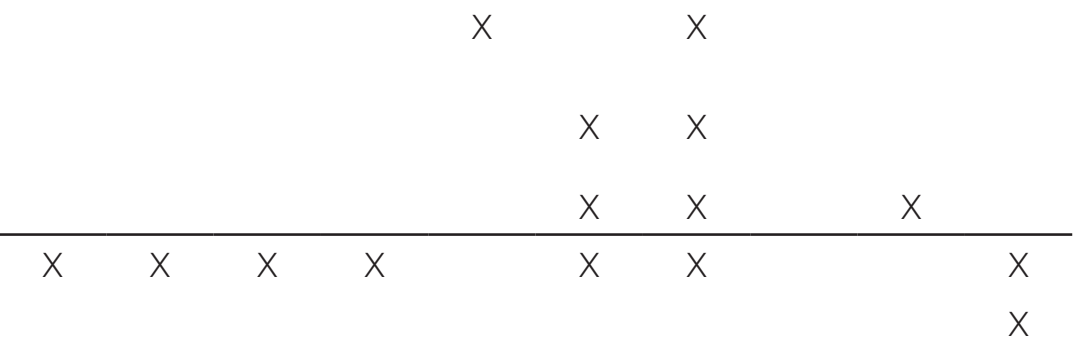

$\begin{array}{lll}x \quad x \quad & x & \\ & x & x \\ x & & x \\ x & & \end{array}$

$\begin{array}{cccccccc}x & & & x & & & & x \\ x & x & x & x & x & x & x & x \\ & x & x & x & x & & x & \\ & x & & & & & & \end{array}$

$\begin{array}{lll}x & x \quad x \\ x & x \\ x & x\end{array}$

$\begin{array}{llll}x & x & x \\ x & \end{array}$

$x$

$x \quad x \quad x \quad x$

$x \quad x$

$x$

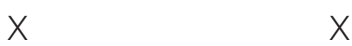

$x \quad x$

$x \quad x$

$x$ 


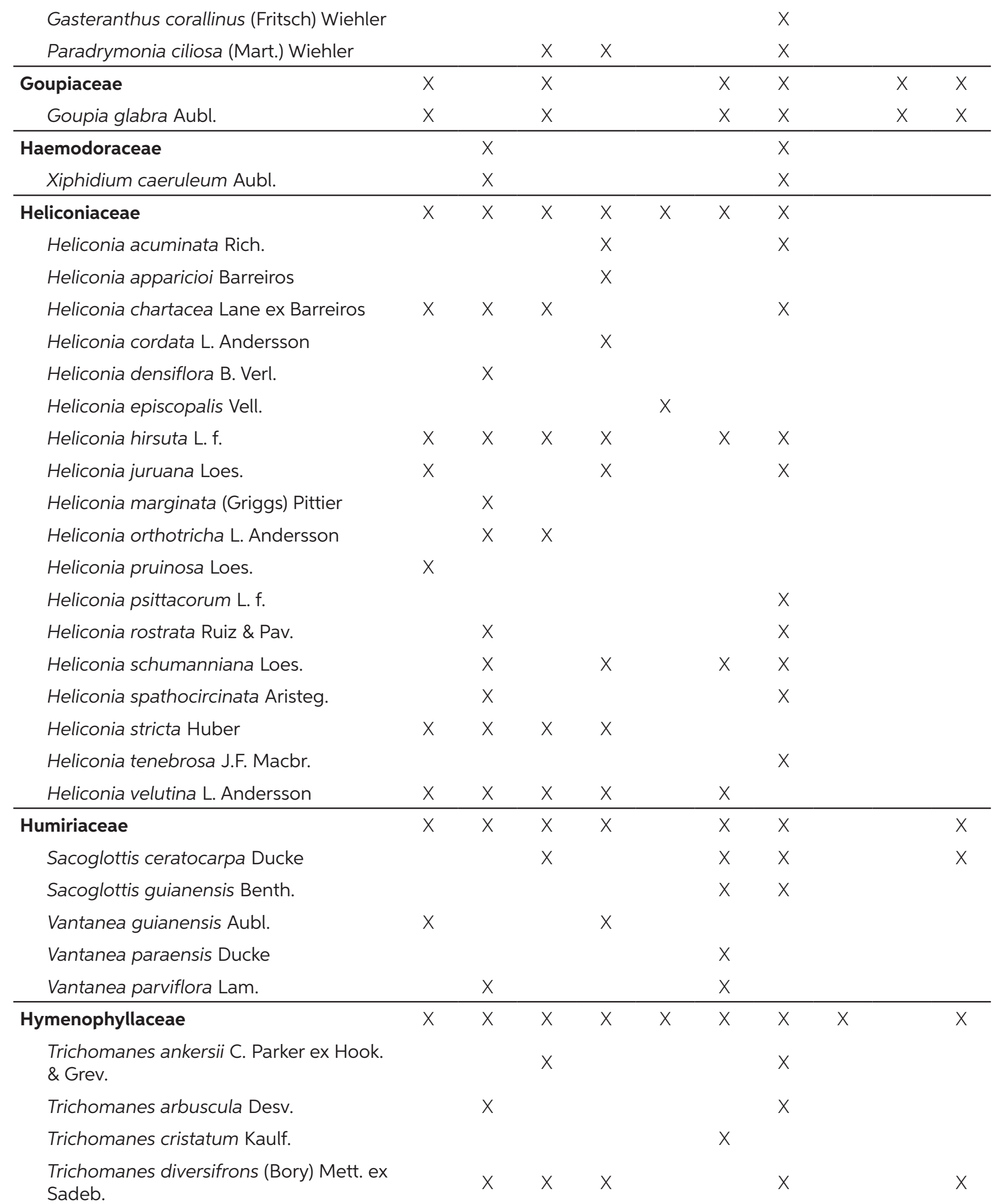


Trichomanes elegans Rich. $\quad X \quad X \quad X \quad X$

Trichomanes hostmannianum (Klotzsch)

Kunze

\begin{tabular}{|c|c|c|c|c|c|}
\hline \multirow[t]{3}{*}{$X$} & $x$ & & $x$ & $x$ & $x$ \\
\hline & & & & $x$ & \\
\hline & $x$ & $x$ & & $x$ & \\
\hline$X$ & $X$ & $X$ & $X$ & $X$ & $X$ \\
\hline
\end{tabular}

Vismia baccifera (L.) Triana \& Planch.

Vismia floribunda Sprague

$x$

Vismia gracilis Hieron.

Vismia laxiflora Reichardt

$\begin{array}{ccccc}x & x & x \\ x & x & x \\ x & x\end{array}$

Vismia macrophylla Kunth

Vismia minutiflora Ewan

Vismia sandwithii Ewan

$x$

Vismia tomentosa Ruiz \& Pav.

Icacinaceae

Poraqueiba sericea Tul.

\section{Lacistemataceae}

Lacistema aggregatum (P.J. Bergius)

Rusby

Lacistema nena J.F. Macbr.

$x \quad x$

$x$

Lozania klugii (Mansf.) Mansf.

\section{Lamiaceae}

Aegiphila cordifolia (Ruiz \& Pav.)

Moldenke

Aegiphila peruviana Turcz.

Aegiphila sufflava Moldenke

Scutellaria coccinea Kunth

Scutellaria leucantha Loes.

Vitex klugii Moldenke

$x$

Vitex triflora Vahl

Lauraceae

Aiouea grandifolia van der Werff

Anaueria brasiliensis Kosterm.

Aniba cylindriflora Kosterm.

Aniba guianensis Aubl.

Aniba hostmanniana (Nees) Mez

Aniba megaphylla Mez

$x+x$

$x$

$\begin{array}{llllll}x & x & x & x & x & x\end{array}$

$x$

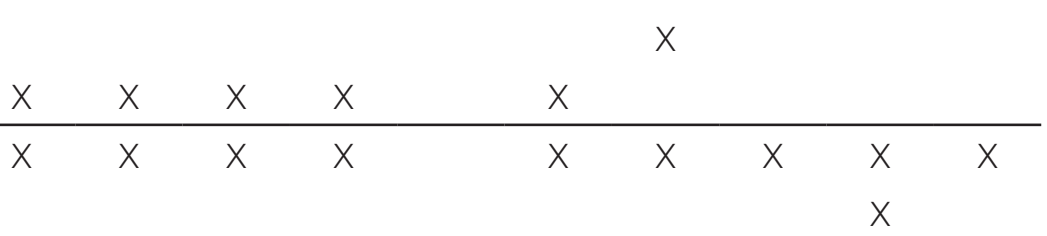

$\begin{array}{lllll}X & x & x & x\end{array}$

$x$

$x$

$x$

$x$

$x$ 
Aniba rosaeodora Ducke

Caryodaphnopsis fosteri van der Werff

$x$

Caryodaphnopsis tomentosa van der Werff

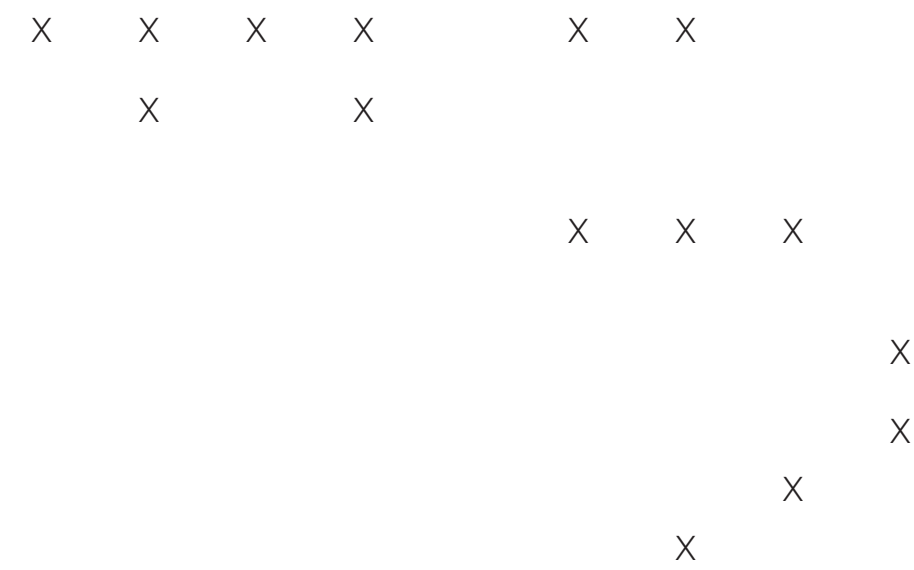

Chlorocardium venenosum (Kosterm. \& Pinkley) Rohwer, H.G. Richt. \& van der Werff

Endlicheria bracteolata (Meisn.) C.K. Allen

Endlicheria citriodora van der Werff

Endlicheria formosa A.C. Sm.

Endlicheria gracilis Kosterm.

Endlicheria macrophylla (Meisn.) Mez

Endlicheria sericea Nees

$x$

Endlicheria sprucei (Meisn.) Mez

Licaria aurea (Huber) Kosterm.

Licaria brasiliensis (Nees) Kosterm.

Licaria canella (Meisn.) Kosterm.

Licaria macrophylla (A.C. Sm.) Kosterm.

Mezilaurus itauba (Meisn.) Taub. ex Mez

Mezilaurus opaca Kubitzki \& van der Werff

Mezilaurus triunca van der Werff

Nectandra acuminata (Nees \& C. Mart.)

J.F. Macbr.

Nectandra aurea Rohwer

Nectandra coeloclada Rohwer

$x$

Nectandra crassiloba Rohwer

Nectandra martinicensis Mez

Ocotea aciphylla (Nees \& Mart.) Mez

$x$

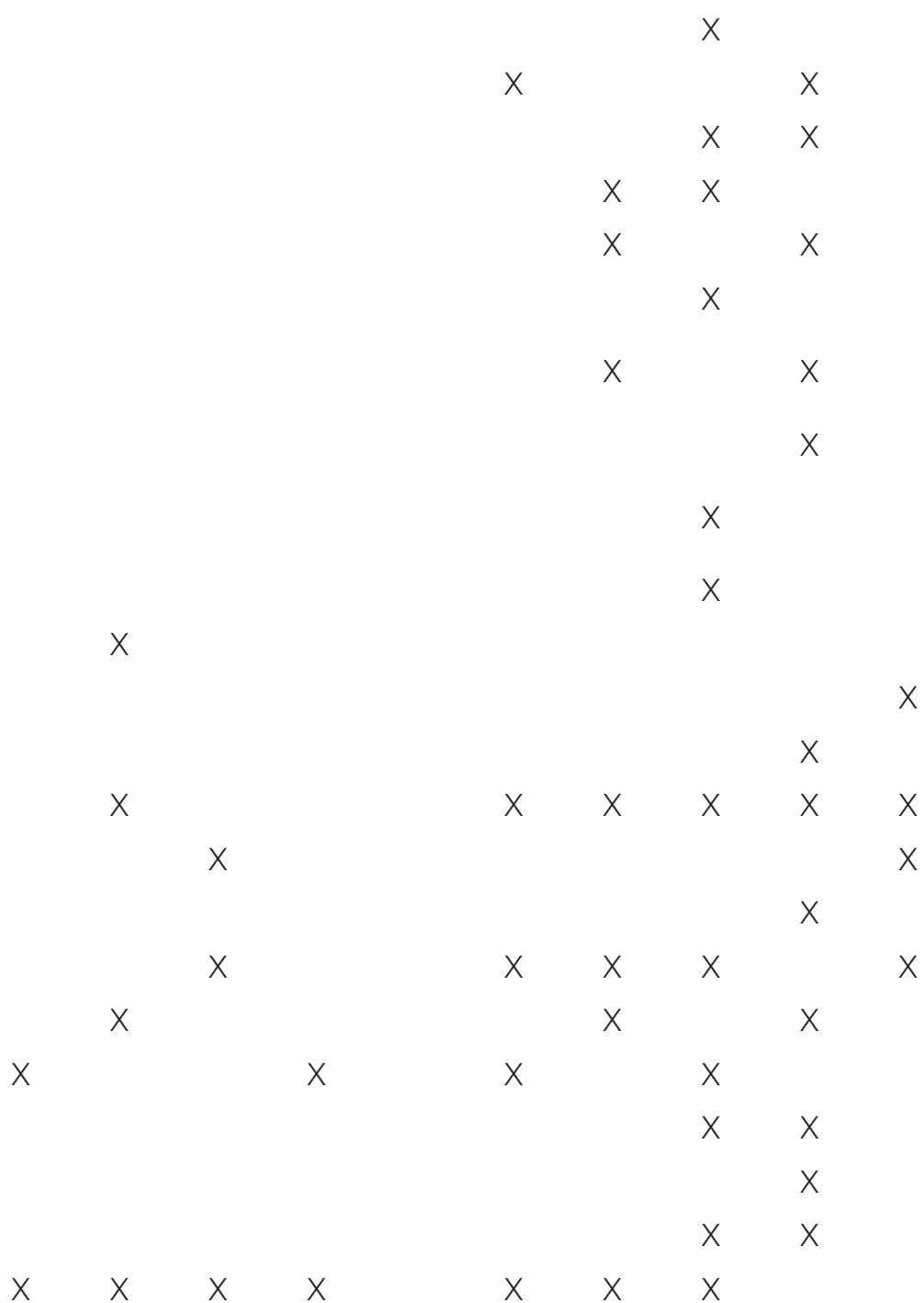

Ocotea alata van der Werff

$x$

Ocotea amazonica (Meisn.) Mez

Ocotea argyrophylla Ducke

Ocotea bofo Kunth

Ocotea cernua (Nees) Mez

Ocotea gardneri (Meisn.) Mez

Ocotea glomerata (Nees) Mez

Ocotea gracilis (Meisn.) Mez

Ocotea javitensis (Kunth) Pittier 
Ocotea leucoxylon (Sw.) Laness.

Ocotea licanioides A.C. Sm.

$\begin{array}{lll} & x & \\ x & x & x \\ x & & x\end{array}$

Ocotea olivacea A.C. Sm.

X

Ocotea pauciflora (Nees) Mez

Sextonia pubescens van der Werff

\section{Lecythidaceae}

Allantoma decandra (Ducke) S.A. Mori, Ya Y.Huang \& Prance

$x$

$x+x$

$x$

$x$

$\begin{array}{lll}x & & \\ x & x\end{array}$

Allantoma lineata (Mart. \& O. Berg)

Miers

$x \quad x \quad x \quad x$

Allantoma pluriflora (Ducke) S.A. Mori,

Y.Y. Huang \& Prance

Couratari guianensis Aubl.

Couratari oligantha A.C. Sm.

Eschweilera alata A.C. Sm.

Eschweilera albiflora (DC.) Miers

Eschweilera andina (Rusby) J.F. Macbr.

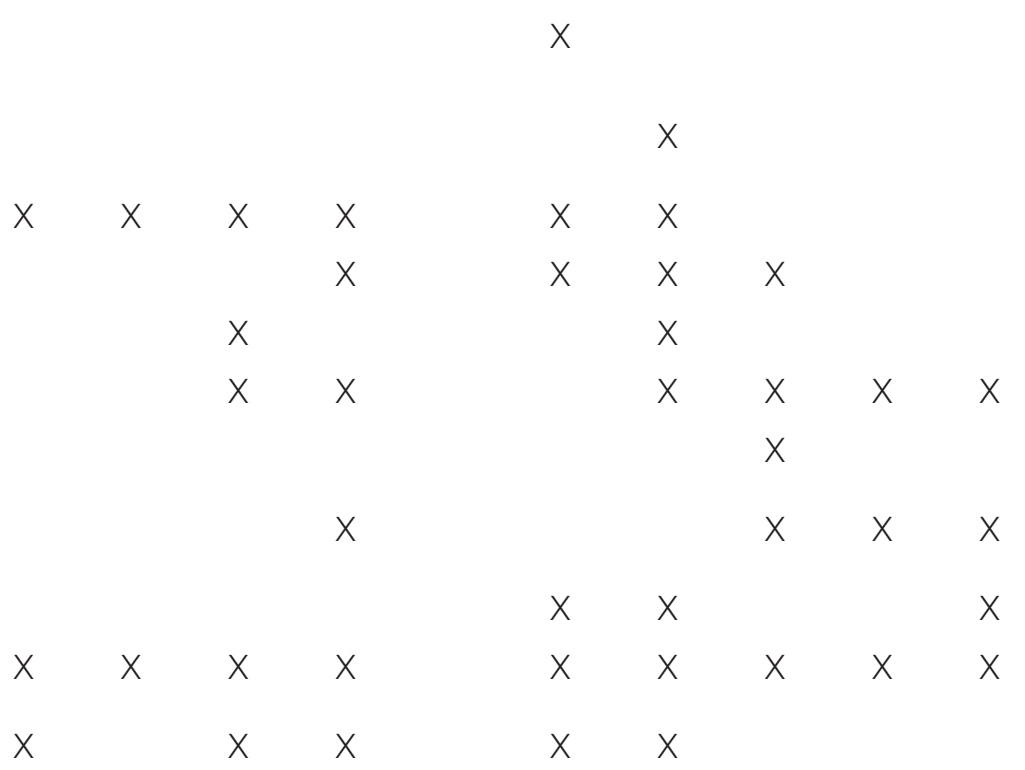

Eschweilera bracteosa (Poepp. ex O.

Berg) Miers

Eschweilera chartaceifolia S.A. Mori

Eschweilera coriacea (DC.) S.A. Mori

Eschweilera gigantea (R. Knuth) J.F.

Macbr.

Eschweilera grandiflora (Aubl.) Sandwith

Eschweilera itayensis R. Knuth

Eschweilera juruensis R. Knuth

Eschweilera laevicarpa S.A. Mori

Eschweilera micrantha (O. Berg) Miers

Eschweilera ovalifolia (DC.) Nied.

$\begin{array}{ccccc} & & x & x & x \\ x & x & x & & \\ & x & x & x & \\ x & x & x & x & x \\ x & & & x & x\end{array}$

Eschweilera parviflora (Aubl.) Miers

Eschweilera parvifolia Mart. ex DC.

Eschweilera rufifolia S.A. Mori

Eschweilera tessmannii R. Knuth

Grias neuberthii J.F. Macbr.

Gustavia hexapetala (Aubl.) Sm.

Gustavia longifolia Poepp. ex O. Berg

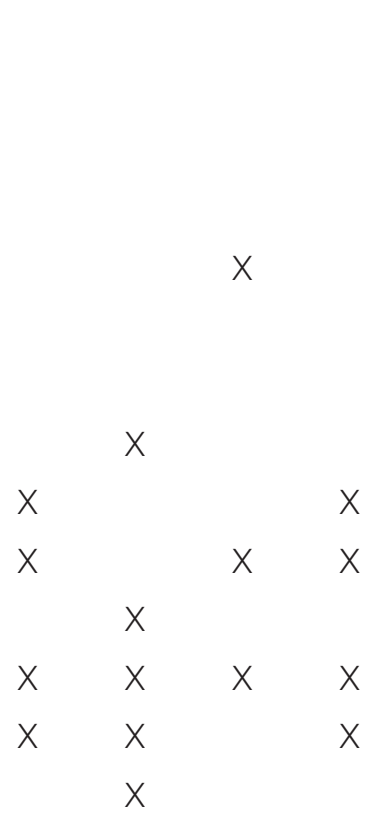

Lecythis ampla Miers

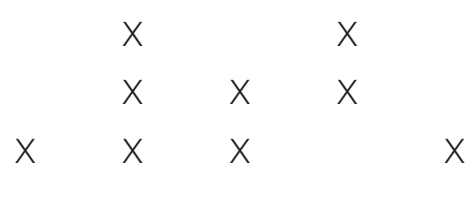

Lecythis chartacea O. Berg 


$\begin{array}{lccc}\text { Lecythis pisonis Cambess. } & X & \times & \times \\ \text { Lecythis zabucajo Aubl. } & \times & X\end{array}$

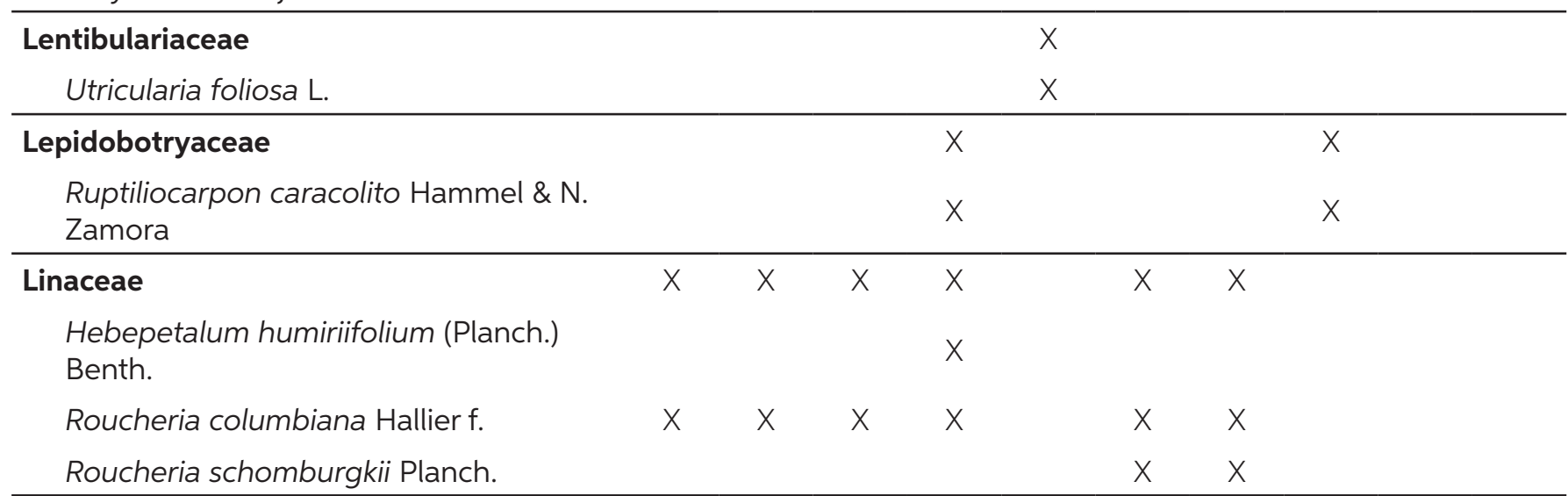

\begin{tabular}{|c|c|c|c|c|c|c|c|c|c|}
\hline \multirow{2}{*}{$\begin{array}{l}\text { Linderniaceae } \\
\qquad \text { Lindernia crustacea (L.) F. Muell. }\end{array}$} & & & & \multicolumn{6}{|l|}{$x$} \\
\hline & & & & $x$ & & & & & \\
\hline Lindsaeaceae & $x$ & $x$ & & $x$ & & $x$ & & & \\
\hline Lindsaea divaricata Klotzsch & $x$ & & & $x$ & & & & & \\
\hline Lindsaea guianensis (Aubl.) Dryand. & & & & & & $x$ & & & \\
\hline Lindsaea lancea (L.) Bedd. & & $x$ & & $x$ & & $x$ & & & \\
\hline Lindsaea ulei Hieron. ex Christ & $x$ & & & $x$ & & & & & \\
\hline Loganiaceae & & $x$ & & $x$ & $x$ & $x$ & $x$ & $x$ & \\
\hline Strychnos javariensis Krukoff & & & & & & & $x$ & & \\
\hline Strychnos jobertiana Baill. & & & & & & & $x$ & & \\
\hline Strychnos mitscherlichii M.R. Schomb. & & & & $x$ & $x$ & & & & \\
\hline $\begin{array}{l}\text { Strychnos panurensis Sprague \& } \\
\text { Sandwith }\end{array}$ & & & & $x$ & & & & $x$ & \\
\hline Strychnos peckii B.L. Rob. & & $x$ & & $x$ & & & & & \\
\hline Strychnos ramentifera Ducke & & & & & & & $x$ & & \\
\hline $\begin{array}{l}\text { Strychnos tarapotensis Sprague \& } \\
\text { Sandwith }\end{array}$ & & & & & $x$ & $x$ & & & \\
\hline Lomariopsidaceae & $x$ & $x$ & $x$ & $x$ & $x$ & $x$ & $x$ & & $x$ \\
\hline Lomariopsis japurensis (Mart.) J. Sm. & $x$ & $x$ & $x$ & $x$ & & $x$ & & & \\
\hline Lomariopsis nigropaleata Holttum & & $x$ & & & $x$ & & $x$ & & $x$ \\
\hline Magnoliaceae & & & & $x$ & & & & & \\
\hline Magnolia amazonica (Ducke) Govaerts & & & & $x$ & & & & & \\
\hline Malpighiaceae & & $x$ & & $x$ & $x$ & $x$ & & $x$ & $x$ \\
\hline Byrsonima japurensis A. Juss. & & $x$ & & & & & & & \\
\hline Byrsonima poeppigiana A. Juss. & & & & & & $x$ & & $x$ & \\
\hline Byrsonima stipulina J.F. Macbr. & & & & $x$ & $x$ & $x$ & & & $x$ \\
\hline
\end{tabular}




\begin{tabular}{|c|c|c|c|c|c|c|c|c|c|c|}
\hline Malvaceae & $x$ & $x$ & $x$ & $x$ & $x$ & $x$ & $x$ & $x$ & $x$ & $x$ \\
\hline Apeiba membranacea Spruce ex Benth. & $x$ & $x$ & $x$ & $x$ & & $x$ & & $x$ & & \\
\hline Apeiba tibourbou Aubl. & & $x$ & & $x$ & & & $x$ & & & \\
\hline Cavanillesia umbellata Ruiz \& Pav. & $x$ & & $x$ & $x$ & & & $x$ & & & \\
\hline Ceiba pentandra (L.) Gaertn. & $x$ & $x$ & $x$ & $x$ & & & $x$ & & & \\
\hline Ceiba samauma (Mart.) K. Schum. & & & & & & & $x$ & & & \\
\hline Eriotheca globosa (Aubl.) A. Robyns & & & $x$ & & & & $x$ & & & \\
\hline $\begin{array}{l}\text { Eriotheca macrophylla (K. Schum.) A. } \\
\text { Robyns }\end{array}$ & & & & & & $x$ & & & & \\
\hline Heliocarpus americanus L. & $x$ & & & $x$ & & & & & & \\
\hline Herrania cuatrecasana García-Barr. & & $x$ & & $x$ & & & & & & \\
\hline Herrania nitida (Poepp.) R.E. Schult. & & $x$ & $x$ & $x$ & & $x$ & $x$ & & & \\
\hline Herrania nycterodendron R.E. Schult. & & & & & & & & & $x$ & \\
\hline Hibiscus peruvianus R.E. Fr. & & & $x$ & & & $x$ & & & & \\
\hline Hibiscus sororius L. & & $x$ & & & & & & & & \\
\hline $\begin{array}{l}\text { Huberodendron swietenioides (Gleason) } \\
\text { Ducke }\end{array}$ & $x$ & $x$ & & & & $x$ & $x$ & & & \\
\hline Luehea cymulosa Spruce ex Benth. & & & & & & & $x$ & & & $x$ \\
\hline Luehea grandiflora Mart. & & $x$ & & & & $x$ & & & & \\
\hline Lueheopsis hoehnei Burret & & & & $x$ & & & & & & \\
\hline Lueheopsis rosea (Ducke) Burret & $x$ & & & & & & & & & \\
\hline Malvaviscus concinnus Kunth & & $x$ & & $x$ & & & & & & \\
\hline Matisia bracteolosa Ducke & $x$ & $x$ & & $x$ & & & $x$ & $x$ & & \\
\hline $\begin{array}{l}\text { Matisia dolichopoda (A. Robyns) } \\
\text { Cuatrec. }\end{array}$ & & & & & & & & $x$ & & \\
\hline Matisia lasiocalyx K. Schum. & & & & $x$ & & & & $x$ & & \\
\hline Matisia lecythicarpa Ducke & & $x$ & & & & & & & & \\
\hline Matisia longiflora Gleason & $x$ & & & $x$ & & & & & & \\
\hline $\begin{array}{l}\text { Matisia malacocalyx (A. Robyns \& S. } \\
\text { Nilsson) W.S. Alverson }\end{array}$ & $x$ & $x$ & $x$ & $x$ & & $x$ & $x$ & $x$ & $x$ & \\
\hline Matisia oblongifolia Poepp. \& Endl. & & $x$ & & $x$ & & & & & & \\
\hline Mollia gracilis Spruce ex Benth. & $x$ & & & & & $x$ & & & & \\
\hline Mollia lepidota Spruce ex Benth. & $x$ & $x$ & $x$ & $x$ & & $x$ & $x$ & & & \\
\hline Ochroma pyramidale (Cav. ex Lam.) Urb. & & & & & & $x$ & $x$ & & & \\
\hline Pachira aquatica Aubl. & $x$ & & & $x$ & & $x$ & $x$ & & $x$ & $x$ \\
\hline Pachira insignis (Sw.) Sw. ex Savigny & $x$ & $x$ & & $x$ & & $x$ & $x$ & & & \\
\hline Patinoa paraensis (Huber) Cuatrec. & & & $x$ & & & & & & & \\
\hline Patinoa sphaerocarpa Cuatrec. & & $x$ & $x$ & & & & & & $x$ & \\
\hline
\end{tabular}


Pseudobombax munguba (Mart.)

Dugand

Quararibea amazonica Ulbr.

$x$

$x$

Quararibea cordata (Bonpl.) Vischer

Quararibea guianensis Aubl.

Quararibea obliquifolia (Standl.) Standl.

Quararibea ochrocalyx (K. Schum.)

Vischer

Quararibea wittii K. Schum. \& Ulbr.

Scleronema praecox (Ducke) Ducke

Sterculia apeibophylla Ducke

Sterculia apetala (Jacq.) H. Karst.

Sterculia colombiana Sprague

Sterculia frondosa Rich.

$x \quad x \quad x$

$x$

$x$

Sterculia killipiana Standl. ex E.L. Taylor

$\begin{array}{cccc}x & x & x & x \\ x & & & x \\ x & x & x & x \\ & & x & x \\ & x & x & x \\ & x & x & x \\ x & x & x & x \\ x & x & & \end{array}$

Sterculia peruviana (D.R. Simpson) E.L.

Taylor ex Brako \& Zarucchi

Sterculia pruriens (Aubl.) K. Schum.

Sterculia tessmannii Mildbr.

Theobroma bicolor Bonpl.

Theobroma cacao L.

$x$

Theobroma glaucum H. Karst.

Theobroma microcarpum Mart.

Theobroma obovatum Klotzsch ex

Bernoulli

Theobroma speciosum Willd. ex Spreng. X X

Theobroma subincanum Mart.

Marantaceae

Calathea altissima (Poepp. \& Endl.)

Horan.

Calathea capitata (Ruiz \& Pav.) Lindl.

Calathea crotalifera S. Watson

Calathea lutea (Aubl.) Schult.

Calathea micans (L. Mathieu) Körn.

Calathea variegata (K. Koch) Linden ex

Körn.

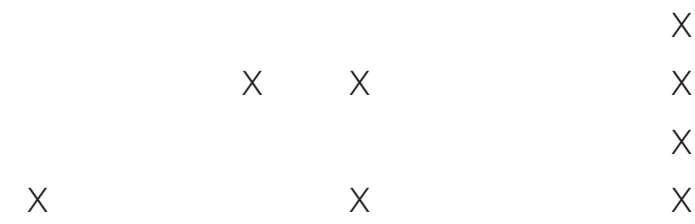

$x$

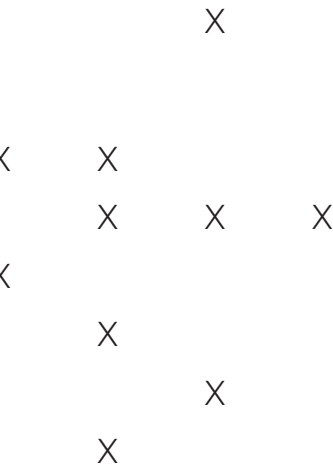

$x$

Ctenanthe ericae L. Andersson

$x$

Goeppertia altissima (Poepp. \& Endl.)

Borchs. \& S. Suárez

X 
Goeppertia capitata (Ruiz \& Pav.) Borchs.

\& S. Suárez

Goeppertia contrafenestra (H. Kenn.)

Borchs. \& S. Suárez

$x \quad x$

Goeppertia fucata (H. Kenn.) Borchs. \&

S. Suárez

Goeppertia gandersii (H. Kenn.) Borchs.

\& S. Suárez

Goeppertia inocephala (Kuntze) Borchs.

\& S. Suárez

Goeppertia lanata (Petersen) Borchs. \&

S. Suárez

Goeppertia leonia (Sander) Borchs. \& S.

Suárez

Goeppertia loeseneri (J.F. Macbr.)

Borchs. \& S. Suárez

Goeppertia micans (L. Mathieu) Borchs.

\& S. Suárez

Goeppertia propinqua (Poepp. \& Endl.)

Borchs. \& S. Suárez

Goeppertia standleyi (J.F. Macbr.)

Borchs. \& S. Suárez

Goeppertia zingiberina (Körn.) Borchs. \&

S. Suárez

Ischnosiphon gracilis (Rudge) Körn.

Ischnosiphon hirsutus Petersen

Ischnosiphon killipii J.F. Macbr.

Ischnosiphon leucophaeus (Poepp. \&

Endl.) Körn.

Ischnosiphon obliquus (Rudge) Körn.

Ischnosiphon surumuensis Loes.

Monophyllanthe araracuarensis S.

Suárez, Galeano \& H. Kenn.

Monotagma angustissimum Loes.

Monotagma juruanum Loes.

Monotagma laxum (Poepp. \& Endl.)

Schum.

Monotagma secundum (Petersen)

Schum.

Monotagma vaginatum Hagberg

Stromanthe stromanthoides (J.F. Macbr.)

L. Andersson $x$

$x$

$x$

$x \quad x$

$x$

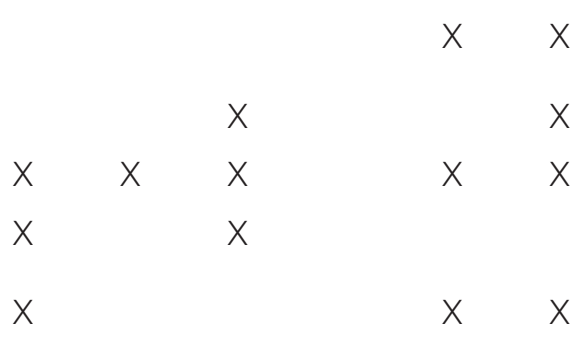

$x$

$x$

$x$

X $\quad X$

$x$

$x$ 


\begin{tabular}{|c|c|c|c|c|c|c|c|c|c|}
\hline Marattiaceae & $x$ & $x$ & & $x$ & & $x$ & & & \\
\hline Danaea leprieurii Kunze & & & & & & $x$ & & & \\
\hline Danaea nodosa (L.) Sm. & $x$ & $x$ & & $x$ & & $x$ & & & \\
\hline Marcgraviaceae & & & $x$ & $x$ & $x$ & $x$ & & & \\
\hline Marcgravia caudata Triana \& Planch. & & & & $x$ & & & & & \\
\hline Marcgravia longifolia J.F. Macbr. & & & $x$ & & $x$ & & & & \\
\hline $\begin{array}{l}\text { Marcgravia pedunculosa Triana \& } \\
\text { Planch. }\end{array}$ & & & & $x$ & & $x$ & & & \\
\hline Marcgravia sprucei (Wittm.) Gilg & & & & $x$ & & & & & \\
\hline Marcgravia williamsii J.F. Macbr. & & & & $x$ & & & & & \\
\hline Norantea guianensis Aubl. & & & & & $x$ & $x$ & & & \\
\hline Souroubea corallina (Mart.) de Roon & & & & $x$ & & & & & \\
\hline Souroubea guianensis Aubl. & & & & $x$ & & & & & \\
\hline Melastomataceae & $x$ & $x$ & $x$ & $x$ & $x$ & $x$ & $x$ & $x$ & $x$ \\
\hline Aciotis acuminifolia (Mart. ex DC.) Triana & & & & $x$ & & & & & \\
\hline Aciotis rubricaulis (Mart. ex DC.) Triana & & $x$ & & & & & & & \\
\hline Adelobotrys adscendens (Sw.) Triana & & & & & & & $x$ & & \\
\hline Adelobotrys macrantha Gleason & & & & $x$ & & & & & \\
\hline Adelobotrys scandens (Aubl.) DC. & & & & $x$ & & & & & \\
\hline Adelobotrys subsessilis Gleason & & & & & $x$ & $x$ & & & \\
\hline Bellucia pentamera Naudin & & $x$ & & & & & & & \\
\hline Bellucia umbellata Gleason & & & & $x$ & & & & & \\
\hline Blakea bracteata Gleason & & $x$ & $x$ & $x$ & & $x$ & & & \\
\hline Blakea ovalis (Ruiz \& Pav.) D. Don & & & & & $x$ & & & & \\
\hline Blakea rosea (Ruiz \& Pav.) D. Don & $x$ & $x$ & & & $x$ & $x$ & $x$ & & \\
\hline Clidemia hirta (L.) D. Don & & & & $x$ & & & & & \\
\hline Clidemia septuplinervia Cogn. & & $x$ & & & & & & & \\
\hline Graffenrieda limbata Triana & & & & $x$ & & $x$ & $x$ & & \\
\hline Henriettea stellaris O. Berg ex Triana & & & & $x$ & & $x$ & & $x$ & \\
\hline Miconia abbreviata Markgr. & & $x$ & & $x$ & & & & & \\
\hline Miconia acutipetala Sprague & & $x$ & & & & & & & \\
\hline Miconia affinis DC. & & & & $x$ & & $x$ & $x$ & & $x$ \\
\hline Miconia allardii (Wurdack) Michelang. & & $x$ & & & & & & & \\
\hline Miconia alternans Naudin & & & & & & $x$ & & & \\
\hline Miconia alternidomatia Michelang. & $x$ & $x$ & & & $x$ & $x$ & & & \\
\hline Miconia amazonica Triana & & & & & $x$ & & & & $x$ \\
\hline Miconia amplexicaulis Naudin & & & & & & & & $x$ & \\
\hline
\end{tabular}


Miconia araneifera (Markgr.) Michelang. \& R. Goldenb.

Miconia aurea (D. Don) Naudin

Miconia aureoides Cogn.

Miconia barbinervis (Benth.) Triana

Miconia biglandulosa Gleason

Miconia bubalina (D. Don) Naudin

Miconia bullifera (Mart. \& Schrank ex

DC.) Michelang.

Miconia candelabrum (J.F. Macbr.) R.

Goldenb.

Miconia caquetana (Sprague)

Michelang.

Miconia chaetodonta R. Goldenb. \&

Michelang.

Miconia cucullata (Gleason) Michelang.

Miconia dimorphica (J.F. Macbr.)

Michelang.

Miconia dispar Benth.

Miconia elata (Sw.) DC.

Miconia epibaterium (DC.) Michelang.

Miconia filiformis (Gleason) Michelang.

Miconia formicofoliosa Michelang.

Miconia formicoheterophylla Michelang.

Miconia fosteri Wurdack

Miconia glanduliflora R. Goldenb. \&

Michelang.

Miconia grandifolia Ule

Miconia heteroclita (Naudin) Michelang.

Miconia klugii Gleason

Miconia lepidota DC.

Miconia longicoma (Cogn.) Ocampo \&

Almeda

Miconia longifolia (Aubl.) DC.

Miconia macrophysca (Spruce ex Triana)

Michelang.

Miconia macrosperma (Mart.)

Michelang.

Miconia mayeta (D. Don) Michelang.

Miconia micrantha Cogn.

$x \quad x$

$x$

$x$

$x \quad x$

$x \quad x$

$x$
X

$x$

$x$

X

X

$x$

X

$x$

$x$

$x$

$x$

X

$x$

$x$

X

$x$

$x$

$x$

$x$

$x$

$x$

$x$

$x$

$\begin{array}{llll}x & x & x\end{array}$ 
Miconia minutiflora (Bonpl.) DC.

Miconia neoepiphytica Michelang.

Miconia phaeophylla Triana

Miconia prasina (Sw.) DC.

Miconia pterocaulon Triana

Miconia pujana Markgr.

Miconia punctata (Desr.) D. Don ex DC.

Miconia radulifolia (Benth.) Naudin

Miconia rimalis Naudin

Miconia serrulata (DC.) Naudin

Miconia splendens (Sw.) Griseb.

Miconia tococa Michelang.

Miconia tococapitata Michelang.

Miconia tococoronata Michelang.

Miconia tomentosa (Rich.) D. Don ex DC.

Miconia trinervia (Sw.) D. Don ex Loudon

Miconia triplinervis Ruiz \& Pav.

Miconia violascens (Pilg.) Michelang. \&

R. Goldenb.

Miconia zubenetana J.F. Macbr.

Monolena primuliflora Hook. f.

Mouriri acutiflora Naudin

Mouriri cauliflora Mart. ex DC.

Mouriri grandiflora DC.

Mouriri huberi Cogn.

Mouriri myrtifolia Spruce ex Triana

Mouriri myrtilloides (Sw.) Poir.

Mouriri nigra (DC.) Morley

Mouriri vernicosa Naudin

Salpinga secunda Schrank \& Mart. ex DC.

Triolena amazonica (Pilg.) Wurdack

\section{Meliaceae}

Carapa guianensis Aubl.

Cedrela fissilis Vell.

Cedrela odorata L.

Guarea carinata Ducke

Guarea cinnamomea Harms

$$
x
$$

$x$

$x$

$x$

$X$

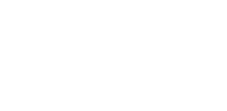

$x$

$X$
$x$

X $\quad X$

X

x

$x$

$x$

$x$

$\begin{array}{llll}x & x & & \\ x & x & & \\ & x & x & x \\ & x & \\ & x & x \\ & & & \\ & & & x\end{array}$

X

$x$

$x$

$x$

X

X

$x$

$x \quad x$

$\begin{array}{rll}x \quad x \quad & x & x \\ & x & \\ & x\end{array}$

X

X
X

$x$

$\begin{array}{lll}x & x \\ & x \\ & x \quad x\end{array}$

X $\quad x$

$x$

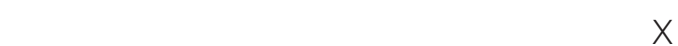


Guarea cristata T.D. Penn.

Guarea ecuadoriensis W. Palacios

Guarea fistulosa W. Palacios

Guarea glabra Vahl

Guarea gomma Pulle

Guarea guidonia (L.) Sleumer

Guarea juglandiformis T.D. Penn.

Guarea kunthiana A. Juss.

Guarea macrophylla Vahl

Guarea pterorhachis Harms

Guarea pubescens (Rich.) A. Juss.

Guarea silvatica C. DC.

Guarea trunciflora C. DC.

Trichilia elsae Harms

Trichilia micrantha Benth.

Trichilia pallida Sw.

Trichilia poeppigii C. DC.

Trichilia quadrijuga Kunth

Trichilia rubra C. DC.

Trichilia schomburgkii C. DC.

Trichilia septentrionalis C. DC.

Trichilia solitudinis Harms

Trichilia stipitata T.D. Penn.

Trichilia tuberculata (Triana \& Planch.) C. DC.

\section{Menispermaceae}

Abuta grandifolia (Mart.) Sandwith

Abuta pahni (Mart.) Krukoff \& Barneby

Abuta rufescens Aubl.

Anomospermum chloranthum Diels

Curarea tecunarum Barneby \& Krukoff

Curarea toxicofera (Wedd.) Barneby \& Krukoff

Odontocarya klugii (A.C. Sm.) Barneby

Orthomene schomburgkii (Miers)

Barneby \& Krukoff

Sciadotenia amazonica Eichler

Sciadotenia toxifera Krukoff \& A.C. Sm.

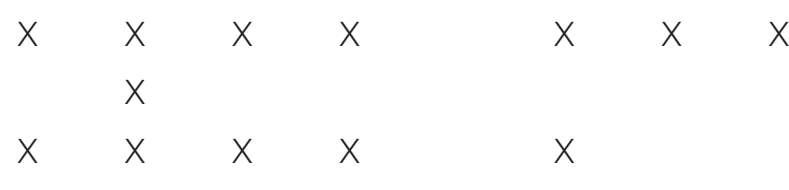

$x$

$\begin{array}{llll}x & x & x\end{array}$

$x \quad x$

$x$

$x$

$x \quad x \quad x$

$x$

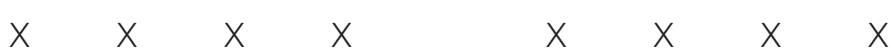

$x \quad x \quad x$

$x \quad x \quad x \quad x$

$x \quad x$

$X$

$x \quad x$

$x \quad x$

$x$

$X$

$x \quad x$

$x \quad x$

$x \quad x \quad x \quad x$

$x$ $x \quad x \quad x$

$x \quad x$

$x \quad x$

$x \quad x$

$x \quad x$

$x$

$x \quad x$ $x$

$x$

$x$

$x$

$x$

X $x \quad x$

X

$x$

$\begin{array}{ccccccccc}x & x & x & x & x & x & x & x & x \\ x & x & x & x & x & x & x & x & x \\ & x & & & & & x & & \\ & & x & x & & & & & \\ x & x & & x & & x & & & x \\ & x & & & & x & x & & \\ & & & & & & & \\ & & & & & & & & \end{array}$

x $\quad x$

$x$

X 
Telitoxicum krukovii Moldenke

\begin{tabular}{|c|c|c|c|c|c|c|c|c|c|c|}
\hline Metaxyaceae & $x$ & $x$ & & & & $x$ & $x$ & & & \\
\hline $\begin{array}{l}\text { Metaxya rostrata (Humb. \& Bonpl. ex } \\
\text { Willd.) C. Presl }\end{array}$ & $x$ & $x$ & & & & $x$ & $x$ & & & \\
\hline Monimiaceae & $x$ & & & $x$ & & $x$ & & & & \\
\hline Mollinedia killipii J.F. Macbr. & $x$ & & & $x$ & & $x$ & & & & \\
\hline Mollinedia ovata Ruiz \& Pav. & $x$ & & & $x$ & & & & & & \\
\hline Moraceae & $x$ & $x$ & $x$ & $x$ & $x$ & $x$ & $x$ & $x$ & $x$ & $x$ \\
\hline Batocarpus orinocensis H. Karst. & & $x$ & $x$ & & & & & & & \\
\hline Brosimum alicastrum Sw. & & & & & & $x$ & & $x$ & & \\
\hline Brosimum guianense (Aubl.) Huber & $x$ & $x$ & $x$ & $x$ & & $x$ & $x$ & $x$ & $x$ & \\
\hline $\begin{array}{l}\text { Brosimum lactescens (S. Moore) C.C. } \\
\text { Berg }\end{array}$ & $x$ & $x$ & $x$ & $x$ & & $x$ & $x$ & & & \\
\hline Brosimum parinarioides Ducke & $x$ & & $x$ & $x$ & & $x$ & $x$ & & & \\
\hline Brosimum potabile Ducke & $x$ & $x$ & $x$ & $x$ & & $x$ & & & & $x$ \\
\hline Brosimum rubescens Taub. & $x$ & $x$ & $x$ & $x$ & & $x$ & $x$ & $x$ & $x$ & $x$ \\
\hline Brosimum utile (Kunth) Oken & $x$ & $x$ & $x$ & $x$ & & $x$ & $x$ & $x$ & $x$ & $x$ \\
\hline Castilla ulei Warb. & & $x$ & $x$ & & & & & & & $x$ \\
\hline Clarisia biflora Ruiz \& Pav. & & & & $x$ & & & & & & \\
\hline Clarisia racemosa Ruiz \& Pav. & $x$ & $x$ & $x$ & $x$ & & $x$ & $x$ & $x$ & $x$ & \\
\hline Ficus albert-smithii Standl. & & & & $x$ & & & $x$ & & & \\
\hline Ficus americana Aubl. & $x$ & $x$ & & $x$ & & $x$ & $x$ & & & $x$ \\
\hline Ficus boliviana C.C. Berg & & $x$ & & & & & & & & \\
\hline Ficus caballina Standl. & $x$ & $x$ & & & & & $x$ & & & \\
\hline Ficus casapiensis (Miq.) Miq. & & & & & & & $x$ & & & \\
\hline Ficus castellviana Dugand & & & & & & & $x$ & & & \\
\hline Ficus citrifolia Mill. & & & & & & & $x$ & & & $x$ \\
\hline Ficus gomelleira Kunth \& C.D. Bouché & & & & & & & $x$ & & & \\
\hline Ficus insipida Willd. & & $x$ & & $x$ & & & $x$ & & & \\
\hline Ficus krukovii Standl. & & & & & & & $x$ & & & \\
\hline Ficus maxima Mill. & $x$ & & & $x$ & $x$ & & $x$ & & & \\
\hline Ficus nymphaeifolia Mill. & $x$ & $x$ & & $x$ & & & $x$ & & & \\
\hline Ficus obtusifolia Kunth & & $x$ & & & & & $x$ & & & \\
\hline Ficus paraensis (Miq.) Miq. & $x$ & $x$ & $x$ & $x$ & & & $x$ & & & \\
\hline Ficus piresiana Vázq. Ávila \& C.C. Berg & & $x$ & & & & & $x$ & & & \\
\hline Ficus popenoei Standl. & $x$ & $x$ & & & & & & & & \\
\hline Ficus schippii Standl. & & $x$ & & & & & & & & \\
\hline Ficus schultesii Dugand & $x$ & & & & & & & & & \\
\hline
\end{tabular}


Ficus sphenophylla Standl.

Ficus trigona L. f.

Ficus yoponensis Desv.

Helicostylis elegans (J.F. Macbr.) C.C.

Berg

Helicostylis scabra (J.F. Macbr.) C.C. Berg X

Helicostylis tomentosa (Poepp. \& Endl.)

Rusby

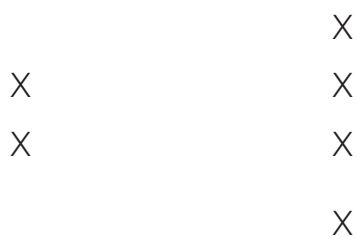

Maquira calophylla (Poepp. \& Endl.) C.C.

Berg

Maquira guianensis Aubl.

Naucleopsis glabra Spruce ex Baill.

Naucleopsis humilis C.C. Berg

Naucleopsis imitans (Ducke) C.C. Berg

Naucleopsis krukovii (Standl.) C.C. Berg

Naucleopsis oblongifolia (Kuhlm.)

Carauta

Naucleopsis pseudonaga (Mildbr.) C.C.

Berg

Naucleopsis ternstroemiiflora (Mildbr.)

C.C. Berg

Naucleopsis ulei (Warb.) Ducke

Perebea angustifolia (Poepp. \& Endl.)

C.C. Berg

Perebea guianensis Aubl.

Perebea humilis C.C. Berg

Perebea longepedunculata C.C. Berg

$x \quad x \quad x$

$x \quad x$

$x \quad x \quad x$

$x \quad x \quad x$

$\begin{array}{lllll}x & X & X & X & x\end{array}$

Perebea mennegae C.C. Berg

Perebea mollis (Poepp. \& Endl.) Huber

Pseudolmedia laevigata Trécul

Pseudolmedia laevis (Ruiz \& Pav.) J.F.

Macbr.

Pseudolmedia macrophylla Trécul

Sorocea briquetii J.F. Macbr.

Sorocea guilleminiana Gaudich.

Sorocea muriculata Miq.

Sorocea pubivena Hemsl.

Sorocea steinbachii C.C. Berg

$\begin{array}{cccc}x & x & x & x \\ & x & x & \\ x & & x & x \\ x & x & & x \\ & & & x\end{array}$

$x$

$$
x
$$

x 


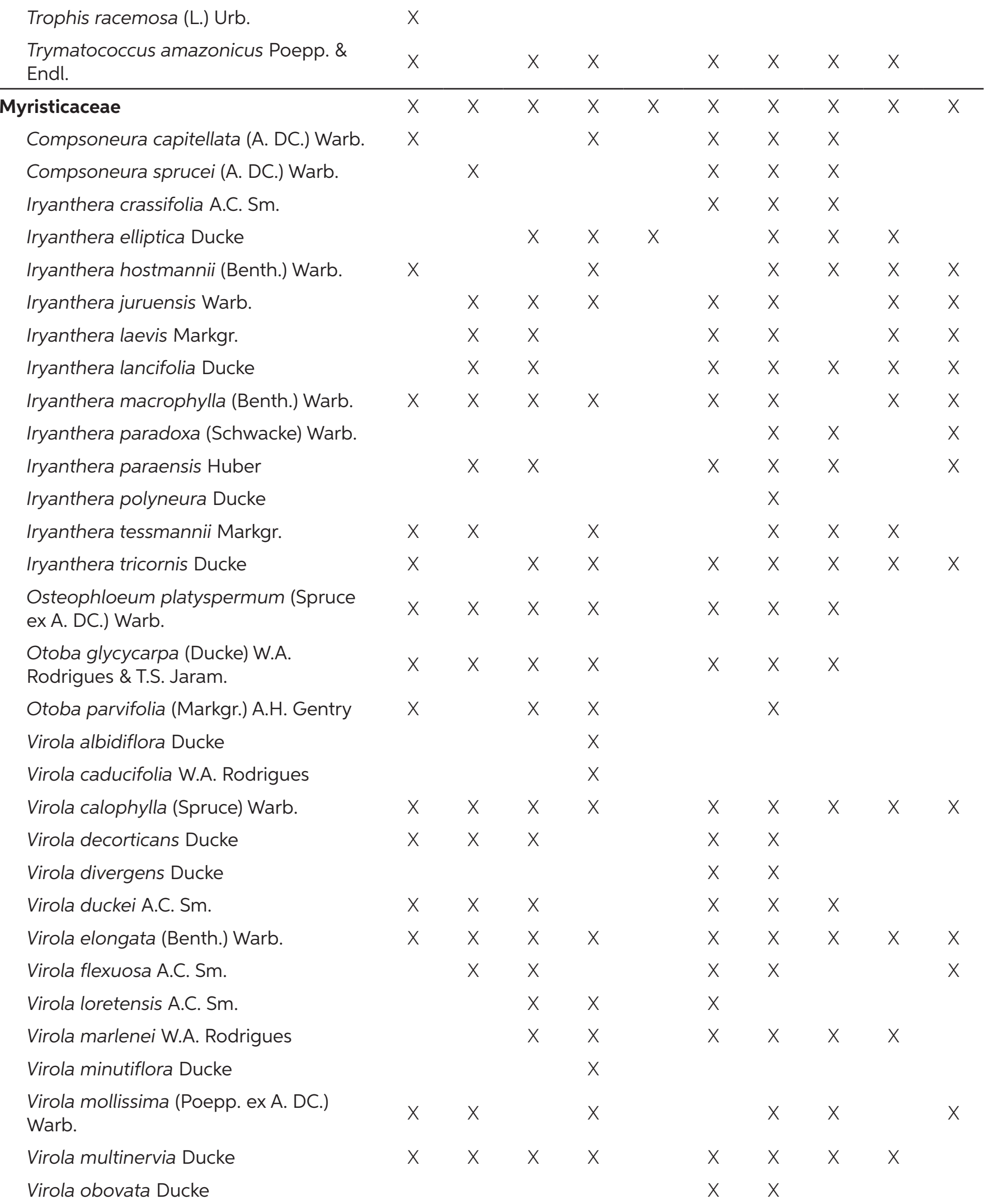


Virola pavonis (A. DC.) A.C. Sm. X

Virola peruviana (A. DC.) Warb.

Virola sebifera Aubl.

Virola surinamensis (Rol. ex Rottb.) Warb.

Myrtaceae

Calyptranthes bipennis O. Berg

Calyptranthes crebra McVaugh

Calyptranthes cuspidata Mart. ex DC.

Calyptranthes glandulosa M.L. Kawas. \&

B. Holst

Calyptranthes krugioides McVaugh

Calyptranthes longifolia O. Berg

Calyptranthes macrophylla O. Berg

Calyptranthes maxima McVaugh

Calyptranthes multiflora Poepp. ex O.

Berg

Calyptranthes nervata M.L. Kawas. \& B. Holst

Calyptranthes paniculata Grosourdy

Calyptranthes pulchella DC.

Calyptranthes ruiziana O. Berg

Calyptranthes simulata McVaugh

Calyptranthes tessmannii Burret ex

McVaugh

Campomanesia lineatifolia Ruiz \& Pav.

Eugenia anastomosans DC.

Eugenia chrysophyllum Poir.

Eugenia cuspidifolia DC.

Eugenia egensis DC.

Eugenia florida DC.

Eugenia heterochroma Diels

Eugenia multirimosa McVaugh

Eugenia patrisii Vahl

Eugenia polystachya Rich.

Eugenia stipitata McVaugh

Eugenia subterminalis DC.

Marlierea caudata McVaugh

Marlierea imperfecta McVaugh

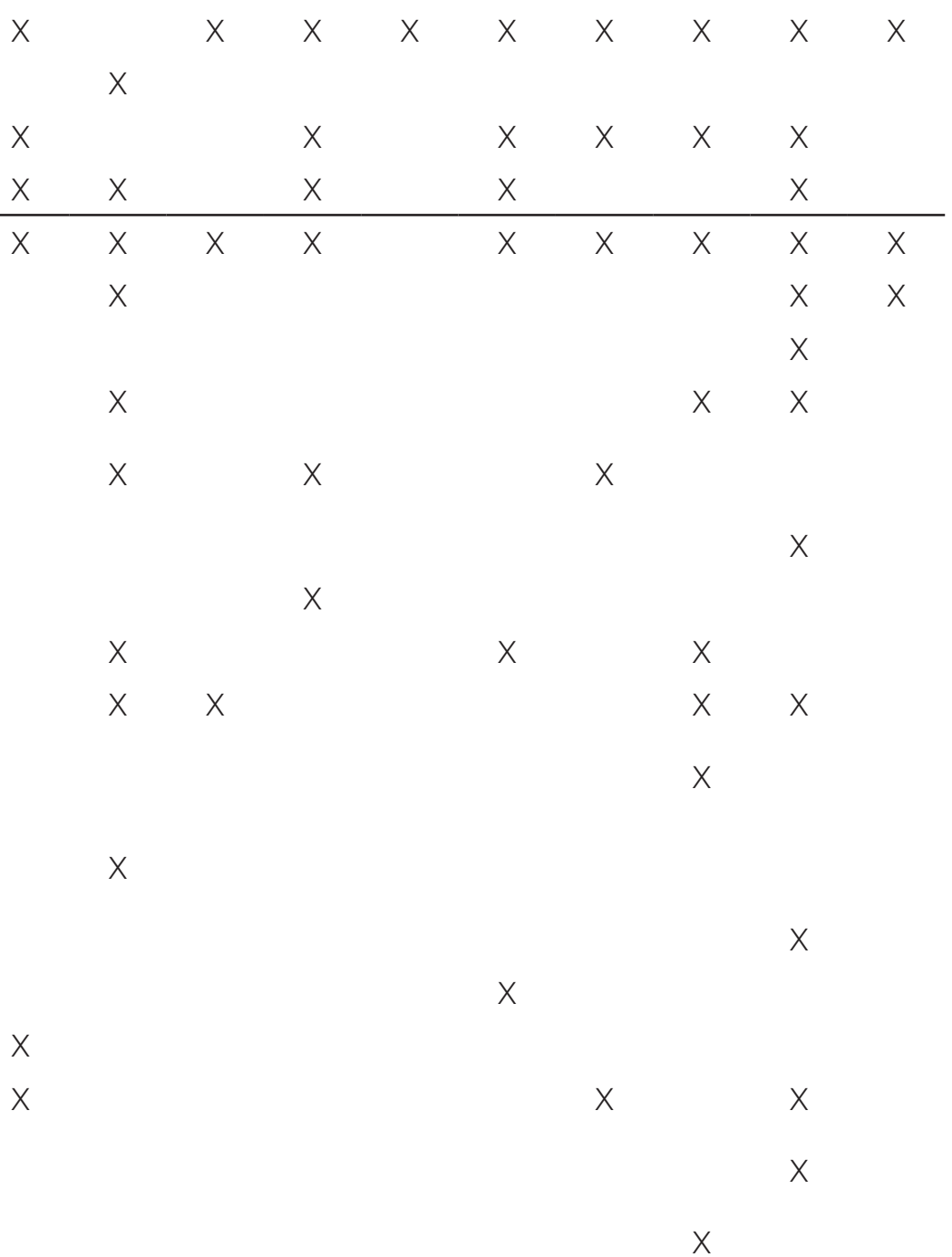

X

$X$

$x$

$x$

$x$

$x$

$x$

$x \quad x$

$x$

$x$

$x \quad x$

$x$

$x$

$x \quad x \quad x$

$X$ 
Marlierea subulata McVaugh

Myrcia bracteata (Rich.) DC.

Myrcia minutiflora Sagot

Myrcia obumbrans (O. Berg) McVaugh

Myrcia splendens (Sw.) DC.

Myrciaria dubia (Kunth) McVaugh

Myrciaria vismeifolia (Benth.) O.Berg

\section{Nyctaginaceae}

Neea divaricata Poepp. \& Endl.

Neea floribunda Poepp. \& Endl.

Neea macrophylla Poepp. \& Endl.

Neea parviflora Poepp. \& Endl.

Neea spruceana Heimerl

Neea verticillata Ruiz \& Pav.

\section{Ochnaceae \\ Cespedesia spathulata (Ruiz \& Pav.) Planch.}

Froesia diffusa Gereau \& Vásquez

Krukoviella disticha (Tiegh.) Dwyer

Lacunaria crenata (Tul.) A.C. Sm.

Lacunaria jenmanii (Oliv.) Ducke

Ouratea amplifolia Sleumer

Ouratea iquitosensis J.F. Macbr.

Ouratea pendula Poepp. ex Engl.

Quiina amazonica A.C. Sm.

Quiina florida Tul.

Quiina macrophylla Tul.

Quiina paraensis Pires \& Fróes

Touroulia amazonica Pires \& A.S. Foster

Touroulia guianensis Aubl.

\section{Olacaceae}

Aptandra caudata A.H. Gentry \& R. Ortiz

Curupira tefeensis G.A. Black

Dulacia candida (Poepp.) Kuntze

Heisteria acuminata (Bonpl.) Engl.

Heisteria duckei Sleumer

Heisteria insculpta Sleumer

$\begin{array}{ccc} & x \\ x & & x \\ & x & \\ & & \\ & & x\end{array}$

$x$

$x$

X

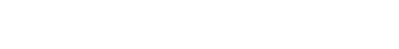

$x$

$x \quad x \quad x$

$x \quad x$

$x \quad x$

$x$

$x$

$x-x$

$x$

$\begin{array}{llll}x & x & x & x \\ x & x & x & x \\ x & & x & x \\ & & x & \end{array}$

$X$

$x$

$x$ $x$

$x$ $x$ $x \quad x$

$x$

$x$

$x \quad x$ 
Heisteria ovata Benth.

Heisteria scandens Ducke

$x$

Heisteria spruceana Engl.

$x$

X

Minquartia guianensis Aubl.

$x \quad x \quad x \quad x \quad x \quad x \quad x$

Tetrastylidium peruvianum Sleumer

Onagraceae

$X$

Ludwigia decurrens Walter

$x$

\section{Opiliaceae}

X

Agonandra brasiliensis Miers ex Benth.

\& Hook. $\mathrm{f}$.

Agonandra peruviana Hiepko

$x$

Agonandra silvatica Ducke

Aganisia fimbriata Rchb. f.

Braemia vittata (Lindl.) Jenny

Christensonella uncata (Lindl.) Szlach.,

Mytnik, Górniak \& Åšmiszek

Epidendrum magnicallosum C.

Schweinf.

Koellensteinia graminea (Lindl.) Rchb. f.

X

Rudolfiella aurantiaca (Lindl.) Hoehne

$x$

Trigonidium acuminatum Bateman ex Lindl.

\section{Oxalidaceae}

Biophytum dendroides (Kunth) DC.

$\begin{array}{lll}x & x & x \\ x & x\end{array}$

$x$

$x \quad x$

Biophytum somnians (Mart. ex Zucc.) G. Don

\begin{tabular}{|c|c|c|c|c|c|c|c|c|}
\hline Passifloraceae & $x$ & $x$ & $x$ & $x$ & $x$ & $x$ & $x$ & \\
\hline Dilkea retusa Mast. & & & & & & & $x$ & \\
\hline Passiflora coccinea Aubl. & $x$ & & $x$ & & $x$ & & & \\
\hline Passiflora involucrata (Mast.) A.H. Gentry & & & & & & & $x$ & \\
\hline Passiflora nitida Kunth & & & & $x$ & & & & \\
\hline Passiflora spinosa (Poepp. \& Endl.) Mast. & $x$ & $x$ & & & & $x$ & & \\
\hline Turnera acuta Willd. ex Schult. & $x$ & & & $x$ & & & & \\
\hline Pentaphylacaceae & & & & & & & $x$ & \\
\hline Ternstroemia klugiana Kobuski & & & & & & & $x$ & \\
\hline Phyllanthaceae & $x$ & $x$ & $x$ & $x$ & $x$ & $x$ & $x$ & $x$ \\
\hline Amanoa guianensis Aubl. & & & & & & & $x$ & $x$ \\
\hline Didymocistus chrysadenius Kuhlm. & & & & $x$ & & & $x$ & \\
\hline
\end{tabular}


Hieronyma alchorneoides Allemão

Hieronyma macrocarpa Müll. Arg.

Hieronyma oblonga (Tul.) Müll. Arg.

Margaritaria nobilis L. $f$.

Phyllanthus fluitans Benth. ex Müll. Arg.

\begin{tabular}{llllll} 
Richeria grandis Vahl & & $X$ & & \\
\hline Picramniaceae & $X$ & $X$ & & $X$ & $X$ \\
Picramnia latifolia Tul. & $X$ & $X$ & & \\
Picramnia magnifolia J.F. Macbr. & & & & $X$ & \\
Picramnia spruceana Engl. & & & &
\end{tabular}

\section{Piperaceae}

Peperomia cardenasii Trel.

Peperomia emarginella (Sw. ex Wikstr.)

C. DC.

Peperomia macrostachya (Vahl) A.Dietr. X

Peperomia mishuyacana Trel.

Peperomia pseudosalicifolia Trel.

Peperomia rotundifolia (L.) Kunth

Peperomia serpens (Sw.) Loudon

Piper anonifolium Kunth

Piper arboreum Aubl.

Piper augustum Rudge

Piper bartlingianum (Miq.) C. DC.

Piper brasiliense C. DC.

Piper cirratum Trel.

Piper coruscans Kunth

Piper crassinervium Kunth

Piper demeraranum (Miq.) C. DC.

Piper dumosum Rudge

Piper hispidum Sw.

Piper longifolium Ruiz \& Pav.

Piper macrotrichum C. DC.

Piper obliquum Ruiz \& Pav.

Piper pebasense Trel.

Piper perstipulare Steyerm.

Piper poporense Trel. \& Yunck.

Piper soledadense Trel.

\begin{tabular}{|c|c|c|c|c|}
\hline \multirow[t]{2}{*}{$x$} & $x$ & $x$ & $x$ & $x$ \\
\hline & & $X$ & & \\
\hline$x$ & $x$ & $X$ & & $x$ \\
\hline
\end{tabular}

$x$

$\begin{array}{lll}x & x & x \\ x & x\end{array}$

$x$

$x \quad x \quad x$

$x$

$x$

$X$

$x$

$x \quad x$

$x$

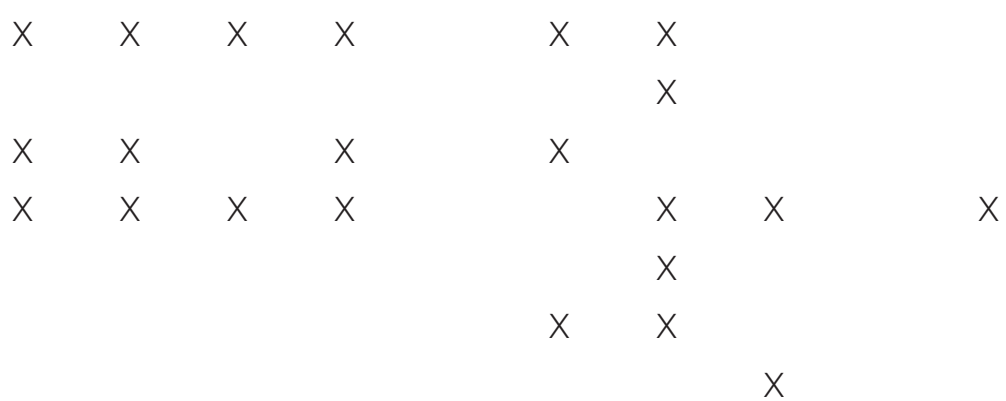

$x$

$x$

$x$

$x \quad x$

$x$
$x$

$x$

$x$

$x \quad x \quad x$

$x$

$\begin{array}{ll}x & x \\ x & \\ x & x\end{array}$


Piper stellipilum (Miq.) C. DC.

Piper umbellatum L.

\section{Poaceae}

Agnesia loretensis (Mez) J.R. Grande

Guadua weberbaueri Pilg.

$x \quad x$

$\begin{array}{lllll} & x & & \\ x & x & x & x \\ x & & & \end{array}$

Hymenachne donacifolia (Raddi) Chase

$x \quad x$

Lasiacis maculata (Aubl.) Urb.

$x$

Orthoclada laxa (Rich.) P. Beauv.

$x$

Pariana campestris Aubl.

$x$

Pharus latifolius L.

$x \quad x \quad x$

Pharus virescens Döll

$x$

Polygalaceae

$x \quad x$

$x \quad x \quad x$

Acanthocladus scleroxylon (Ducke) B.

Eriksen \& B. Ståhl

$x \quad x$

Moutabea aculeata (Ruiz \& Pav.) Poepp. \& Endl.

\section{Polygonaceae}

Coccoloba densifrons Mart. ex Meisn.

Coccoloba marginata Benth.

Coccoloba mollis Casar.

$x \quad x$

X

Coccoloba padiformis Meisn.

$x$

Coccoloba paraensis Meisn.

Symmeria paniculata Benth.

Triplaris americana L.

$\begin{array}{lll}x & x \\ x & x\end{array}$

Triplaris peruviana Fisch. \& E. Mey. ex C.A. Mey.

$\begin{array}{llll}x & x & x & x \\ x & x & x & x\end{array}$

$x$

Triplaris weigeltiana (Rchb.) Kuntze

\section{Polypodiaceae}

Campyloneurum phyllitidis (L.) C. Presl

Campyloneurum repens (Aubl.) C. Presl

Dicranoglossum desvauxii (Klotzsch)

Proctor

Microgramma baldwinii Brade

Microgramma dictyophylla (Kunze ex

Mett.) de la Sota

Microgramma fuscopunctata (Hook.)

Vareschi

$x \quad x \quad x \quad x$

$x$

Microgramma mauritiana (Willd.) Tardieu $\quad X$ 
Microgramma megalophylla (Desv.) de la Sota

Microgramma percussa (Cav.) de la Sota $x \quad x$

Microgramma persicariifolia (Schrad.) C. Presl

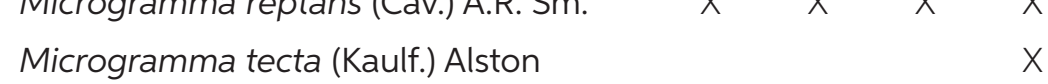

Niphidium crassifolium (L.) Lellinger $\quad X$

Phlebodium decumanum (Willd.) J. Sm. X

Polypodium adnatum Kunze ex Klotzsch $\quad$ X

\begin{tabular}{|c|c|c|c|c|c|c|c|c|}
\hline Polypodium fraxinifolium Jacq. & & $x$ & & & & & & \\
\hline Pontederiaceae & $x$ & $x$ & & $x$ & $x$ & & & \\
\hline Eichhornia crassipes (Mart.) Solms & & $x$ & & & & & & \\
\hline Heteranthera reniformis Ruiz \& Pav. & & & & & $x$ & & & \\
\hline Pontederia rotundifolia L. f. & $x$ & & & $x$ & & & & \\
\hline Primulaceae & $x$ & $x$ & $x$ & $x$ & & & $x$ & $x$ \\
\hline Ardisia loretensis Lundell & & & & $x$ & & & & \\
\hline Clavija longifolia Ruiz \& Pav. & & $x$ & $x$ & & & & & \\
\hline Clavija tarapotana Mez & & $x$ & & & & & & \\
\hline Clavija venosa B. Ståhl & & $x$ & & & & & & \\
\hline Clavija weberbaueri Mez & $x$ & $x$ & & $x$ & & & & \\
\hline Cybianthus kayapii (Lundell) Pipoly & & & & $x$ & & & $x$ & \\
\hline $\begin{array}{l}\text { Cybianthus nanayensis (J.F. Macbr.) G. } \\
\text { Agostini }\end{array}$ & & & & & & & & $x$ \\
\hline Cybianthus peruvianus (A. DC.) Miq. & & & & & & & X & $x$ \\
\hline Stylogyne ardisioides (Kunth) Mez & $x$ & $x$ & & $x$ & & & & \\
\hline Stylogyne laxiflora Mez & & & & $x$ & & & $x$ & \\
\hline Proteaceae & & $x$ & & & & $x$ & & \\
\hline Panopsis rubescens (Pohl) Pittier & & $x$ & & & & & & \\
\hline Roupala montana Aubl. & & $x$ & & & & $x$ & & \\
\hline Pteridaceae & $x$ & $x$ & & $x$ & $x$ & $x$ & $x$ & \\
\hline Adiantum argutum Splitg. & & & & & & & $x$ & \\
\hline Adiantum pulverulentum L. & $x$ & & & & & & $x$ & \\
\hline Adiantum tomentosum Klotzsch & & & & X & & & & \\
\hline Anetium citrifolium (L.) Splitg. & $x$ & & & X & & & & \\
\hline Antrophyum guayanense Hieron. & $x$ & & & & & $X$ & & \\
\hline Hecistopteris pumila (A. Spreng.) J. Sm. & & & & & & & $x$ & \\
\hline Pityrogramma calomelanos (L.) Link & $x$ & $x$ & & $x$ & $X$ & & & \\
\hline
\end{tabular}


Polytaenium guayanense (Hieron.)

Alston

Pteris propinqua J. Agardh

Putranjivaceae

$x \quad x$

$x$

Drypetes amazonica Steyerm.

$x$

Drypetes gentryi Monach.

$x$

Drypetes variabilis Uittien

\section{Rapateaceae}

Rapatea paludosa Aubl.

Rapatea spectabilis Pilg.

Rapatea ulei Pilg.

$x$

$x$

$x$

Rapatea undulata Ducke

\section{Rhamnaceae}

Ampelozizyphus amazonicus Ducke

Colubrina glandulosa Perkins

$x$

$x$

$x$

$x$

$x$

$x$

Ziziphus cinnamomum Triana \& Planch.

\section{Rhizophoraceae}

Cassipourea peruviana Alston

$x$
$x \quad x$

Sterigmapetalum obovatum Kuhlm.

\section{Rubiaceae}

Agouticarpa curviflora (Dwyer) C.H.

Perss.

Agouticarpa isernii (Standl.) C.H. Perss.

Alibertia bertierifolia K. Schum.

$\begin{array}{lll} & x & x \\ x & x & x \\ x & & x\end{array}$

Alibertia latifolia (Benth.) K. Schum.

Amaioua corymbosa Kunth

Amaioua guianensis Aubl.

Amphidasya colombiana (Standl.)

Steyerm.

Bertiera guianensis Aubl.

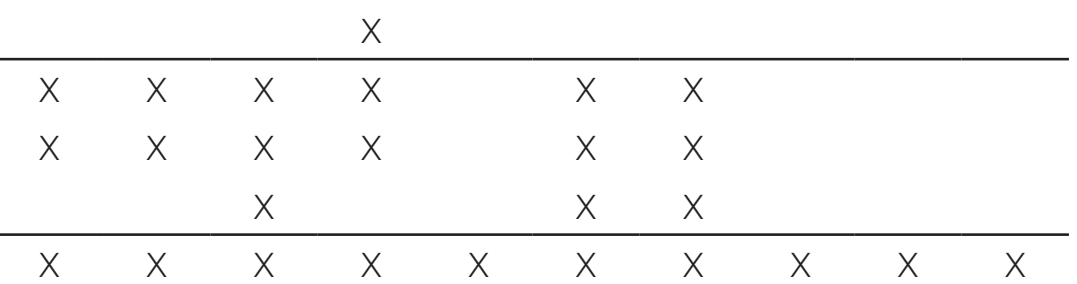

Bothriospora corymbosa (Benth.) Hook.

f.

Capirona decorticans Spruce

Carapichea dolichophylla (Standl.) C.M.

Taylor

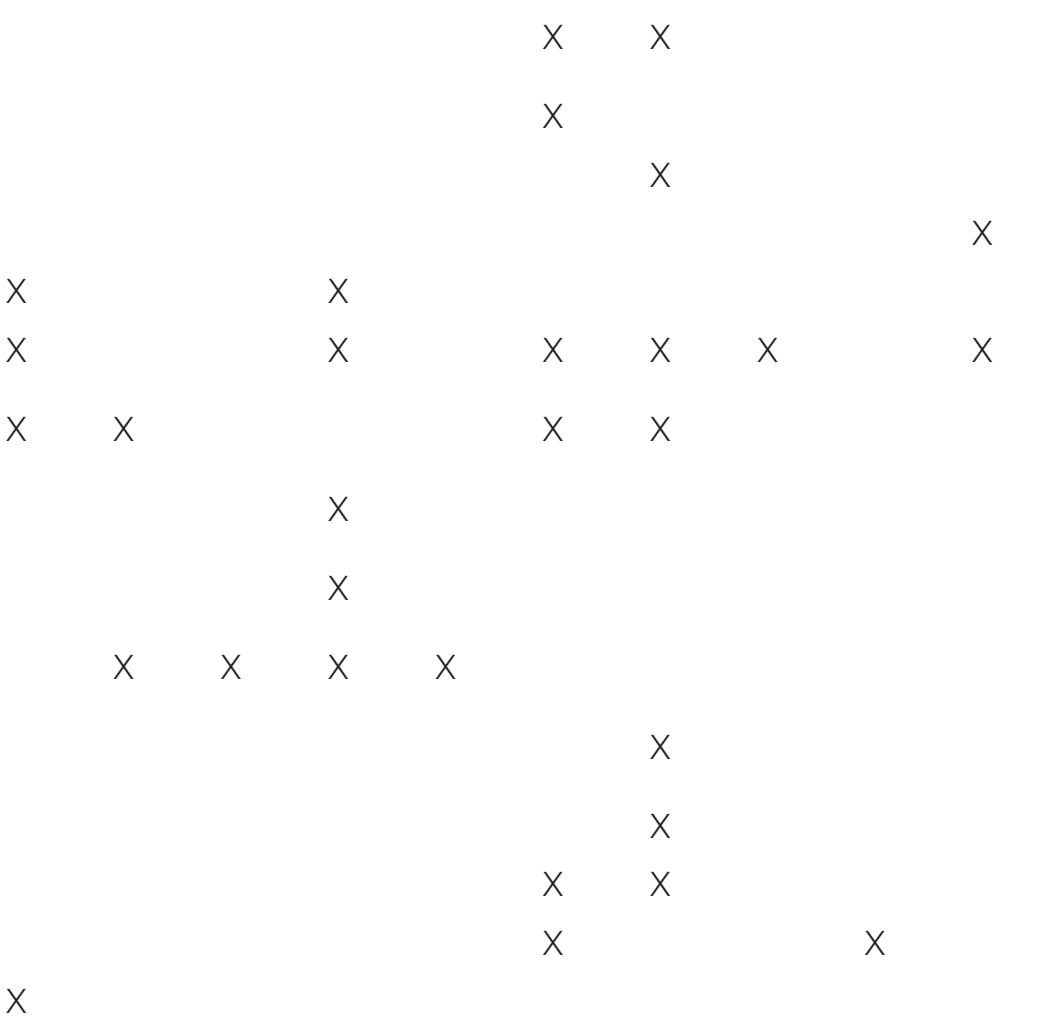

Carapichea klugii (Standl.) C.M. Taylor

Chimarrhis gentryana Delprete

Chimarrhis hookeri K. Schum.

Chomelia klugii (Standl.) Steyerm. 
Cinchona micrantha Ruiz \& Pav.

Coussarea albescens (DC.) Müll. Arg.

Coussarea brevicaulis K. Krause

Coussarea klugii Steyerm.

Coussarea paniculata (Willd.) Standl.

Duroia fusifera Hook. f. ex K. Schum.

Duroia hirsuta (Poepp.) K. Schum.

Duroia saccifera (Mart. ex Roem. \&

Schult.) Hook. f. ex Schumann

Eumachia boliviana (Standl.) Delprete \& J.H. Kirkbr.

Eumachia cephalantha (Müll. Arg.)

Delprete \& J.H. Kirkbr.

Eumachia inconspicua (C.M. Taylor) C.M.

Taylor \& Razafim.

Eumachia nana (K. Krause) Delprete \&

J.H. Kirkbr.

Faramea anisocalyx Poepp. \& Endl.

Faramea axillaris Standl.

Faramea capillipes Müll. Arg.

Faramea glandulosa Poepp. \& Endl.

Faramea multiflora A. Rich.

Faramea occidentalis (L.) A. Rich.

Faramea quinqueflora Poepp. \& Endl.

Faramea tamberlikiana Müll. Arg.

Faramea uniflora Dwyer \& M.V. Hayden

Ferdinandusa chlorantha (Wedd.) Standl.

Ferdinandusa hirsuta Standl.

Ferdinandusa loretensis Standl.

Genipa americana L.

Genipa spruceana Steyerm.

Geophila cordifolia Miq.

Geophila repens (L.) I.M. Johnst.

Hamelia patens Jacq.

Hippotis albiflora H. Karst.

Hippotis brevipes Spruce ex K. Schum.

Isertia hypoleuca Benth.

Isertia rosea Spruce ex K. Schum.

Ixora killipii Standl. $x$

$\begin{array}{ll}x & x \\ x & \end{array}$

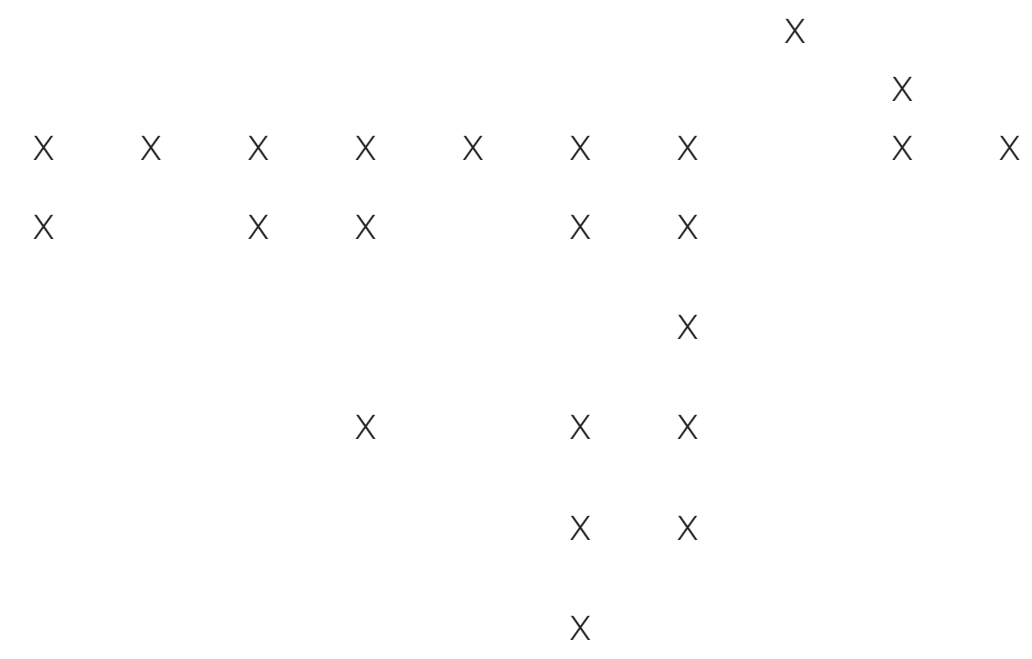

$\begin{array}{llllll} & x & & \\ x & x & x & x & x \\ x & & x & \end{array}$

$x$

$x \quad x \quad x$

$x$

$X$

$x$

X

$x$

$x \quad x \quad x \quad x$

$x \quad x \quad x$

$x$

$x \quad x$

$x \quad x$

$x$

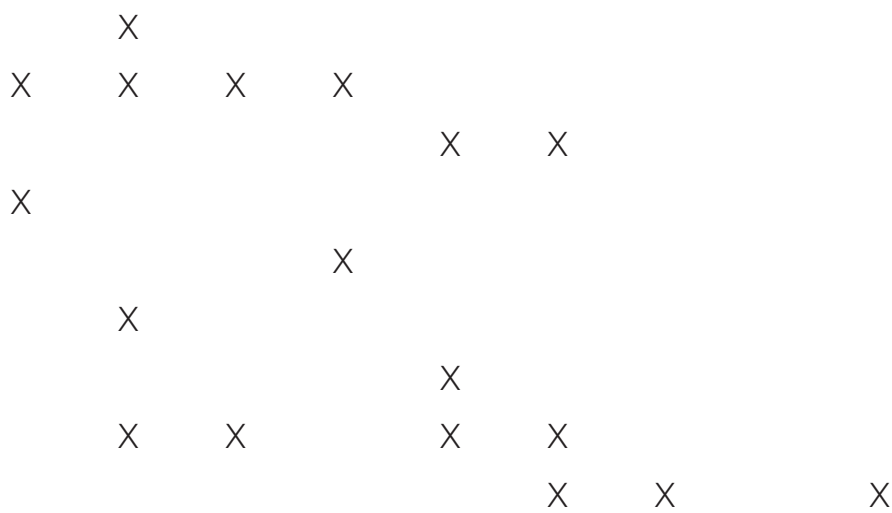


Ixora sparsifolia K. Krause

Ixora spruceana Müll. Arg.

Ixora yavitensis Steyerm.

Kutchubaea oocarpa (Standl.) C.H. Perss.

Kutchubaea sericantha Standl.

Ladenbergia amazonensis Ducke

$x$

Ladenbergia oblongifolia (Humb. ex

Mutis) L. Andersson

Macrocnemum roseum (Ruiz \& Pav.)

Wedd.

\section{$x$}

$x$

$x$

$x$

\section{$x$}

$x$

$x$

$x$

$x$

Malanea ecuadorensis C.M. Taylor

Notopleura congesta C.M. Taylor

Notopleura iridescens C.M. Taylor

Notopleura leucantha (K. Krause) C.M.

Taylor

Notopleura parasiggersiana C.M. Taylor

Notopleura plagiantha (Standl.) C.M.

Taylor

Notopleura polyphlebia (Donn. Sm.)

C.M. Taylor

Pagamea coriacea Spruce ex Benth.

Pagamea guianensis Aubl.

$x$

Pagamea plicata Spruce ex Benth.

Palicourea corymbifera (Müll. Arg.)

Standl.

Palicourea crocea (Sw.) Schult.

Palicourea cuspidata (Bredem. ex

Schult.) C.M. Taylor

Palicourea cuspidulata (K. Krause) C.M.

Taylor

Palicourea guianensis Aubl.

$x$

Palicourea huampamiensis (C.M. Taylor)

C.M. Taylor

Palicourea hypochlorina (C.M. Taylor)

C.M. Taylor

Palicourea iquitoensis K. Krause

Palicourea lachnantha Standl.

Palicourea lasiantha K. Krause

Palicourea macrobotrys (Ruiz \& Pav.) DC. $x$

$x$

$x$

$x$

$x$

$x \quad x$
X

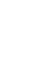

X $\quad x$

$x$

$x$

\section{$x$}

$x$

$x$

\section{$x$}

$x$
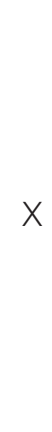

$x \quad x$

$\begin{array}{lll}x & x \\ x & x \\ x & x\end{array}$


Palicourea nigricans K. Krause

Palicourea punicea (Ruiz \& Pav.) DC.

Palicourea racemosa (Aubl.) G.

Nicholson

Palicourea schunkei (C.M. Taylor) C.M.

Taylor

Palicourea stenostachya (Standl.) C.M.

Taylor

Palicourea subfusca (Müll. Arg.) C.M.

Taylor

Palicourea subspicata Huber

Palicourea virens (Poepp.) Standl.

Palicourea zevallosii (C.M. Taylor) C.M.

Taylor

Pentagonia amazonica (Ducke) L.

Andersson \& Rova

Pentagonia gigantifolia Ducke

Pentagonia macrophylla Benth.

Pentagonia spathicalyx K. Schum.

Posoqueria latifolia (Rudge) Schult.

Psychotria anceps Kunth

Psychotria bertieroides Wernham

Psychotria capitata Ruiz \& Pav.

Psychotria hoffmannseggiana (Schult.)

Müll. Arg.

Psychotria limitanea Standl.

Psychotria longicuspis Müll. Arg.

Psychotria lupulina Benth.

Psychotria marcgraviella Standl.

Psychotria medusula Müll. Arg.

Psychotria micrantha Kunth

Psychotria microbotrys Ruiz ex Standl.

Psychotria peruviana Steyerm.

Psychotria poeppigiana Müll. Arg.

Psychotria remota Benth.

Psychotria romolerouxiana C.M. Taylor

Psychotria sacciformis C.M. Taylor

Psychotria trichocephala Poepp. \& Endl.

Psychotria ulviformis Steyerm.

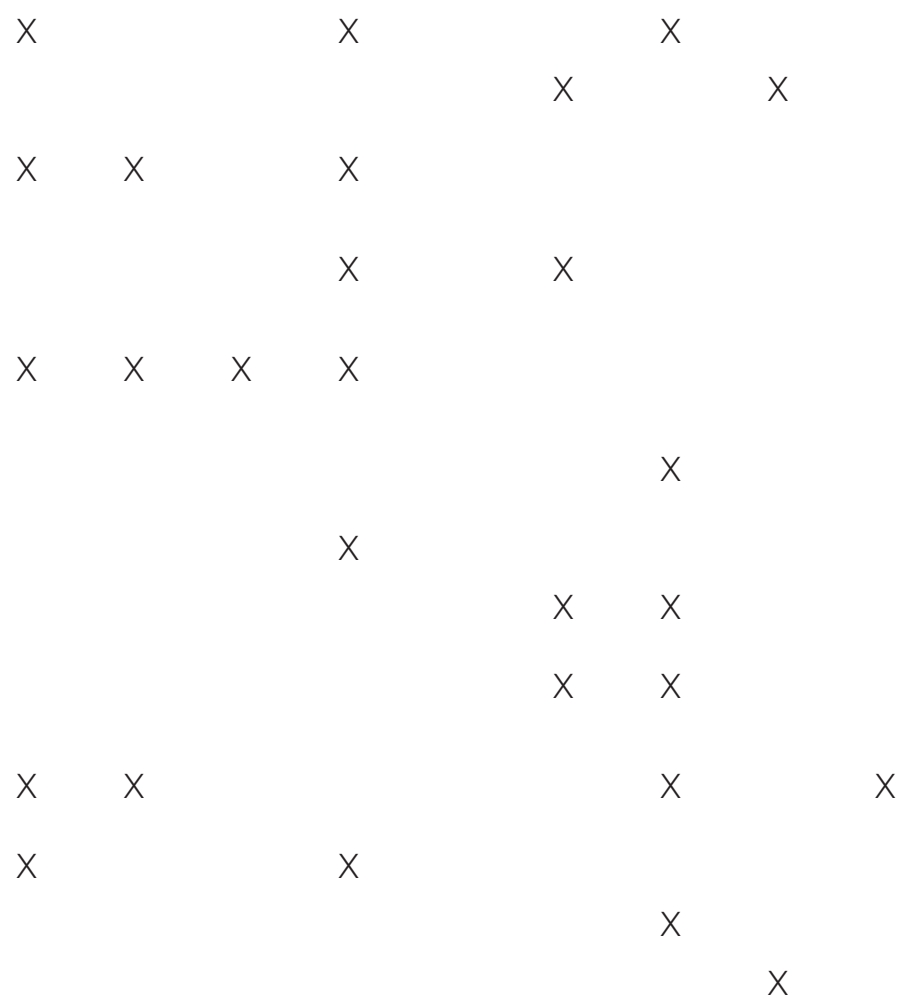

$x \quad x$

$x$

$x \quad x$

$X$

$x$

$x$

$x \quad x$

$x$ $x$

X $\quad x$

$x \quad x$

X

$\begin{array}{cccc} & & & \\ & & & \\ & & & \\ x & x & x & x \\ & & x & x \\ & & x \\ & & x \\ & & x\end{array}$


Psychotria viridis Ruiz \& Pav.

Psychotria williamsii Standl.

Randia armata (Sw.) DC.

Remijia pacimonica Standl.

Remijia ulei K. Krause

Ronabea latifolia Aubl.

Rosenbergiodendron longiflorum (Ruiz \& Pav.) Fagerl.

Rothmannia hispida (K. Schum.) Fagerl.

Rudgea cornifolia (Kunth) Standl.

Rudgea cryptantha Standl.

Rudgea lanceifolia Salisb.

Rudgea loretensis Standl.

Rudgea panurensis Müll. Arg.

Rudgea stipulacea (DC.) Steyerm.

Simira rubescens (Benth.) Bremek. ex Steyerm.

Sphinctanthus maculatus Spruce ex K. Schum.

Uncaria guianensis (Aubl.) J.F. Gmel.

Uncaria tomentosa (Willd.) DC.

Warszewiczia coccinea (Vahl) Klotzsch

Warszewiczia cordata Spruce ex K.

Schum.

Rutaceae

Conchocarpus guyanensis (Pulle)

Kallunki \& Pirani

Conchocarpus toxicarius (Spruce ex

Engl.) Kallunki \& Pirani

Conchocarpus ucayalinus (Huber)

Kallunki \& Pirani

Esenbeckia amazonica Kaastra

Esenbeckia kallunkiae Pirani

Raputia hirsuta (Gereau) Kallunki

Raputiarana subsigmoidea (Ducke)

Emmerich

Rauia prancei W.A. Rodrigues \& M.F.F.

Silva

Spiranthera parviflora Sandwith

Ticorea tubiflora (A.C. Sm.) Gereau

\begin{abstract}
$x$
\end{abstract}
$x$

$x$

$x$

$x$

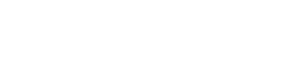

$$
x \quad x
$$

$x$

$x$

$x$

$x$

$x$

$X$

X

X

X

$x$
$x \quad x$

X

$x \quad x$

$x$

$x$

X

X 


\begin{tabular}{|c|c|c|c|c|c|c|c|c|c|c|}
\hline \multirow{2}{*}{\multicolumn{2}{|c|}{$\begin{array}{l}\text { Sabiaceae } \\
\text { Meliosma loretoyacuensis Cuatrec. \& } \\
\text { Idrobo }\end{array}$}} & $x$ & $x$ & $x$ & & $x$ & $x$ & $x$ & & \\
\hline & & & & & & $x$ & & & & \\
\hline $\begin{array}{l}\text { Ophiocaryon heterophyllum (Benth.) } \\
\text { Urb. }\end{array}$ & & $x$ & $x$ & & & $x$ & $x$ & $x$ & & \\
\hline Ophiocaryon klugii Barneby & & & $x$ & & & & & $x$ & & \\
\hline $\begin{array}{l}\text { Ophiocaryon manausense (W.A. } \\
\text { Rodrigues) Barneby }\end{array}$ & & & & $x$ & & & $x$ & $x$ & & \\
\hline Saccolomataceae & $x$ & $x$ & & $x$ & & $x$ & $x$ & & & \\
\hline Saccoloma elegans Kaulf. & $x$ & & & $x$ & & & & & & \\
\hline Saccoloma inaequale (Kunze) Mett. & $x$ & $x$ & & & & $x$ & $x$ & & & \\
\hline Salicaceae & $x$ & $x$ & $x$ & $x$ & & $x$ & $x$ & $x$ & $x$ & X \\
\hline Casearia aculeata Jacq. & $x$ & $x$ & & & & & & & & \\
\hline Casearia arborea (Rich.) Urb. & & & & & & & & & & $x$ \\
\hline Casearia bicolor Urb. & $x$ & $x$ & & & & $x$ & & & & \\
\hline Casearia javitensis Kunth & & $x$ & & $x$ & & $x$ & $x$ & $x$ & & \\
\hline Casearia pitumba Sleumer & & & & $x$ & & & & & $x$ & \\
\hline Casearia prunifolia Kunth & & & & $x$ & & & & & & \\
\hline Casearia resinifera Spruce ex Eichler & & & & & & & $x$ & & & \\
\hline Casearia sylvestris Sw. & & & & $x$ & & & & & & \\
\hline Hasseltia floribunda Kunth & $x$ & $x$ & & & & & & & & \\
\hline Laetia suaveolens (Poepp.) Benth. & & & & & & & $x$ & & & \\
\hline Lunania parviflora Spruce ex Benth. & & & & & & & & & & X \\
\hline $\begin{array}{l}\text { Neoptychocarpus killipii (Monach.) } \\
\text { Buchheim }\end{array}$ & $x$ & $x$ & $x$ & $x$ & & $x$ & $x$ & $x$ & & \\
\hline Tetrathylacium macrophyllum Poepp. & & & & $x$ & & & & & & \\
\hline Salviniaceae & & $x$ & & & $x$ & & & & & \\
\hline Azolla filiculoides Lam. & & & & & $x$ & & & & & \\
\hline Salvinia auriculata Aubl. & & $x$ & & & $x$ & & & & & \\
\hline Sapindaceae & $x$ & $x$ & & $x$ & & $x$ & $x$ & $x$ & $x$ & $x$ \\
\hline Allophylus floribundus (Poepp.) Radlk. & & & & & & & $x$ & & & \\
\hline $\begin{array}{l}\text { Allophylus pilosus (J.F. Macbr.) A.H. } \\
\text { Gentry }\end{array}$ & & $x$ & & & & & & & & \\
\hline Cupania cinerea Poepp. & & & & $x$ & & & $x$ & & & \\
\hline Cupania latifolia Kunth & & & & & & & & $x$ & & \\
\hline Matayba adenanthera Radlk. & & & & & & & & $x$ & & \\
\hline Matayba arborescens (Aubl.) Radlk. & & & & & & & $x$ & $x$ & & \\
\hline Matayba inelegans Spruce ex Radlk. & & & & & & & $x$ & $x$ & $x$ & $x$ \\
\hline Matayba macrocarpa Gereau & & & & & & & & & $x$ & \\
\hline
\end{tabular}


Matayba purgans (Poepp.) Radlk.

Paullinia alata (Ruiz \& Pav.) G. Don

Paullinia bracteosa Radlk.

Paullinia faginea (Triana \& Planch.)

Radlk.

Paullinia ingifolia Rich. ex Juss.

Paullinia rugosa Benth. ex Radlk.

Paullinia serjaniifolia Triana \& Planch.

Talisia carinata Radlk.

Talisia cerasina (Benth.) Radlk.

Talisia sylvatica (Aubl.) Radlk.

Toulicia reticulata Radlk.

\section{Sapotaceae}

Chrysophyllum argenteum Jacq.

Chrysophyllum bombycinum T.D. Penn.

Chrysophyllum colombianum (Aubrév.)

T.D. Penn.

Chrysophyllum manaosense (Aubrév.)

T.D. Penn.

Chrysophyllum prieurii A. DC.

Chrysophyllum sanguinolentum (Pierre) Baehni

Chrysophyllum venezuelanense (Pierre)

T.D. Penn.

Ecclinusa lanceolata (Mart. \& Eichler)

Pierre

Manilkara bidentata (A. DC.) A. Chev.

Manilkara inundata (Ducke) Ducke

Micropholis egensis (A. DC.) Pierre

Micropholis guyanensis (A. DC.) Pierre

Micropholis macrophylla (Krause) T.D.

Penn.

Micropholis madeirensis (Baehni)

Aubrév.

Micropholis porphyrocarpa (Baehni)

Monach.

Micropholis venulosa (Mart. \& Eichler)

Pierre

Pouteria amazonica Radlk.

Pouteria aubrevillei Bernardi

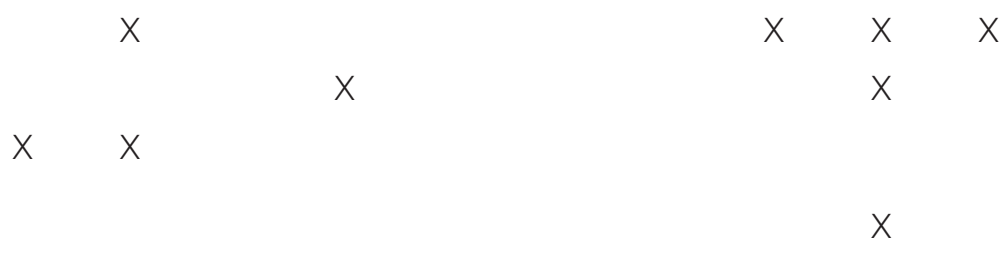

$x \quad x \quad x$

X $\quad x$

$x \quad x \quad x$

$x$

$x$

$x$

$x$

$\begin{array}{cccccccccc}x & x & x & x & x & x & x & x & x & x \\ x & & x & x & & & & x & & x \\ & & x & & & x & x & & & \end{array}$

$X$

X $\quad x$

$x \quad x \quad x$

$x \quad x \quad x$

X

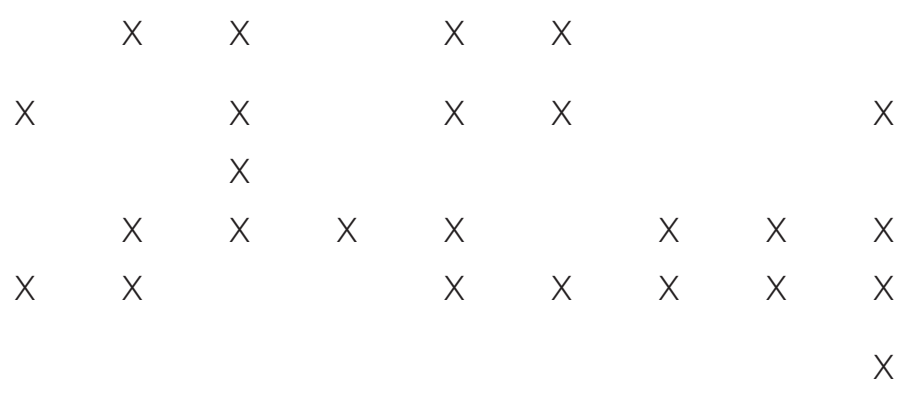

$x$

$X$

$x$

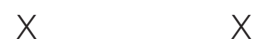

$x \quad x \quad x$

$x \quad x \quad x$

$x$ $x$

$x$

$x$ 
Pouteria baehniana Monach.

Pouteria bangii (Rusby) T.D. Penn.

Pouteria campanulata Baehni

Pouteria cuspidata (A. DC.) Baehni

Pouteria durlandii (Standl.) Baehni

Pouteria ephedrantha (A.C. Sm.) T.D.

Penn.

Pouteria gomphiifolia (Mart. ex Miq.)

Radlk.

Pouteria glauca T.D. Penn.

Pouteria guianensis Aubl.

Pouteria hispida Eyma

Pouteria laevigata (Mart.) Radlk.

Pouteria lucumifolia (Reissek ex Maxim.)

T.D. Penn.

Pouteria oblanceolata Pires

Pouteria platyphylla (A.C. Sm.) Baehni

$x \quad x \quad \begin{array}{lll}x & x & x\end{array}$

$x \quad x$

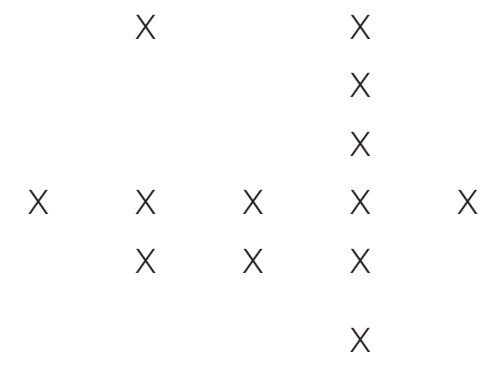

Pouteria plicata T.D. Penn.

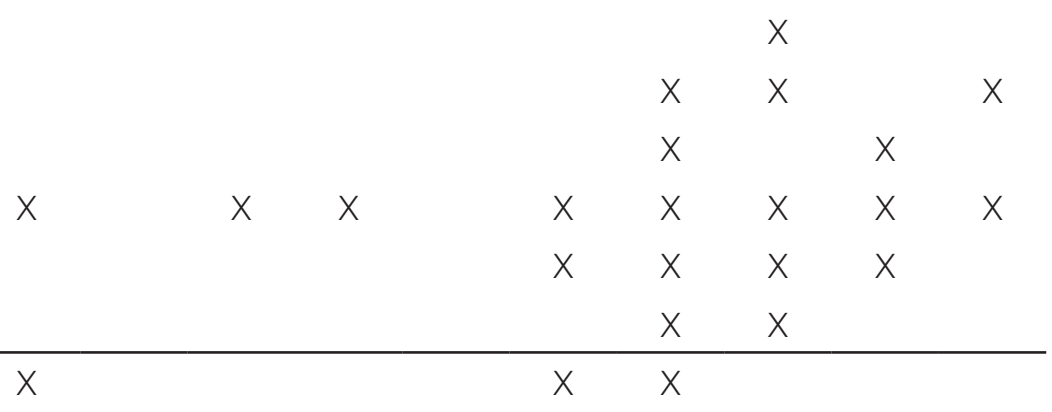

Pouteria putamen-ovi T.D. Penn.

Pouteria reticulata (Engl.) Eyma

Pouteria rostrata (Huber) Baehni

Pouteria torta (Mart.) Radlk.

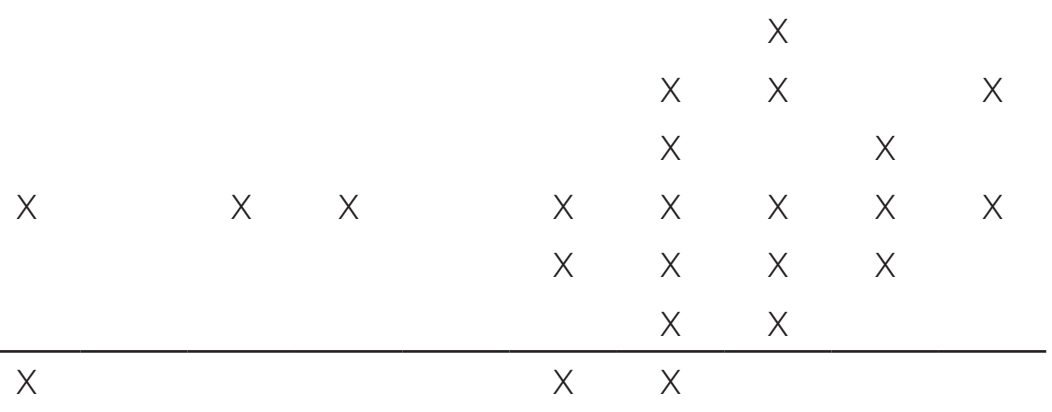

Pouteria vernicosa T.D. Penn.

Sarcaulus brasiliensis (A. DC.) Eyma

\section{Schlegeliaceae}

Schlegelia cauliflora A.H. Gentry

\section{Selaginellaceae}

Selaginella exaltata (Kunze) Spring

Selaginella speciosa A. Braun

\section{Simaroubaceae}

Picrolemma sprucei Hook. f.

$\begin{array}{lll}x & x & x \\ x & x & x\end{array}$

Simaba guianensis Aubl.

Simaba polyphylla (Cavalcante) W.W.

Thomas

$x \quad x \quad x$

Simarouba amara Aubl.

Siparunaceae

Siparuna bifida (Poepp. \& Endl.) A. DC.

Siparuna cervicornis Perkins

\begin{tabular}{|c|c|c|c|c|c|c|c|}
\hline & & & & $x$ & & & \\
\hline \multirow[t]{3}{*}{$x$} & $x$ & $x$ & $x$ & $x$ & $x$ & $x$ & $x$ \\
\hline & $x$ & & $x$ & $x$ & $x$ & & \\
\hline & & & $x$ & & & & \\
\hline$x$ & & $x$ & $x$ & $x$ & $x$ & & \\
\hline$x$ & $x$ & $x$ & $x$ & $x$ & & $x$ & $x$ \\
\hline \multirow[t]{2}{*}{$x$} & $x$ & $x$ & $x$ & $x$ & & $x$ & \\
\hline & & & & $x$ & & $x$ & \\
\hline
\end{tabular}


Siparuna cristata (Poepp. \& Endl.) A. DC.

Siparuna cuspidata (Tul.) A. DC.

$\begin{array}{lll} & x & x \\ x & x & x\end{array}$

$x \quad x$

Siparuna decipiens (Tul.) A. DC.

Siparuna grandiflora (Kunth) Perkins

$x \quad x$

Siparuna guianensis Aubl.

$x$

Siparuna obstipa J.F. Macbr.

$x \quad x$

Siparuna reginae (Tul.) A. DC.

$x$

Siparuna thecaphora (Poepp. \& Endl.) A.

DC.

\section{Solanaceae}

Cestrum acuminatissimum Dunal

Juanulloa parasitica Ruiz \& Pav.

Markea ulei (Dammer) Cuatrec.

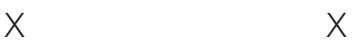

Solanum anceps Ruiz \& Pav.

Solanum leptopodum Van Heurck \&

Müll. Arg.

Solanum monarchostemon S. Knapp

Solanum pedemontanum M. Nee

Solanum sessile Ruiz \& Pav.

$x$

$x \quad x \quad x$

$x$

Solanum uleanum Bitter

$\begin{array}{ll} & x \\ & x \\ x & \\ x & x \\ x & x \\ x & \end{array}$

Solanum yanamonense S. Knapp

\section{Staphyleaceae}

$x$
$x$

Turpinia occidentalis (Sw.) G. Don

\begin{tabular}{|c|c|c|c|c|c|c|c|}
\hline Stemonuraceae & $x$ & $x$ & $x$ & $x$ & $x$ & $x$ & \\
\hline Discophora guianensis Miers & $x$ & $x$ & $x$ & $x$ & $x$ & $x$ & \\
\hline Strelitziaceae & $x$ & $x$ & & $x$ & $x$ & $x$ & $x$ \\
\hline $\begin{array}{l}\text { Phenakospermum guyannense (Rich.) } \\
\text { Endl. }\end{array}$ & $x$ & $x$ & & $x$ & $x$ & $x$ & $x$ \\
\hline Styracaceae & & $x$ & & & & & \\
\hline Styrax guyanensis A. DC. & & $x$ & & & & & \\
\hline Tapisciaceae & $x$ & $x$ & & $x$ & & & \\
\hline Huertea glandulosa Ruiz \& Pav. & $x$ & $x$ & & $x$ & & & \\
\hline Tectariaceae & & $x$ & & & & $x$ & \\
\hline $\begin{array}{l}\text { Tectaria draconoptera (D.C. Eaton) } \\
\text { Copel. }\end{array}$ & & $x$ & & & & $x$ & \\
\hline Tectaria incisa Cav. & & $x$ & & & & & \\
\hline Tectaria microsora A.R. Sm. & & & & & & $x$ & \\
\hline Triplophyllum funestum (Kunze) Holttum & & $x$ & & & & $x$ & \\
\hline
\end{tabular}




\begin{tabular}{|c|c|c|c|c|c|c|c|c|c|c|}
\hline Thelypteridaceae & $x$ & $x$ & & $x$ & & & & & & \\
\hline Thelypteris decussata (L.) Proctor & & $x$ & & & & & & & & \\
\hline $\begin{array}{l}\text { Thelypteris macrophylla (Kunze) C.V. } \\
\text { Morton }\end{array}$ & $x$ & $x$ & & $x$ & & & & & & \\
\hline Triuridaceae & & & & & & & $x$ & & & \\
\hline Sciaphila purpurea Benth. & & & & & & & $x$ & & & \\
\hline Ulmaceae & $x$ & $x$ & & $x$ & & & & & $x$ & \\
\hline Ampelocera edentula Kuhlm. & $x$ & $x$ & & $x$ & & & & & $x$ & \\
\hline Urticaceae & $x$ & $x$ & $x$ & $x$ & $x$ & $x$ & $x$ & $x$ & $x$ & $x$ \\
\hline Cecropia distachya Huber & & & & & & $x$ & $x$ & & $x$ & \\
\hline Cecropia engleriana Snethl. & & $x$ & & & & & $x$ & & & \\
\hline Cecropia ficifolia Warb. ex Snethl. & $x$ & $x$ & & & $x$ & $x$ & $x$ & $x$ & & \\
\hline Cecropia latiloba Miq. & $x$ & $x$ & & $x$ & & $x$ & $x$ & & & \\
\hline Cecropia membranacea Trécul & $x$ & $x$ & $x$ & $x$ & & & $x$ & & & \\
\hline Cecropia sciadophylla Mart. & $x$ & $x$ & $x$ & $x$ & $x$ & $x$ & $x$ & & & \\
\hline Coussapoa herthae Mildbr. & & $x$ & & & & & & & & \\
\hline Coussapoa orthoneura Standl. & $x$ & $x$ & & & & $x$ & & $x$ & $x$ & \\
\hline Coussapoa ovalifolia Trécul & $x$ & & & & & & & & & \\
\hline Coussapoa trinervia Spruce ex Mildbr. & $x$ & $x$ & $x$ & $x$ & & $x$ & $x$ & $x$ & $x$ & $x$ \\
\hline Coussapoa villosa Poepp. \& Endl. & $x$ & & & $x$ & & & $x$ & & & \\
\hline Pourouma bicolor Mart. & $x$ & $x$ & & $x$ & & $x$ & $x$ & $x$ & $x$ & $x$ \\
\hline Pourouma cecropiifolia Mart. & $x$ & $x$ & & $x$ & $x$ & $x$ & $x$ & & & $x$ \\
\hline Pourouma cucura Standl. \& Cuatrec. & & & & & & & $x$ & & & \\
\hline Pourouma guianensis Aubl. & & $x$ & & $x$ & & $x$ & $x$ & & & $x$ \\
\hline Pourouma herrerensis C.C. Berg & & & $x$ & $x$ & & & & & & \\
\hline Pourouma melinonii Benoist & & & & $x$ & & & & & & \\
\hline Pourouma minor Benoist & $x$ & $x$ & $x$ & $x$ & & $x$ & $x$ & $x$ & & $x$ \\
\hline Pourouma mollis Trécul & & & & & & & $x$ & & & \\
\hline Pourouma myrmecophila Ducke & & & & & & $x$ & $x$ & & & \\
\hline Pourouma napoensis C.C. Berg & & $x$ & & & & & & & & \\
\hline Pourouma ovata Trécul & $x$ & & & $x$ & & & $x$ & $x$ & & $x$ \\
\hline Pourouma phaeotricha Mildbr. & & & & $x$ & & $x$ & $x$ & & & \\
\hline Pourouma tomentosa Mart. ex Miq. & & & & & & $x$ & $x$ & & & \\
\hline Urera baccifera (L.) Gaudich. ex Wedd. & $x$ & $x$ & & $x$ & & $x$ & & & & \\
\hline $\begin{array}{l}\text { Urera caracasana (Jacq.) Gaudich. ex } \\
\text { Griseb. }\end{array}$ & & & $x$ & & $x$ & & & & & \\
\hline Verbenaceae & $x$ & & $x$ & & & & & & & \\
\hline Lantana camara L. & & & $x$ & & & & & & & \\
\hline
\end{tabular}


Petrea blanchetiana Schauer
Petrea maynensis Huber

Violaceae

Gloeospermum equatoriense Hekking

Gloeospermum longifolium Hekking

Gloeospermum sphaerocarpum Triana \& Planch.

Leonia crassa L.B. Sm. \& Á. Fernández

Leonia cymosa Mart.

Leonia glycycarpa Ruiz \& Pav.

Leonia racemosa Mart.

Paypayrola grandiflora Tul.

Paypayrola guianensis Aubl.

Rinorea flavescens (Aubl.) Kuntze

Rinorea lindeniana (Tul.) Kuntze

Rinorea macrocarpa (C. Mart. ex Eichler)

Kuntze

Rinorea racemosa (Mart.) Kuntze

Rinorea viridifolia Rusby

Rinoreocarpus ulei (Melch.) Ducke

\begin{abstract}
$x$
\end{abstract}
$x$

\begin{tabular}{|c|c|c|c|c|c|c|c|c|}
\hline \multirow[t]{3}{*}{$x$} & $x$ & $x$ & $x$ & $x$ & $x$ & $x$ & $x$ & $x$ \\
\hline & $x$ & & & & $X$ & & & \\
\hline & $x$ & & & & $x$ & & & \\
\hline$X$ & & & $X$ & & $X$ & & & \\
\hline \multirow[t]{2}{*}{$x$} & $x$ & $x$ & $x$ & $x$ & $x$ & & $X$ & \\
\hline & $x$ & $x$ & & $X$ & $X$ & $X$ & & \\
\hline$X$ & $X$ & $X$ & $x$ & $x$ & $x$ & $x$ & & \\
\hline$X$ & & $x$ & $x$ & & & & & \\
\hline \multirow[t]{3}{*}{$x$} & & & $x$ & & $x$ & & & \\
\hline & $x$ & & & & & & & \\
\hline & & $x$ & & & & & & \\
\hline \multirow[t]{2}{*}{$x$} & $X$ & $X$ & $X$ & $x$ & & $X$ & $X$ & \\
\hline & & & & $x$ & & & & \\
\hline$X$ & & $x$ & $x$ & $x$ & $x$ & $x$ & $X$ & \\
\hline \multirow[t]{2}{*}{$x$} & $x$ & $x$ & $x$ & $x$ & $x$ & $x$ & & $x$ \\
\hline & & & $x$ & & & & & \\
\hline
\end{tabular}

\section{Vitaceae}

Cissus erosa Rich.

Vochysiaceae

Erisma bicolor Ducke

Erisma calcaratum (Link) Warm.

Erisma floribundum Rudge

Erisma uncinatum Warm.

Qualea acuminata Spruce ex Warm.

Qualea paraensis Ducke

Ruizterania trichanthera (Warm.) Marc.-

Berti

Vochysia biloba Ducke

Vochysia braceliniae Standl.

Vochysia diversa J.F. Macbr.

Vochysia ferruginea Mart.

Vochysia floribunda Mart.

Vochysia inundata Ducke

Vochysia lomatophylla Standl.

$x$

X

\begin{tabular}{|c|c|c|c|c|c|c|c|}
\hline \multirow[t]{4}{*}{$x$} & $x$ & $x$ & $x$ & $x$ & $x$ & $x$ & $X$ \\
\hline & & $x$ & $x$ & $x$ & $x$ & & \\
\hline & & $x$ & & & & & \\
\hline & & & & & $x$ & & \\
\hline$X$ & $x$ & & $X$ & $x$ & & & \\
\hline$x$ & $x$ & & & & $x$ & & \\
\hline$x$ & $x$ & & $X$ & & & $x$ & $x$ \\
\hline & & $x$ & $x$ & & & & \\
\hline & & & $X$ & & & & \\
\hline & $x$ & & & & $x$ & & \\
\hline & & & $x$ & & & & \\
\hline & $x$ & & & & & & \\
\hline & & & $X$ & & & & \\
\hline & & & $x$ & & & & \\
\hline & & $x$ & $X$ & $x$ & $x$ & $x$ & $x$ \\
\hline
\end{tabular}


Vochysia mapirensis Rusby

Vochysia stafleui Marc.-Berti

Vochysia venulosa Warm.

Vochysia vismiifolia Spruce ex Warm.
X

$x$

X $\quad x$

X

$x \quad x$

Zamia hymenophyllidia D.W. Stev.

Zamia macrochiera D.W. Stev.

Zamia ulei Dammer

Zingiberaceae

Renealmia alpinia (Rottb.) Maas

Renealmia breviscapa Poepp. \& Endl.

Renealmia krukovii Maas

Renealmia nicolaioides Loes.

Renealmia thyrsoidea (Ruiz \& Pav.)

Poepp. \& Endl.

$x \quad x$

\section{$x$}

$x$

$x \quad x$

$x \quad x \quad x \quad x$

$x \quad x$

$x \quad x \quad x$

$x \quad x \quad x$

$x \quad x$

$x \quad x \quad x$

$x$

Recibido: 19 de octubre de 2020 Aceptado para publicación: 3 de diciembre de 2020

Esta obra está bajo una Licencia Creative Commons Atribución-NoComercial-SinDerivar 4.0 Internacional. 